\title{
Inhibition of ischemic organ damage with anti- coagulant agents : ASIS and APC in myocardial and renal ischemia/reperfusion
}

Citation for published version (APA):

Loubele, S. T. B. G. (2009). Inhibition of ischemic organ damage with anti-coagulant agents : ASIS and $A P C$ in myocardial and renal ischemia/reperfusion. [Doctoral Thesis, Maastricht University]. Maastricht University. https://doi.org/10.26481/dis.20090618sl

Document status and date:

Published: 01/01/2009

DOI:

10.26481/dis.20090618s

Document Version:

Publisher's PDF, also known as Version of record

\section{Please check the document version of this publication:}

- A submitted manuscript is the version of the article upon submission and before peer-review. There can be important differences between the submitted version and the official published version of record.

People interested in the research are advised to contact the author for the final version of the publication, or visit the DOI to the publisher's website.

- The final author version and the galley proof are versions of the publication after peer review.

- The final published version features the final layout of the paper including the volume, issue and page numbers.

Link to publication

\footnotetext{
General rights rights.

- You may freely distribute the URL identifying the publication in the public portal. please follow below link for the End User Agreement:

www.umlib.nl/taverne-license

Take down policy

If you believe that this document breaches copyright please contact us at:

repository@maastrichtuniversity.nl

providing details and we will investigate your claim.
}

Copyright and moral rights for the publications made accessible in the public portal are retained by the authors and/or other copyright owners and it is a condition of accessing publications that users recognise and abide by the legal requirements associated with these

- Users may download and print one copy of any publication from the public portal for the purpose of private study or research.

- You may not further distribute the material or use it for any profit-making activity or commercial gain

If the publication is distributed under the terms of Article 25fa of the Dutch Copyright Act, indicated by the "Taverne" license above, 


\section{INHIBITION OF ISCHEMIC ORGAN DAMAGE WITH ANTI-COAGULANT AGENTS}

ASIS AND APC IN MYOCARDIAL AND RENAL ISCHEMIA/REPERFUSION 
(C) S.T.B.G Loubele, Maastricht 2009

Thesis Maastricht University

ISBN 978-90-9024329-0

Printed by: Drukkerij Pietermans n.v., Lanaken

Coverdesign by: Julian Ilcheff Borissoff and Sarah TBG Loubele 


\section{INHIBITION OF ISCHEMIC ORGAN DAMAGE WITH ANTI-COAGULANT AGENTS}

ASIS AND APC IN MYOCARDIAL AND RENAL ISCHEMIA/REPERFUSION

\section{Proefschrift}

ter verkrijging van de graad van doctor aan de Universiteit Maastricht, op gezag van de Rector Magnificus, Prof. Mr. G.P.M.F. Mols, volgens het besluit van het College van Decanen,

in het openbaar te verdedigen op donderdag 18 juni 2009 om 12.00 uur door

Sarah Trinette Brigitte Giel Loubele

Geboren op 30 juli 1981 te Turnhout 


\section{Promotor}

Prof. dr. H. ten Cate

\section{Co-promotor}

Dr. H.M.H. Spronk

\section{Beoordelingscommissie}

Prof. dr. R. Koopmans (voorzitter)

Dr. E.C.M. van Gorp (Slotervaartziekenhuis, Amsterdam)

Prof. dr. P. H. Reitsma (LUMC, Leiden)

Prof. dr. J.L. Waltenberger

Prof. dr. C Reutelingsperger

The research described in this thesis was supported by a grant of the Netherlands Heart Foundation (NHF-2003B065).

Financial support by the Netherland Heart Foundation for the publication of this thesis is gratefully acknowledged. 
RESEARCH IS TO SEE WHAT EVERYBODY ELSE HAS SEEN, AND TO THINK WHAT NOBODY ELSE HAS THOUGHT.

ALBERT SZENT-GYÖRGI 



\section{CONTENTS}

Chapter $1 \quad$ General introduction 9

Outline of this thesis $\quad 25$

Chapter 2 ASIS reduces myocardial infarct size: an explorative study 33

Chapter $3 \quad$ ASIS attenuates myocardial I/R injury in mice 49

Chapter $4 \quad$ APC protects against myocardial I/R injury via inhibition $\quad 73$ of apoptosis and inflammation

Chapter 5 The anti-coagulants ASIS and APC do not protect against 91 renal I/R injury

Chapter $6 \quad$ General discussion

Addendum

Summary/Samenvatting

Publications

Curriculum vitae

Dankwoord 



\section{Chapter 1}

\section{General introduction}

Based on:

STBG Loubele, HMH Spronk, $\mathrm{H}$ ten Cate.

Activated protein C: a promising drug with multiple effects?

Mini Reviews in Medicinal Chemistry 2009;9(5):620-626 



\section{ISCHEMIA/REPERFUSION INJURY}

THE PATHOPHYSIOLOGY OF MYOCARDIAL ISCHEMIA/REPERFUSION INJURY

According to the World Health Organization (WHO), cardiovascular disease (CVD) is the most common cause of death worldwide at this moment. In 2005, 17.5 million people died from CVD which represents $30 \%$ of all deaths. Of these deaths, $43 \%$ were caused by a myocardial infarction and $32 \%$ by ischemic stroke.

Myocardial ischemia is caused by rupture of an atherosclerotic lesion in one or more coronary arteries and the subsequent exposure of its content to the bloodstream leading to formation of an occlusive thrombus. This process appears to occur repeatedly prior to myocardial infarction, due to the fact that thrombotic occlusion is oftentimes followed by reperfusion as a result of clot lysis and embolization. This process of reperfusion, required to restore blood flow in the ischemic area is associated with a broad range of pathologies that may in fact contribute to (irreversible) damage of the affected organ. Collectively, the reperfusion process is referred to as ischemia/reperfusion injury comprising of four distinct features: depressed left-ventricular systolic function (or myocardial stunning), ventricular arrhythmias, reversible micro vascular injury, and irreversible cell damage ${ }^{1}$. Myocardial stunning refers to a mechanical dysfunction of ischemic tissue in the absence of irreversibly damaged tissue. A myocardial ischemia/reperfusion experiment in dogs revealed that a $48 \mathrm{hrs}$ reperfusion period after 15 minutes of ischemia is sufficient to allow full recovery of myocardial contractility ${ }^{2}$. Ventricular tachycardia and fibrillation remain the most important causes of sudden death after induction of reperfusion and free radicals are thought to play an essential role in this process ${ }^{3}$. Micro-vascular injury following reperfusion is known to limit adequate perfusion, also known as the no-reflow phenomenon. It is characterized by vascular alterations, a decreased blood flow, as well as areas of hypo-perfusion in the ischemic tissue ${ }^{4}$. Furthermore, micro-vascular injury contributes to left ventricular remodeling of the ischemic heart ${ }^{5}$. At a cellular level, induction of ischemia leads to depletion of high energy phosphates eventually resulting in ultra structural changes such as accumulation of water and electrolytes leading to cell swelling and disruption of cellular organelles ${ }^{6}$. This irreversible process of cell death initiates an acute inflammatory response within and around the infarcted area ${ }^{7}$. Furthermore, reperfusion is associated with the generation of reactive oxygen species (ROS). ROS can further trigger 
the inflammatory response through induction of cytokines, chemokines, and adhesion molecules expression via the Nuclear Factor-Kappa B (NF-KB) pathway ${ }^{8,9}$. The recruitment of monocytes following the generation of cytokines into the affected tissue leads to damage of the ischemic area due to the secretion of cytotoxic molecules. Besides triggering the inflammatory process, ROS can also trigger apoptosis via different mechanisms such as the p53, JAK/STAT, and tumor necrosis factor (TNF)- $\alpha$ mediated pathways ${ }^{10}$. Furthermore, the complement cascade is activated by ischemic myocardial injury ${ }^{11,12}$ which also evolves in neutrophil and monocyte recruitment into the ischemic area ${ }^{13}$.

\section{THE PATHOPHYSIOLOGY OF RENAL ISCHEMIA/REPERFUSION INJURY}

Renal ischemia is the major cause of acute renal failure (ARF) as it accounts for $50 \%$ of the causes of $\mathrm{ARF}^{14}$ and is of great importance in graft rejection following kidney transplantation. The causes of ARF can be diverse and usually do not relate to acute thrombotic occlusion of renal arteries, although atherosclerosis of renal arteries is a contributor to chronic renal failure in conditions like hypertension and diabetes. ARF in graft rejection can, however, be caused by thrombotic occlusion and/or fibrinous occlusion of the microvasculature.

Upon acute renal ischemia, the proximal tubulair epithelial cells are the most affected and damage of these cells causes a reduction in glomerular filtration rate (GFR). A number of mechanisms seem to be involved in this process, revealing an important role for the actin cytoskeleton ${ }^{15}$. First, ischemia causes the shedding of cell debris including the apical brush border and detached tubular cells into the tubular lumen resulting in cast formation, tubular obstruction, and increased tubular pressure ${ }^{16,17}$. Secondly, the process of ischemia leads to an opening of the tight junctions resulting in leakage of the glomerular filtrate into the blood and this process impairs glomerular filtration ${ }^{18}$. Thirdly, ATP deficiency causes tubular cell swelling due to a disturbed sodium reabsorption leading to further cellular injury ${ }^{19}$. In the past, ischemic cell death was thought to be caused by necrosis. However, a number of apoptotic pathways seem to be involved in ischemic cell death including mitochondrial non-caspase and caspase pathways ${ }^{20}$. The process of inflammation which results from cell death plays an important role in renal ischemia/reperfusion injury. Furthermore, the increase in vascular permeability 
leads to the recruitment of leukocytes into the kidney and to the up-regulation of several inflammatory mediators including interleukin (IL) -1, IL-6, IL-8 and TNF- $\alpha^{21,22}$.

CROSSTALK BETWEEN COAGULATION AND INFLAMMATION IN ISCHEMIA/REPERFUSION INJURY: THE INTERACTIONS WITH PARS

Coagulation and inflammation are two distinct processes that gain large interest due to their interacting potential. This interesting finding is already studied for a long time and plays an important role in diverse pathologies including systemic lupus erythematosus (SLE) and disseminated intravascular coagulation $(\mathrm{DIC})^{23,24}$. Also in ischemia/reperfusion injury the crosstalk between inflammation and coagulation is shown to be of major importance.

Coagulation triggers the ischemic process as tissue factor (TF) is exposed to the bloodstream, forming a complex with factor (F)VII. The catalytic TF/FVIIa complex activates FIX and FX. Subsequently, FXa forms the prothrombinase complex with FVa, calcium and phospholipids, activating prothrombin into thrombin. Thrombin in its turn can activate FV and FVIII. Moreover, FVIIla together with FIXa form the tenase complex also activating FX. Eventually, thrombin converts fibrinogen into fibrin forming the fibrin $\operatorname{clot}^{25}$. Different procoagulant pathways can be inhibited by different inhibitors including activated protein $C$ (APC), tissue factor pathway inhibitor (TFPI) that attenuates the extrinsic route, and antithrombin (AT) that blocks several proteases including FXIa, FIXa, FXa and thrombin. The specific working mechanisms of TFPI, AT, and APC were previously described ${ }^{26-29}$, the functions of APC however, will be discussed in more detail in part 2 of the introduction. An overview of the coagulation cascade with its inhibitors is given in Figure 1.

Coagulation proteases can play important roles in cell signaling through activation of G-protein coupled protease activated receptors (PARs). Four types of PARs have been identified and each is activated by a serine protease, which cleaves specific sites leading to the formation of a neo $\mathrm{N}$-terminus beginning with a specific sequence functioning as a tethered ligand (Figure 2A). The ligand binds to a second transmembrane loop of the receptor, triggering G-protein binding and intracellular signaling. 


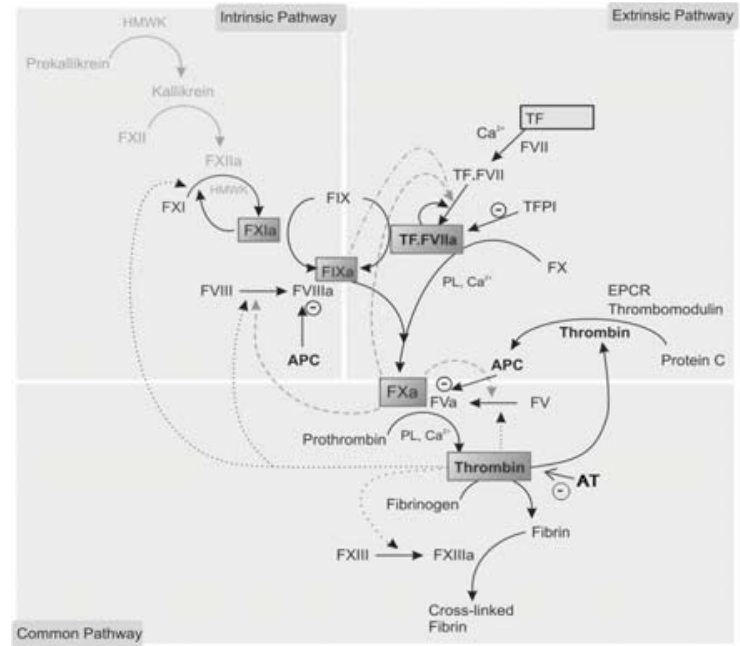

Figure 1: Schematic overview of the coagulation cascade. TF/FVIIa complex activates FX, which in turn activates prothrombin (II) into thrombin (IIa). Subsequently, thrombin binds to thrombomodulin (TM) and activates protein $\mathrm{C}$ into activated protein C (APC). Furthermore, FIXa in complex with FVIIIa can activate FX. APC then inhibits coagulation through inhibition of FVa or FVIIIa. Coagulation can further be inhibited by TFPI which inhibits TF:VIIa:Xa and AT which inactivates IIa, Xa, and IXa. The inhibitory effects of both are enhanced by heparin.

Despite their similar mechanisms of activation, the different PARs have various functions and are present on different cell types including endothelial cells, cardiomyocytes, and vascular smooth muscle cells ${ }^{30}$. PAR-1 is primarily a thrombin receptor but can also be activated by the TF/FVIla complex, FXa, and APC although their affinity for PAR-1 is less than that of thrombin. PAR-1 activation results in the expression of adhesion molecules on endothelial cells and the activation of monocytes and endothelial cells which release various cytokines and chemokines ${ }^{31,32}$. The role of PAR-1 in ischemia/reperfusion has been revealed by Junge et al. They showed that mice lacking PAR-1 had a reduced infarct size after cerebral ischemia compared to normal mice ${ }^{33}$.

Furthermore, PAR-1 plays a mediating role in cardiomyocyte hypertrophy and remodeling upon ischemia ${ }^{34}$. In contrast to PAR-1, PAR-2 is not a thrombin receptor but can be activated by the TF/FVIla complex ${ }^{35}$, FXa, and APC, although APC is most likely to signal only through PAR-1 ${ }^{36}$. 


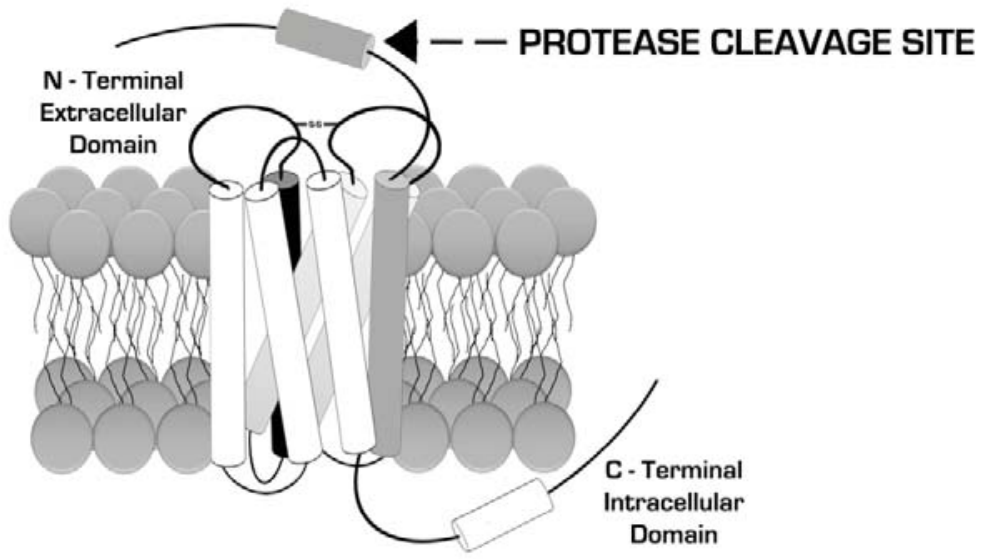

\begin{tabular}{cc}
\hline PAR RECEPTOR & CLEAVAGE SITE \\
\hline & Human / Mice \\
\hline PAR-1 & SFLLRN / SFFLRN \\
PAR-2 & SLIGKV / SLIGRL \\
PAR-3 & TFRGAP / SFNGCP \\
PAR-4 & GYPGQV / GYPGKF \\
\hline
\end{tabular}

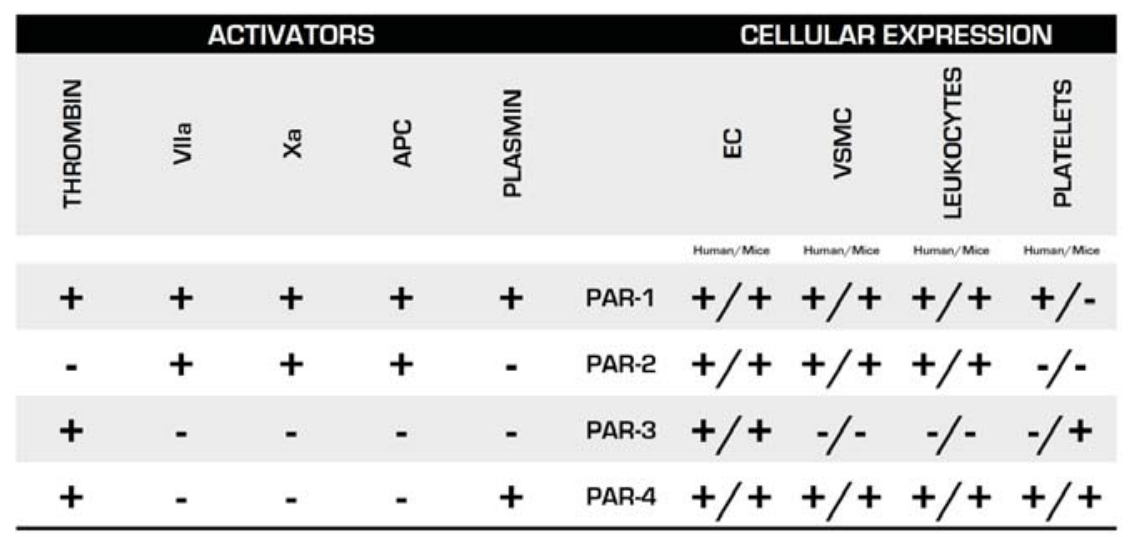

Figure 2: Panel A: Representation the working mechanism of PAR and the specific cleavage sequences of the different PARs. Panel B: Overview of the activators and the tissue distribution of the distinct PARs. $(\mathrm{EC}=$ endothelial cells, $\mathrm{VSMC}=\mathrm{vascular}$ smooth muscle cells, $\mathrm{Pl}=$ platelets). 
Furthermore, PAR-1 plays a mediating role in cardiomyocyte hypertrophy and remodeling upon ischemia ${ }^{34}$. In contrast to PAR-1, PAR-2 is not a thrombin receptor but can be activated by the TF/FVIla complex ${ }^{35}$, FXa, and APC, although APC is most likely to signal only through PAR $-1^{36}$. Activation of PAR-2 by TF/FVIla leads to an upregulation of the inflammatory response in macrophages by the expression of cell adhesion molecules and production of ROS and an increase in leukocyte infiltration combined with increased expression levels of TNF- $\alpha$ and IL-1 $\beta^{37}$. A combination of thrombin inhibition and PAR-2 deficiency reduced mortality and inflammation in endotoxemic mice ${ }^{38}$. Furthermore, PAR-2 has a modulating effect on myocardial ischemia/ reperfusion injury in rats ${ }^{39}$. PAR-3 is a thrombin receptor that does not have any direct signaling functions but serves as a co-receptor that augments the efficacy of PAR-4 cleavage upon thrombin binding ${ }^{40}$. Nevertheless, PAR-3/- mice are protected against thrombosis ${ }^{41}$. PAR- 4 is also activated by thrombin and plays a role in cardiovascular events as PAR-4 deficient mice showed an absence of platelet activity and were protected against experimental arterial thrombosis ${ }^{42}$. The tissue distribution of the different PARs is given in Figure 2B.

\section{ACTIVATED PROTEIN C}

APC: THE ANTI-COAGULANT AGENT WITH CELL SIGNALING PROPERTIES

The anti-coagulant role of $A P C$

APC's best known function is its anti-coagulant activity. The zymogen protein C, which is a vitamin $\mathrm{K}$-dependent protein, circulates in plasma in a concentration of $70 \mathrm{nM}$ and consists of a Gla domain, 2 epidermal growth factor domains, and a serine protease domain. The activation of protein $C$ is dependent on proteolytic activation by thrombin at Arg169, which removes the activation peptide, thereby creating APC, a trypsin-like serine protease. Upon activation of coagulation, thrombin binds to thrombomodulin (TM), which is mostly located on the surface of endothelial cells. The thrombin-TM complex then activates protein $C$ into APC at a relatively slow rate. However, the rate of $P C$ activation is increased 20-fold upon the presence of $E P C R^{43,44}$. APC together with protein $S$ can exert its anti-coagulant effect via the proteolytic cleavage of either FVa or FVIIIa $^{45}$. For APC to exert its anti-coagulant activity, the Gla domain is necessary for binding to phospholipids, whereas binding to the endothelial cell protein $C$ receptor (EPCR) is, besides for enhancing APC formation, also necessary for 
cytoprotective activities, which will be discussed below in further detail ${ }^{46,47}$. APC, either free or bound to EPCR, can be inhibited by protein $C$ inhibitor ( $P C I)$, a serine protease that can be classified as a heparin-binding serpin. This reaction occurs at a relatively slow rate forming a complex with APC through reaction with its active site ${ }^{48}$. This process is accelerated by the presence of heparin. Besides inhibiting APC, PCl also inhibits FXa and thrombin, in which TM is shown to be an important regulator ${ }^{49}$. Another inhibitor of APC is $\alpha 1-$ antitrypsin. As a result of the complex formation with both inhibitors, APC has a short half life of about 20 minutes, this in contrast to the half life of 10 hrs for protein $\mathrm{C}^{50}$. The pharmacokinetics of APC was studied in guinea pigs, in which $15 \%$ of the injected dose was already eliminated after 1 to 2 minutes and 2 mechanisms of APC elimination were proposed: either via direct elimination by the liver, or by binding to protease inhibitors and subsequent clearance by the liver. In plasma, the half life of APC activity is about $15-25$ minutes $^{51}$.

\section{APC: cell signaling via protease activated receptors (PARs)}

Besides its role in anticoagulation, APC is also involved in cell signaling mechanisms via PAR-1 ${ }^{31}$. PAR-1, present on endothelial cells, is cleaved by APC in an EPCR-dependent manner ${ }^{52}$. The specific contributions of signaling through PAR-1 either via thrombin, leading to pro-inflammatory effects or via APC, leading to anti-inflammatory effects, are being discussed below. Since the specificity and affinity of thrombin for PAR-1 cleavage is much higher than that of APC, and thrombin is needed to activate protein $C$ to APC, it is not completely clear yet to which extend APC can exert its (protective) effects via PAR-1 in the presence of thrombin. Recently, this question was partially answered by Bae et al., who showed that the receptors TM and EPCR (involved in protein C activation) as well as the receptors EPCR and PAR-1 (required for cell signaling through APC), are co-localized in lipid rafts on endothelial cells, thereby facilitating an adjacent neighborhood for all transmembrane proteins involved. In this way APC could activate PAR-1 despite the presence of nearby thrombin bound with high affinity to $\mathrm{TM}^{53}$. The presence of these factors in the same environment eventually allows APC to signal through PAR-154,55. Although APC's cell signaling functions require the presence of EPCR and PAR-1, novel signaling pathways of APC have been recently revealed in which EPCR and PAR-1 are not involved ${ }^{56}$. Using an in vitro monocyte-like cell culture study, it 
was proposed that apolipoprotein E receptor 2 (ApoER2)-dependent signaling by APC induced phosphorylation of the adaptor protein disabled-1 (Dab1) and subsequent signaling through PI3K and Akt was not dependent on EPCR and PAR-1. Whether the signaling is cell-type dependent or requires the involvement of other proteins such as the platelet integrin GP1ba ${ }^{57}$, remains unknown and needs to be clarified. An overview of the different functions of APC is given in Figure 3.

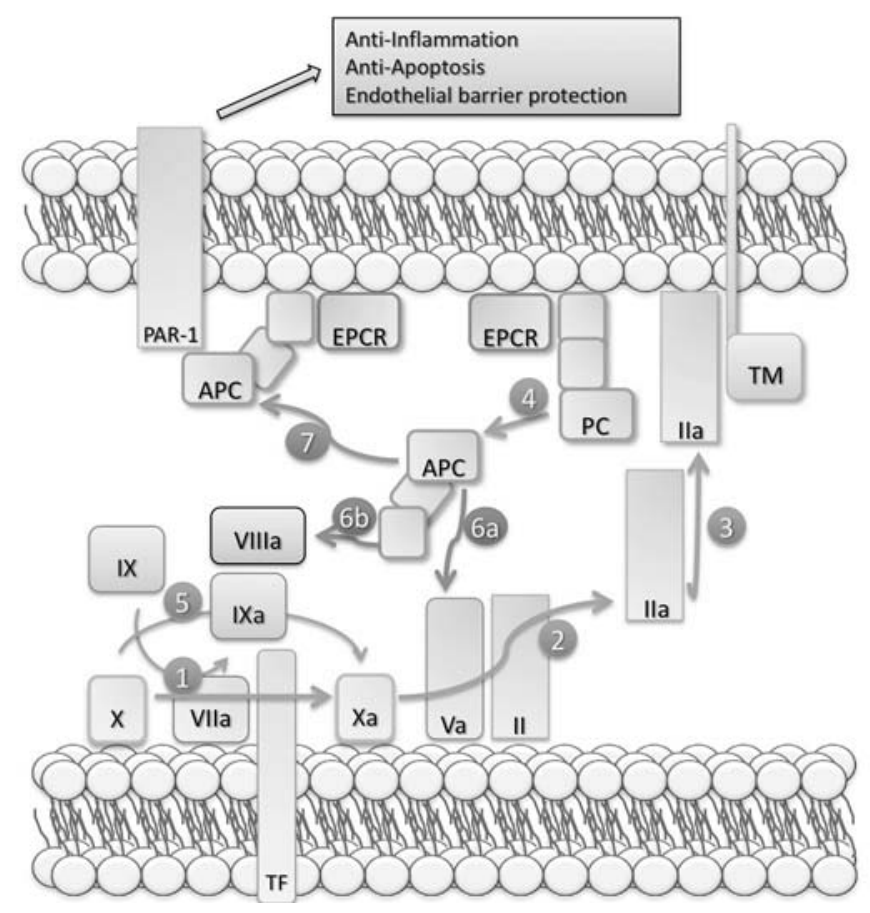

Figure 3: Schematic overview of the working mechanisms of APC. Tissue factor (TF):Factor VIIa complex activates FX (1), which in turn activates prothrombin (II) into thrombin (IIa, 2). Subsequently, thrombin binds to thrombomodulin (TM, 3) and activates protein C into APC (4). Furthermore, FIXa in complex with FVIIIa can activate FX (5). APC then inhibits coagulation through inhibition of FVa (6a) or FVIIIa (6b) or acts as anti-apoptotic/inflammatory molecule through activation of PAR-1 (7). 
CYTOPROTECTIVE FUNCTIONS OF APC: FROM CELL CULTURE TO ANIMAL STUDIES

\section{Anti-inflammatory and anti-apoptotic functions}

In vitro studies revealed much of the cytoprotective and cell signaling properties of APC. In 2001 Joyce et al. revealed a marked modulation of a number of apoptotic genes including the $\mathrm{Bcl}-2$ homologue gene, the inhibitor of apoptosis (IAP), and TNF- $\alpha$ as well as down-regulation of inflammation related genes including intercellular adhesion molecule-1 (ICAM-1), vascular adhesion molecule-1 (VCAM-1), and E-selectin upon APC administration ${ }^{58}$. Using APC, it was demonstrated that APC inhibited apoptosis directly through reducing the NF-кB signaling in endothelial cells. Other studies on endothelial cells also revealed protective effects of APC including a reduced expression of the adhesion molecule ICAM-1, the interleukins IL-6, IL-8, and monocyte chemotactic protein-1 (MCP-1), and attenuating effects on apoptosis related genes via the inhibition of $\mathrm{p} 53$, normalization of the $\mathrm{Bax} / \mathrm{BCl}-2$ ratio, and the reduction of caspase-3 activation ${ }^{36,59-61}$. Furthermore, in vitro work on TNF- $\alpha$ stimulated neutrophils isolated from healthy volunteers, showed a reduction in CD18 expression and ROS generation after administration of $A P C^{62}$. The mechanisms of these processes are not yet completely revealed, but EPCRdependent PAR-1 signaling seems to contribute in an important manner. Besides its function on gene expression, APC has the potency to inhibit the release of inflammatory mediators from leukocytes as well as endothelial cells and to down regulate vascular adhesion molecules thereby attenuating the inflammatory response. In the course of this process Mosnier et al. ${ }^{63}$ speculated that EPCR, located on monocytes and neutrophils, is shown to be of substantial importance, as EPCR can possibly interact with the integrin CD11b/CD18 on leukocytes influencing leukocyte adhesion. Also proteinase-3 (PR-3), which is expressed on neutrophils is believed to mediate the binding of EPCR to CD11b/ CD18 and can in complex with EPCR bind to APC. However, the exact cell signaling mechanisms of APC in this process are not fully understood and need to be further investigated ${ }^{63-65}$. In a model of hypoxic brain endothelial cell injury, APC exerts its anti-apoptotic effect via down regulation of $p 53$, normalization of the $\mathrm{Bax} / \mathrm{Bcl}-2$ ratio, and via inhibition of caspase- 3 signaling. The anti-apoptotic mechanisms also seem to require the presence of PAR-1 and EPCR as blockage of PAR-1 and EPCR inhibited APC to exert its protective effects whereas blockage of PAR-2 did not ${ }^{59,66}$. 
The cytoprotective functions of APC were demonstrated in vivo using a lung injury model, in which APC attenuated inflammation via IL-1 $\beta^{67,68}$. Furthermore, APC inhalation in a LPS-induced lung injury model, reduced pulmonary inflammation, reduced endothelial cell leakage and improved lung function ${ }^{69}$. APC also showed protective effects in several ischemia models. In an ischemic stroke model, APC has been proven to have anti-inflammatory, antithrombotic, and neuroprotective effects as the administration of APC increased the average survival time and restored cerebral blood flow. Cellular effects of APC on ischemic stroke were recognized by a decrease in leukocyte and fibrin deposition and a reduction in ICAM-1 at the blood brain barrier preventing neutrophil adhesion ${ }^{59,70,71}$. APC has been shown to have anti-inflammatory properties in an acute ischemia reperfusion model in the skeletal muscle where APC reduced myeloperoxidase (MPO) content and improved electrical properties of skeletal muscle. Mizutani et al. demonstrated a reduction in ischemia/reperfusion induced renal injury by APC as administration of APC led to an improved renal blood flow after ischemia/reperfusion, to an increased vascular permeability, and to reduction in fibrin degradation products in plasma. Plasma concentrations of TNF- $\alpha$, IL- 8 and MPO, which were increased by ischemia/reperfusion, also normalized upon APC administration ${ }^{72}$. Furthermore, APC had anti-inflammatory properties in a rat model of spinal cord ischemia/reperfusion by inhibition of neutrophil activation ${ }^{73}$. Recently, APC administration was proven to be effective in an animal model of multiple sclerosis as APC administration ameliorated the disease severity in EAE mice. Administration of APC decreased $1 \kappa B \alpha$ breakdown in T-cells, suggesting an inhibiting effect of APC on NF-KB signaling ${ }^{74}$.

Cheng et al. have shown an anti-apoptotic role for APC in vitro in a focal ischemic stroke model. Here, administration of APC reduced brain infarction volumes and brain edema, requiring the presence of EPCR and PAR-1. Furthermore, APC administration showed reduced fibrin deposition and a reduction in neutrophil deposition ${ }^{59}$. In a diabetes model, APC is shown to protect against nephropathy through the inhibition of apoptosis in podocytes and endothelial cells ${ }^{75}$. Furthermore, APC was shown to have a protective effect on myocardial ischemia/reperfusion injury through a combined effect on inflammation and apoptosis (Chapter 4 in this thesis). 


\section{Protection of endothelial barrier function}

The loss of endothelial barrier function facilitating the infiltration of inflammatory cells is a critical component of the tissue inflammatory reaction. As previously mentioned the barrier-protective properties of APC require S1P and its receptor S1P1 and also involve the presence of PAR-1 and EPCR. PAR-1, activated by APC, stimulates sphingosine kinase-1 (SphK-1) to form S1P. S1P signaling is mediated through the cell surface receptors that are part of the endothelial differentiation gene (Edg) family, expressed on endothelial cells, cardiomyocytes and leukocytes. Activation of Edg receptors leads to improved cellular motility and a decreased permeability via Rho family GTPases and mitogen activated protein (MAP) kinase ${ }^{76,77}$. EPCR also interacts with Edg receptors to improve endothelial barrier function ${ }^{78}$. In this context, the question remains how APC can have a positive effect on endothelial barrier function via PAR-1 in the presence of thrombin. A recent study by Bae et al., demonstrated that when EPCR is bound to protein $C$, the protective signaling properties of PAR-1 can be mediated either via thrombin or via APC. When EPCR is however associated with caveolin-1 in cavaolae/lipid rafts and when APC is bound to EPCR this leads to dissociation from caveolin-1, resulting in a protective signaling of PAR-1 ${ }^{79}$.

In vivo, the endothelial barrier protective functions of APC are demonstrated in a stroke model in which brain hemorrhage induced by t-PA administration is reduced upon administration of $A P C$, probably due protective effects on endothelial barrier function ${ }^{80,81}$. Also in a lung injury model, APC has

cytoprotective effects via preservation of the micro vascular permeability ${ }^{67,68}$. A schematic overview of the cytoprotective properties of APC is given in Figure 4.

\section{ACTIVE SITE INHIBITED FVIIA (ASIS)}

\section{ASIS IN COAGULATION}

Active site inhibited FVIIa (ASIS), or FVIlai, is a recombinant FVIla which is blocked at its catalytic site by the tripeptide (Phe-Phe-Arg) chloromethyl ketone, thereby competitively inhibiting FVIla binding to TF. Pharmacokinetic studies showed that human ASIS was cleared from the circulation with a mean retention time of 2.7 hours when a dose of $10 \mathrm{mg} / \mathrm{kg}$ was administered to $\mathrm{C} 57 \mathrm{BI} / 6$ mice. Peak value was obtained after approximately $5 \mathrm{~min}$. Experiments 
comparing 125-I labeled mouse and human FVIla showed no significant difference in pharmacokinetic parameters when administered, just as clearance of FVIla was not affected by active site blockage (unpublished data).

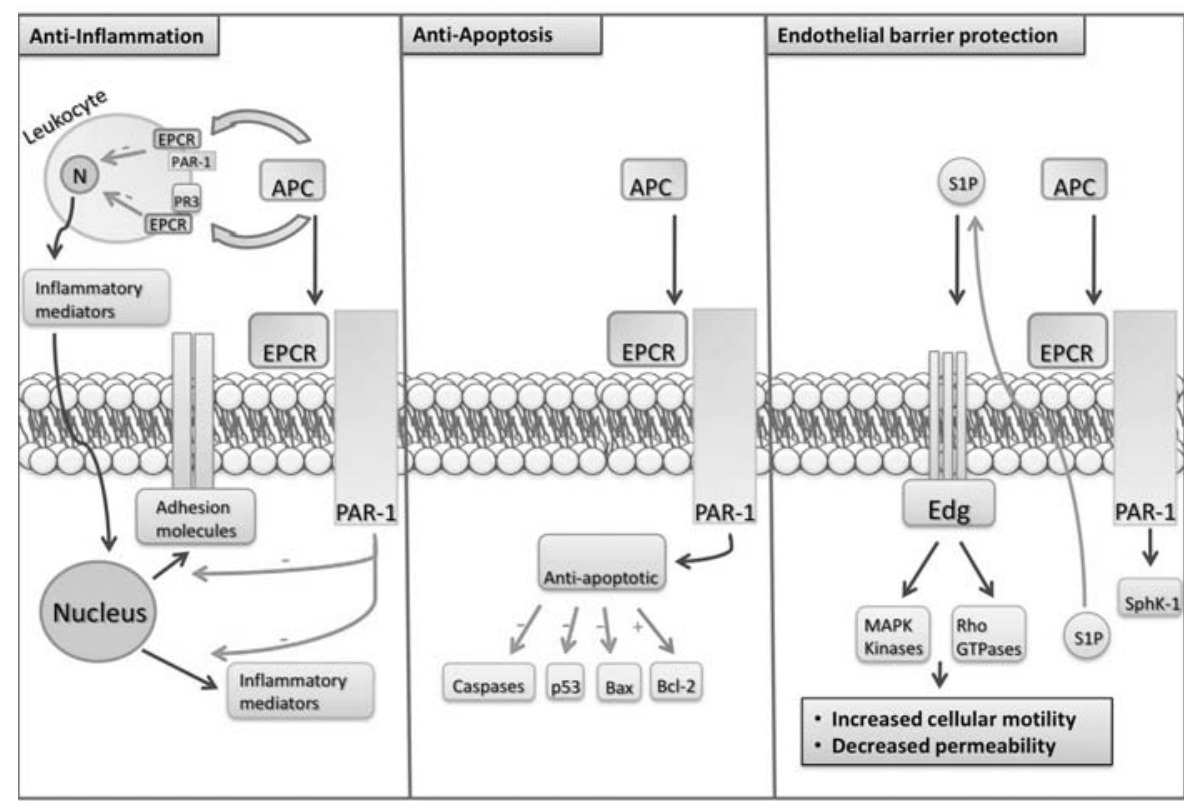

Figure 4: Schematic overview of the cytoprotective functions of APC. The antiinflammatory effects of APC are depicted in the left panel. The middle panel represents the anti-apoptotic properties of APC. The endothelial barrier protective effects of APC are depicted in the right panel.

The antithrombotic effect of FVIlai was proven in several animal models. The intravenous or topical administration of FVIlai revealed an antithrombotic effect in models of arterial injury. Using a rabbit ear arterial injury model, Arnljots et al. demonstrated that the topical administration of ASIS produced a pronounced antithrombotic effect without causing an increased bleeding risk. On the other hand, the intravenous administration of ASIS has no antithrombotic properties probably due to the poor interaction between human FVIlai and rabbit TF ${ }^{82}$. The antithrombotic properties of ASIS were confirmed in a rabbit model of carotid artery thrombosis ${ }^{83}$. 


\section{TF/FVIIA SIGNALING}

ASIS has via inhibition of TF/FVIla signaling a direct function on several cellular processes. Besides its role in thrombus formation, TF plays a role in the regulation of inflammation, migration and proliferation of vascular smooth muscle cells, and the formation of embryonic blood vessels, mostly via its interaction with FVII ${ }^{84-86}$. TF is a transmembrane glycoprotein which consists of a large extracellular domain, a smaller transmembrane region and a C-terminal intracellular tail containing 2 phosphorylation sites ${ }^{87}$. The source of TF is disputable as besides the localization in cell membranes, it is reported that TF is present in the circulation either in a free, soluble form or associated with microparticles 88,89 . A number of studies propose a role for the cytoplasmatic tail of TF in cell adhesion and migration ${ }^{90,91}$ but most of the cell signaling functions exist through the complex formation of TF with FVIla. The binding of FVII or FVIla to TF is $\mathrm{Ca}^{2+}$ dependent and mediates several cell signaling functions that result in regulation of apoptosis and gene expression ${ }^{92,93}$. Most of these processes are regulated via PAR-2 as blocking PAR-2 also blocks TF/FVIIa regulated cell migration ${ }^{94}$. Regulation of the inflammatory response via TF/FVIIa is however not believed to be regulated by the PARs as none of PAR-1, -2 , or- 4 deficient mice showed increased survival rates or reduced cytokine response upon endotoxemic challenge ${ }^{95}$.

\section{CYTOPROTECTIVE FUNCTIONS OF TF/FVIIA INHIBITION}

During ischemia/reperfusion injury, human recombinant FVIlai reduced infarct size in a rabbit myocardial ischemia/reperfusion model via inhibition of the procoagulant activity of $\mathrm{TF}^{96}$. Furthermore, the anti-inflammatory role of FVIIai was demonstrated using a sepsis baboon model in which administration of FVIlai attenuated fibrinogen depletion and decreased proinflammatory cytokine responses ${ }^{97,98}$. In a rat model of intestinal ischemia/reperfusion, FVIlai displayed anti-inflammatory properties. Intestinal ischemia was induced for $\mathbf{4 0}$ minutes followed by a $6 \mathrm{hr}$ reperfusion period. Pretreatment with FVIlai in this ischemia/reperfusion model reduced the permeability of the endothelial barrier, and lowered MPO activity and matrix inflammatory protein (MIP)-2 levels ${ }^{99}$. An anti-apoptotic role for FVIlai has not yet been revealed. Experiments performed in mice either expressing $1 \%$ of the human TF levels (low-TF mice) or mice lacking PAR-1 however demonstrated that these mice were protected from renal failure after 25 minutes of renal ischemia and 
varying periods of reperfusion. Furthermore, these mice showed reduced mortality rates, reduced neutrophil accumulation, and lower chemokine levels indicating a role for TF in ischemia/reperfusion injury regulated by PAR-1 ${ }^{100}$.

The use of anti-TF antibodies revealed antithrombotic effects in a rabbit model of carotid artery injury. In this model of recurrent intravascular thrombosis an anti-rabbit TF monoclonal antibody was used and the resulting antithrombotic properties may indicate a possible therapeutic intervention method in humans ${ }^{101}$. Erlich et al. showed a positive effect of an anti-rabbit TF monoclonal antibody on infarct size in a myocardial ischemia/reperfusion model most likely through attenuation of inflammation. A rabbit coronary ligation model was used in which administration of a TF antibody reduced infarct size and decreased both chemokine expression and leukocyte infiltration ${ }^{102}$. The consequences of competition of ASIS with binding of FVIla to TF on cell signaling properties are not extensively known. 


\section{OUTLINE OF THIS THESIS}

Haemostasis maintains the balance in blood coagulation, preventing either bleeding or thrombosis, respectively. Blood coagulation and the formation of a thrombus are critical elements in the pathogenesis of ischemia/reperfusion injury. Several anti-coagulants are known for their protective properties in ischemia/reperfusion injury where the coagulant function of coagulation proteases is coupled to processes of inflammation and apoptosis.

In this thesis, we described the effects of two of these anti-coagulants namely ASIS and APC in mouse models of ischemia/reperfusion injury of the heart and the kidney, respectively. In chapter $\mathbf{1}$, a short overview is given of the pathophysiologies of both renal and myocardial ischemia/reperfusion. Furthermore, the specific working mechanisms of APC and ASIS are described including an overview of the different results that were obtained from animal studies performed with these anti-coagulants. In chapter 2, an explorative study was performed in which ASIS was administered at different stages in the ischemic or reperfusion phase to assess the optimal moment of drug administration with regard to its protective effects in myocardial ischemia/ reperfusion injury. This study was used as a basis for the study performed in chapter 3. Here, the specific working mechanism of ASIS was determined in an animal model of myocardial ischemia/reperfusion injury using mRNA and protein analysis in order to unravel the cell signaling pathways involved in the protective effects of ASIS. In Chapter 4, the same experimental set-up was used to study the effects of APC on myocardial ischemia/reperfusion injury. The effect of APC on myocardial infarct size was determined and a number of mRNA, protein, and immunohistochemical analyses were performed. The focus in this chapter is on the effect of APC on myocardial ischemia/reperfusion injury linked to the crosstalk between coagulation and cell protective functions and the role of PARs in this process. In chapter 5, both APC and ASIS were used in a mouse model of renal ischemia/reperfusion injury. Here the effect of these anti-coagulants was determined on renal injury and function and a correlation between coagulation and inflammation was investigated. The findings of these studies are discussed in chapter 6 and are compared to relevant results known from literature. Possible clinical applications are discussed at the end of this chapter. 


\section{REFERENCES}

1. Braunwald E, Kloner RA. Myocardial reperfusion: a double-edged sword? J Clin Invest. 1985;76:1713-1719.

2. Charlat ML, O'Neill PG, Hartley CJ, Roberts R, Bolli R. Prolonged abnormalities of left ventricular diastolic wall thinning in the "stunned" myocardium in conscious dogs: time course and relation to systolic function. J Am Coll Cardiol. 1989;13:185-194.

3. Bernier M, Manning AS, Hearse DJ. Reperfusion arrhythmias: dose-related protection by anti-free radical interventions. Am J Physiol. 1989;256:H1344-1352.

4. Kloner RA, Rude RE, Carlson N, Maroko PR, DeBoer LW, Braunwald E. Ultrastructural evidence of microvascular damage and myocardial cell injury after coronary artery occlusion: which comes first? Circulation. 1980;62:945-952.

5. Ito H, Okamura A, Iwakura K, Masuyama T, Hori M, Takiuchi S, Negoro S, Nakatsuchi Y, Taniyama Y, Higashino Y, Fujii K, Minamino T. Myocardial perfusion patterns related to thrombolysis in myocardial infarction perfusion grades after coronary angioplasty in patients with acute anterior wall myocardial infarction. Circulation. 1996;93:1993-1999.

6. Jennings RB, Murry CE, Steenbergen C, Jr., Reimer KA. Development of cell injury in sustained acute ischemia. Circulation. 1990;82:II2-12.

7. Bolli R. Oxygen-derived free radicals and postischemic myocardial dysfunction ("stunned myocardium"). J Am Coll Cardiol. 1988;12:239-249.

8. Dhalla NS, Elmoselhi AB, Hata T, Makino N. Status of myocardial antioxidants in ischemia-reperfusion injury. Cardiovasc Res. 2000;47:446-456.

9. Sellak H, Franzini E, Hakim J, Pasquier C. Reactive oxygen species rapidly increase endothelial ICAM-1 ability to bind neutrophils without detectable upregulation. Blood. 1994;83:2669-2677.

10. Krijnen PA, Nijmeijer R, Meijer CJ, Visser CA, Hack CE, Niessen HW. Apoptosis in myocardial ischaemia and infarction. J Clin Pathol. 2002;55:801-811.

11. Hill JH, Ward PA. The phlogistic role of C3 leukotactic fragments in myocardial infarcts of rats. J Exp Med. 1971;133:885-900.

12. Vakeva AP, Agah A, Rollins SA, Matis LA, Li L, Stahl GL. Myocardial infarction and apoptosis after myocardial ischemia and reperfusion: role of the terminal complement components and inhibition by anti-C5 therapy. Circulation. 1998;97:2259-2267.

13. Birdsall HH, Green DM, Trial J, Youker KA, Burns AR, Mackay CR, LaRosa GJ, Hawkins HK, Smith CW, Michael LH, Entman ML, Rossen RD. Complement C5a, TGF-beta 1, and MCP-1, in sequence, induce migration of monocytes into ischemic canine myocardium within the first one to five hours after reperfusion. Circulation. 1997;95:684-692.

14. Thadhani R, Pascual $\mathrm{M}$, Bonventre JV. Acute renal failure. $N$ Engl J Med. 1996;334:1448-1460.

15. Molitoris BA, Dahl R, Geerdes A. Cytoskeleton disruption and apical redistribution of

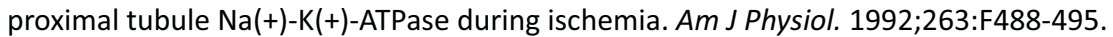

16. Bayati A. A study in the maintenance phase of ischaemic acute renal failure in the rat. Acta Physiol Scand. 1990;138:349-357.

17. Arendshorst WJ, Finn WF, Gottschalk CW. Pathogenesis of acute renal failure following temporary renal ischemia in the rat. Circ Res. 1975;37:558-568. 
18. Alejandro V, Scandling JD, Jr., Sibley RK, Dafoe D, Alfrey E, Deen W, Myers BD. Mechanisms of filtration failure during postischemic injury of the human kidney. A study of the reperfused renal allograft. J Clin Invest. 1995;95:820-831.

19. Flores J, DiBona DR, Beck $\mathrm{CH}$, Leaf $\mathrm{A}$. The role of cell swelling in ischemic renal damage and the protective effect of hypertonic solute. J Clin Invest. 1972;51:118-126.

20. Kaushal GP, Basnakian AG, Shah SV. Apoptotic pathways in ischemic acute renal failure. Kidney Int. 2004;66:500-506.

21. Rabb H, O'Meara YM, Maderna P, Coleman P, Brady HR. Leukocytes, cell adhesion molecules and ischemic acute renal failure. Kidney Int. 1997;51:1463-1468.

22. Sutton TA, Fisher CJ, Molitoris BA. Microvascular endothelial injury and dysfunction during ischemic acute renal failure. Kidney Int. 2002;62:1539-1549.

23. Meesters EW, Hansen H, Spronk HM, Hamulyak K, Rosing J, Rowshani AT, ten Berge IJ, ten Cate $\mathrm{H}$. The inflammation and coagulation cross-talk in patients with systemic lupus erythematosus. Blood Coagul Fibrinolysis. 2007;18:21-28.

24. Levi $\mathrm{M}$, Ten Cate $\mathrm{H}$. Disseminated intravascular coagulation. $N$ Engl J Med. 1999;341:586-592.

25. Mackman N, Tilley RE, Key NS. Role of the extrinsic pathway of blood coagulation in hemostasis and thrombosis. Arterioscler Thromb Vasc Biol. 2007;27:1687-1693.

26. Girard TJ, Warren LA, Novotny WF, Likert KM, Brown SG, Miletich JP, Broze GJ, Jr. Functional significance of the Kunitz-type inhibitory domains of lipoproteinassociated coagulation inhibitor. Nature. 1989;338:518-520.

27. Baugh RJ, Broze GJ, Jr., Krishnaswamy S. Regulation of extrinsic pathway factor Xa formation by tissue factor pathway inhibitor. J Biol Chem. 1998;273:4378-4386.

28. Spronk HM, Govers-Riemslag JW, ten Cate H. The blood coagulation system as a molecular machine. Bioessays. 2003;25:1220-1228.

29. Beresford CH. Antithrombin III deficiency. Blood Rev. 1988;2:239-250.

30. Barnes JA, Singh S, Gomes AV. Protease activated receptors in cardiovascular function and disease. Mol Cell Biochem. 2004;263:227-239.

31. Vu TK, Hung DT, Wheaton VI, Coughlin SR. Molecular cloning of a functional thrombin receptor reveals a novel proteolytic mechanism of receptor activation. Cell. 1991;64:1057-1068.

32. Coughlin SR. Thrombin signalling and protease-activated receptors. Nature. 2000;407:258-264.

33. Junge CE, Sugawara T, Mannaioni G, Alagarsamy S, Conn PJ, Brat DJ, Chan PH, Traynelis SF. The contribution of protease-activated receptor 1 to neuronal damage caused by transient focal cerebral ischemia. Proc Natl Acad Sci U S A. 2003;100:13019-13024.

34. Pawlinski R, Tencati M, Hampton CR, Shishido T, Bullard TA, Casey LM, AndradeGordon P, Kotzsch M, Spring D, Luther T, Abe J, Pohlman TH, Verrier ED, Blaxall BC, Mackman N. Protease-activated receptor-1 contributes to cardiac remodeling and hypertrophy. Circulation. 2007;116:2298-2306.

35. Camerer E, Huang W, Coughlin SR. Tissue factor- and factor X-dependent activation of protease-activated receptor 2 by factor VIla. Proc Natl Acad Sci U S A. 2000;97:5255-5260.

36. Riewald M, Petrovan RJ, Donner A, Mueller BM, Ruf W. Activation of endothelial cell protease activated receptor 1 by the protein $C$ pathway. Science. 2002;296:1880-1882.

37. Cunningham MA, Romas P, Hutchinson P, Holdsworth SR, Tipping PG. Tissue factor and factor VIla receptor/ligand interactions induce proinflammatory effects in macrophages. Blood. 1999;94:3413-3420. 
38. Pawlinski R, Pedersen B, Schabbauer G, Tencati M, Holscher T, Boisvert W, AndradeGordon P, Frank RD, Mackman N. Role of tissue factor and protease-activated receptors in a mouse model of endotoxemia. Blood. 2004;103:1342-1347.

39. Napoli C, Cicala C, Wallace JL, de Nigris F, Santagada V, Caliendo G, Franconi F, Ignarro LJ, Cirino G. Protease-activated receptor-2 modulates myocardial ischemiareperfusion injury in the rat heart. Proc Natl Acad Sci U S A. 2000;97:3678-3683.

40. Nakanishi-Matsui M, Zheng YW, Sulciner DJ, Weiss EJ, Ludeman MJ, Coughlin SR. PAR3 is a cofactor for PAR4 activation by thrombin. Nature. 2000;404:609-613.

41. Weiss EJ, Hamilton JR, Lease KE, Coughlin SR. Protection against thrombosis in mice lacking PAR3. Blood. 2002;100:3240-3244.

42. Sambrano GR, Weiss EJ, Zheng YW, Huang W, Coughlin SR. Role of thrombin signalling in platelets in haemostasis and thrombosis. Nature. 2001;413:74-78.

43. Taylor FB, Jr., Peer GT, Lockhart MS, Ferrell G, Esmon CT. Endothelial cell protein C receptor plays an important role in protein $\mathrm{C}$ activation in vivo. Blood. 2001;97:1685-1688.

44. Stearns-Kurosawa DJ, Kurosawa S, Mollica JS, Ferrell GL, Esmon CT. The endothelial cell protein $C$ receptor augments protein $C$ activation by the thrombinthrombomodulin complex. Proc Natl Acad Sci U S A. 1996;93:10212-10216.

45. Esmon CT. Coagulation and inflammation. J Endotoxin Res. 2003;9:192-198.

46. Zhang L, Jhingan A, Castellino FJ. Role of individual gamma-carboxyglutamic acid residues of activated human protein $\mathrm{C}$ in defining its in vitro anticoagulant activity. Blood. 1992;80:942-952.

47. Liaw PC, Mather T, Oganesyan N, Ferrell GL, Esmon CT. Identification of the protein C/ activated protein $\mathrm{C}$ binding sites on the endothelial cell protein $\mathrm{C}$ receptor. Implications for a novel mode of ligand recognition by a major histocompatibility complex class 1-type receptor. J Biol Chem. 2001;276:8364-8370.

48. Regan LM, Stearns-Kurosawa DJ, Kurosawa S, Mollica J, Fukudome K, Esmon CT. The endothelial cell protein $C$ receptor. Inhibition of activated protein $C$ anticoagulant function without modulation of reaction with proteinase inhibitors. $J$ Biol Chem. 1996;271:17499-17503.

49. Rezaie AR, Cooper ST, Church FC, Esmon CT. Protein C inhibitor is a potent inhibitor of the thrombin-thrombomodulin complex. J Biol Chem. 1995;270:25336-25339.

50. Okajima K, Koga S, Kaji M, Inoue M, Nakagaki T, Funatsu A, Okabe H, Takatsuki K, Aoki $\mathrm{N}$. Effect of protein $\mathrm{C}$ and activated protein $\mathrm{C}$ on coagulation and fibrinolysis in normal human subjects. Thromb Haemost. 1990;63:48-53.

51. Berger H, Jr., Kirstein CG, Orthner CL. Pharmacokinetics of activated protein C in guinea pigs. Blood. 1991;77:2174-2184.

52. Riewald M, Petrovan RJ, Donner A, Ruf W. Activated protein C signals through the thrombin receptor PAR1 in endothelial cells. J Endotoxin Res. 2003;9:317-321.

53. Lane DA, Philippou H, Huntington JA. Directing thrombin. Blood. 2005;106:2605-2612.

54. Bae JS, Yang L, Rezaie AR. Receptors of the protein C activation and activated protein C signaling pathways are colocalized in lipid rafts of endothelial cells. Proc Natl Acad Sci U S A. 2007;104:2867-2872.

55. Bae JS, Yang L, Rezaie AR. Lipid raft localization regulates the cleavage specificity of protease activated receptor 1 in endothelial cells. J Thromb Haemost. 2008;6:954-961.

56. Yang XV, Banerjee Y, Fernandez JA, Deguchi H, Xu X, Mosnier LO, Urbanus RT, de Groot PG, White-Adams TC, McCarty OJ, Griffin JH. Activated protein C ligation of ApoER2 (LRP8) causes Dab1-dependent signaling in U937 cells. Proc Natl Acad Sci U S A. 2009;106:274-279. 
57. White TC, Berny MA, Tucker El, Urbanus RT, de Groot PG, Fernandez JA, Griffin JH, Gruber A, McCarty OJ. Protein $C$ supports platelet binding and activation under flow: role of glycoprotein $\mathrm{Ib}$ and apolipoprotein $\mathrm{E}$ receptor 2. J Thromb Haemost. 2008;6:995-1002.

58. Joyce DE, Gelbert L, Ciaccia A, DeHoff B, Grinnell BW. Gene expression profile of antithrombotic protein $\mathrm{C}$ defines new mechanisms modulating inflammation and apoptosis. J Biol Chem. 2001;276:11199-11203.

59. Cheng T, Liu D, Griffin JH, Fernandez JA, Castellino F, Rosen ED, Fukudome K, Zlokovic BV. Activated protein C blocks p53-mediated apoptosis in ischemic human brain endothelium and is neuroprotective. Nat Med. 2003;9:338-342.

60. Joyce DE, Grinnell BW. Recombinant human activated protein $\mathrm{C}$ attenuates the inflammatory response in endothelium and monocytes by modulating nuclear factorkappaB. Crit Care Med. 2002;30:S288-293.

61. Franscini N, Bachli EB, Blau N, Leikauf MS, Schaffner A, Schoedon G. Gene expression profiling of inflamed human endothelial cells and influence of activated protein $\mathrm{C}$. Circulation. 2004;110:2903-2909.

62. Dillon JP, Laing AJ, Cahill RA, O'Brien GC, Street JT, Wang JH, Mc Guinness A, Redmond HP. Activated protein $C$ attenuates acute ischaemia reperfusion injury in skeletal muscle. J Orthop Res. 2005;23:1454-1459.

63. Mosnier LO, Zlokovic BV, Griffin JH. The cytoprotective protein C pathway. Blood. 2007;109:3161-3172.

64. Stephenson DA, ToltI LJ, Beaudin S, Liaw PC. Modulation of monocyte function by activated protein C, a natural anticoagulant. J Immunol. 2006;177:2115-2122.

65. Kurosawa S, Esmon CT, Stearns-Kurosawa DJ. The soluble endothelial protein C receptor binds to activated neutrophils: involvement of proteinase-3 and CD11b/ CD18. J Immunol. 2000;165:4697-4703.

66. Mosnier LO, Griffin JH. Inhibition of staurosporine-induced apoptosis of endothelial cells by activated protein $C$ requires protease-activated receptor- 1 and endothelial cell protein C receptor. Biochem J. 2003;373:65-70.

67. Jian MY, Koizumi T, Tsushima K, Fujimoto K, Kubo K. Activated protein C attenuates acid-aspiration lung injury in rats. Pulm Pharmacol Ther. 2005;18:291-296.

68. Wong SS, Sun NN, Hyde JD, Ruiz L, Meigs E, Herrin BR, Fastje CD, Macdonald SJ, Witten ML. Drotrecogin alfa (activated) prevents smoke-induced increases in pulmonary microvascular permeability and proinflammatory cytokine IL-1beta in rats. Lung. 2004;182:319-330.

69. Slofstra SH, Groot AP, Maris NA, Reitsma PH, Cate HT, Spek CA. Inhalation of activated protein $\mathrm{C}$ inhibits endotoxin-induced pulmonary inflammation in mice independent of neutrophil recruitment. Br J Pharmacol. 2006;149:740-746.

70. Shibata M, Kumar SR, Amar A, Fernandez JA, Hofman F, Griffin JH, Zlokovic BV. Antiinflammatory, antithrombotic, and neuroprotective effects of activated protein $\mathrm{C}$ in a murine model of focal ischemic stroke. Circulation. 2001;103:1799-1805.

71. Zlokovic BV, Zhang C, Liu D, Fernandez J, Griffin JH, Chopp M. Functional recovery after embolic stroke in rodents by activated protein C. Ann Neurol. 2005;58:474-477.

72. Mizutani A, Okajima K, Uchiba M, Noguchi T. Activated protein C reduces ischemia/ reperfusion-induced renal injury in rats by inhibiting leukocyte activation. Blood. 2000;95:3781-3787.

73. Hirose K, Okajima K, Taoka Y, Uchiba M, Tagami H, Nakano K, Utoh J, Okabe H, Kitamura N. Activated protein $\mathrm{C}$ reduces the ischemia/reperfusion-induced spinal cord injury in rats by inhibiting neutrophil activation. Ann Surg. 2000;232:272-280. 
74. Han MH, Hwang SI, Roy DB, Lundgren DH, Price JV, Ousman SS, Fernald GH, Gerlitz B, Robinson WH, Baranzini SE, Grinnell BW, Raine CS, Sobel RA, Han DK, Steinman L. Proteomic analysis of active multiple sclerosis lesions reveals therapeutic targets. Nature. 2008;451:1076-1081.

75. Isermann B, Vinnikov IA, Madhusudhan T, Herzog S, Kashif M, Blautzik J, Corat MA, Zeier M, Blessing E, Oh J, Gerlitz B, Berg DT, Grinnell BW, Chavakis T, Esmon CT, Weiler $\mathrm{H}$, Bierhaus A, Nawroth PP. Activated protein C protects against diabetic nephropathy by inhibiting endothelial and podocyte apoptosis. Nat Med. 2007;13:1349-1358.

76. Feistritzer $C$, Riewald $M$. Endothelial barrier protection by activated protein $C$ through PAR1-dependent sphingosine 1-phosphate receptor-1 crossactivation. Blood. 2005;105:3178-3184.

77. McVerry BJ, Garcia JG. Endothelial cell barrier regulation by sphingosine 1-phosphate. J Cell Biochem. 2004;92:1075-1085.

78. Finigan JH, Dudek SM, Singleton PA, Chiang ET, Jacobson JR, Camp SM, Ye SQ, Garcia JG. Activated protein $C$ mediates novel lung endothelial barrier enhancement: role of sphingosine 1-phosphate receptor transactivation. J Biol Chem. 2005;280:17286-17293.

79. Bae JS, Yang L, Manithody C, Rezaie AR. The ligand occupancy of endothelial protein C receptor switches the protease-activated receptor 1-dependent signaling specificity of thrombin from a permeability-enhancing to a barrier-protective response in endothelial cells. Blood. 2007;110:3909-3916.

80. Liu D, Cheng T, Guo H, Fernandez JA, Griffin JH, Song X, Zlokovic BV. Tissue plasminogen activator neurovascular toxicity is controlled by activated protein $\mathrm{C}$. Nat Med. 2004;10:1379-1383.

81. Cheng T, Petraglia AL, Li Z, Thiyagarajan M, Zhong Z, Wu Z, Liu D, Maggirwar SB, Deane R, Fernandez JA, LaRue B, Griffin JH, Chopp M, Zlokovic BV. Activated protein C inhibits tissue plasminogen activator-induced brain hemorrhage. Nat Med. 2006;12:1278-1285.

82. Arnljots B, Ezban M, Hedner U. Prevention of experimental arterial thrombosis by topical administration of active site-inactivated factor VIla. J Vasc Surg. 1997;25:341-346.

83. Golino P, Ragni M, Cirillo P, D'Andrea D, Scognamiglio A, Ravera A, Buono C, Ezban M, Corcione N, Vigorito F, Condorelli M, Chiariello M. Antithrombotic effects of recombinant human, active site-blocked factor VIla in a rabbit model of recurrent arterial thrombosis. Circ Res. 1998;82:39-46.

84. Mackman N. Role of tissue factor in hemostasis and thrombosis. Blood Cells Mol Dis. 2006;36:104-107.

85. Pyo RT, Sato Y, Mackman N, Taubman MB. Mice deficient in tissue factor demonstrate attenuated intimal hyperplasia in response to vascular injury and decreased smooth muscle cell migration. Thromb Haemost. 2004;92:451-458.

86. Carmeliet $\mathrm{P}$, Mackman N, Moons L, Luther T, Gressens $\mathrm{P}$, Van Vlaenderen I, Demunck H, Kasper M, Breier G, Evrard P, Muller M, Risau W, Edgington T, Collen D. Role of tissue factor in embryonic blood vessel development. Nature. 1996;383:73-75.

87. Ruf W, Edgington TS. Structural biology of tissue factor, the initiator of thrombogenesis in vivo. FASEB J. 1994;8:385-390.

88. Giesen PL, Rauch U, Bohrmann B, Kling D, Roque M, Fallon JT, Badimon JJ, Himber J, Riederer MA, Nemerson Y. Blood-borne tissue factor: another view of thrombosis. Proc Natl Acad Sci U S A. 1999;96:2311-2315.

89. Mandal SK, Pendurthi UR, Rao LV. Cellular localization and trafficking of tissue factor. Blood. 2006;107:4746-4753. 
90. Ott I, Fischer EG, Miyagi Y, Mueller BM, Ruf W. A role for tissue factor in cell adhesion and migration mediated by interaction with actin-binding protein 280. J Cell Biol. 1998;140:1241-1253.

91. Abe K, Shoji M, Chen J, Bierhaus A, Danave I, Micko C, Casper K, Dillehay DL, Nawroth PP, Rickles FR. Regulation of vascular endothelial growth factor production and angiogenesis by the cytoplasmic tail of tissue factor. Proc Natl Acad Sci U S A. 1999;96:8663-8668.

92. Versteeg HH, Sorensen BB, Slofstra SH, Van den Brande JH, Stam JC, van Bergen en Henegouwen PM, Richel DJ, Petersen LC, Peppelenbosch MP. VIla/tissue factor interaction results in a tissue factor cytoplasmic domain-independent activation of protein synthesis, p70, and p90 S6 kinase phosphorylation. J Biol Chem. 2002;277:27065-27072.

93. Sorensen BB, Rao LV, Tornehave D, Gammeltoft S, Petersen LC. Antiapoptotic effect of coagulation factor VIla. Blood. 2003;102:1708-1715.

94. Hjortoe GM, Petersen LC, Albrektsen T, Sorensen BB, Norby PL, Mandal SK, Pendurthi UR, Rao LV. Tissue factor-factor VIla-specific up-regulation of IL-8 expression in MDAMB-231 cells is mediated by PAR-2 and results in increased cell migration. Blood. 2004;103:3029-3037.

95. Camerer E, Cornelissen I, Kataoka H, Duong DN, Zheng YW, Coughlin SR. Roles of protease-activated receptors in a mouse model of endotoxemia. Blood. 2006;107:3912-3921.

96. Golino P, Ragni M, Cirillo P, Scognamiglio A, Ravera A, Buono C, Guarino A, Piro O, Lambiase C, Botticella F, Ezban M, Condorelli M, Chiariello M. Recombinant human, active site-blocked factor VIla reduces infarct size and no-reflow phenomenon in rabbits. Am J Physiol Heart Circ Physiol. 2000;278:H1507-1516.

97. Welty-Wolf KE, Carraway MS, Miller DL, Ortel TL, Ezban M, Ghio AJ, Idell S, Piantadosi CA. Coagulation blockade prevents sepsis-induced respiratory and renal failure in baboons. Am J Respir Crit Care Med. 2001;164:1988-1996.

98. Taylor FB, Chang AC, Peer G, Li A, Ezban M, Hedner U. Active site inhibited factor VIla (DEGR VIla) attenuates the coagulant and interleukin- 6 and -8 , but not tumor necrosis factor, responses of the baboon to LD100 Escherichia coli. Blood. 1998;91:1609-1615.

99. Olanders K, Borjesson A, Zhao X, Andersson R. Effects of anticoagulant treatment on intestinal ischaemia and reperfusion injury in rats. Acta Anaesthesiol Scand. 2005;49:517-524.

100. Sevastos J, Kennedy SE, Davis DR, Sam M, Peake PW, Charlesworth JA, Mackman N, Erlich $\mathrm{JH}$. Tissue factor deficiency and PAR-1 deficiency are protective against renal ischemia reperfusion injury. Blood. 2007;109:577-583.

101. Pawashe AB, Golino P, Ambrosio G, Migliaccio F, Ragni M, Pascucci I, Chiariello M, Bach R, Garen A, Konigsberg WK, et al. A monoclonal antibody against rabbit tissue factor inhibits thrombus formation in stenotic injured rabbit carotid arteries. Circ Res. 1994;74:56-63.

102. Erlich JH, Boyle EM, Labriola J, Kovacich JC, Santucci RA, Fearns C, Morgan EN, Yun W, Luther T, Kojikawa O, Martin TR, Pohlman TH, Verrier ED, Mackman N. Inhibition of the tissue factor-thrombin pathway limits infarct size after myocardial ischemiareperfusion injury by reducing inflammation. Am J Pathol. 2000;157:1849-1862.

\section{Acknowledgments}

We kindly acknowledge Julian Ilcheff Borissoff for providing Figure 2. 



\section{Chapter 2}

\section{ASIS reduces myocardial infarct size: an explorative study}

STBG Loubele, CA Spek, P Leenders, R van Oerle, HMH Spronk, H ten Cate. 


\section{AbSTRACT}

The anti-coagulant active site inhibited FVIla (ASIS) has been shown to be protective against myocardial ischemia/reperfusion (I/R) injury. In these studies however, no working mechanism of ASIS was revealed nor was its role in inflammation, apoptosis and cell signaling pathways investigated.

In this explorative study, we administered ASIS in a myocardial I/R injury model. ASIS was administered either in a single dose during ischemia, in a single dose during reperfusion or 2 times in a single dose during ischemia and reperfusion in order to determine the optimal time point of administration in regard to decreasing the infarct size.

Our results show an optimal effect of ASIS when administered during ischemia and reperfusion as revealed by a decrease in infarct size in combination with a maximal effect on coagulation and inflammation. 


\section{INTRODUCTION}

Tissue factor (TF) is the most important contributor in the physiological activation of blood coagulation. TF is a transmembrane protein, which after complex formation with factor (F)VIla starts the activation of the extrinsic pathway of blood coagulation. TF is known to be abundantly present in atherosclerotic lesions, where it is co-localized with vascular smooth muscle cells and macrophages, and in thrombi formed within the coronary artery. After disruption of an atherosclerotic lesion, TF is exposed to the bloodstream were it activates the blood coagulation system. A natural inhibitor of TF is tissue factor pathway inhibitor (TFPI), which is a serine protease inhibitor of the TF/FVIIa complex and is the only regulator of the TF-dependent pathway of coagulation known so far $^{1,2}$. Active site inhibited factor VIla or ASIS is a synthetically developed anti-coagulant which is a competitive inhibitor of FVIla, being a recombinant FVIla which is blocked at its catalytic site by the tripeptide (PhePhe-Arg) chloromethyl ketone.

Previous studies revealed a protective role for ASIS or blockage of TF in a rabbit model of myocardial $\mathrm{I} / \mathrm{R}$ injury but underlying mechanisms were not revealed $^{3,4}$. In the current study we tested the administration of ASIS during 3 different time points in a mouse model of $I / R$ injury to determine the optimal time point of administration and to achieve a maximal effect of the intervention. 


\section{MATERIALS AND METHODS}

Mouse Myocardial Ischemia/Reperfusion Model. Myocardial I/R was induced according to the method of Jong et al. ${ }^{5}$. A detailed protocol is provided in addendum 1.

Intervention. Recombinant mouse ASIS (Novo, Denmark) in a dose of $1 \mathrm{mg} / \mathrm{kg}$ $(100 \mu \mathrm{l})$ or placebo $(0.9 \% \mathrm{NaCl})$ was administered i.v. $15 \mathrm{~min}$ after induction of ischemia as a single dose (I), 5 min after induction of reperfusion as a single dose $(R)$, or as a repeated i.v. dose $15 \mathrm{~min}$ after ischemia and $5 \mathrm{~min}$ after reperfusion $(\mathrm{I}+\mathrm{R})$.

Plasma and tissue collection. A detailed protocol is provided in addendum 2.

Determination of myocardial I/R injury: Evans Blue/TTC staining. A detailed protocol is provided in addendum 3.

Fatty acid binding protein. Heart fatty acid binding protein (H-FABP) levels were determined in the plasma's of the ASIS and placebo treated animals. Analyses were performed according to the manufacturer's instructions (Hycult Biotechnology Bv, Uden, the Netherlands).

TF activity. A detailed protocol is provided in addendum 4.

Calibrated Automated Thrombogram (CAT). The CAT was obtained from Thrombinoscope BV (Maastricht, The Netherlands) and all samples were analyzed as described for tissue by Frederix et $a{ }^{6}{ }^{6}$. In brief, each well contained $5 \mathrm{pM}$ of recombinant TF and $4 \mu \mathrm{M}$ of phosphatidylserine/ phosphathidylcholine/phosphatidyl- ethanolamine vesicles and FluCa-solution contained Hepes, pH 7.35, $100 \mathrm{nM} \mathrm{CaCl}, 60 \mathrm{mg} / \mathrm{ml} \mathrm{BSA}$ and $2.5 \mathrm{mM}$ Z-Gly-GlyArg-AMC. From each experimental group, 5 heart homogenates with a protein concentration of $5 \mathrm{mg} / \mathrm{ml}$ were pooled and measured in duplo. Lag time, time to peak, peak height, endogenous thrombin potential (ETP) and time to tail were derived from the thrombin generation curves.

Fibrin staining. Mouse heart paraffin sections $(4 \mu \mathrm{m})$ were deparaffinized and underwent microwave pretreatment. Sections were washed in tris-buffered saline (TBS) for 3 times during 5 minutes and incubated with rabbit anti-rat fibrin antibody for 45 minutes at room temperature (RT). Then, the sections were washed 3 times for 5 minutes with TBS and incubated with a secondary biotinylated swine anti-rabbit antibody (Dako, Glostrup, Denmark) for 30 
minutes at RT. After washing, streptavidine-ABC-alkaline phosphatase antibody (Dako, Glostrup, Denmark) was administered for 30 minutes at RT. After washing 3 times for 5 minutes in TBS, the slides were stained with Vector Red (Vector, Burlingame, CA) and counterstained with haematoxylin (Klinipath, Duiven, the Netherlands). Finally, sections were mounted with Imsol and Entellan.

Multiplex Ligation dependent Probe Amplification (MLPA). Coagulation, inflammation, and cell signaling related gene expression levels were determined in isolated RNA of the mouse hearts ( $n=6$ per group). $50 \mathrm{ng} / \mu \mathrm{l}$ RNA was analyzed according to the method described previously by Spek et al. ${ }^{7}$. Several genes involved in cellular signaling, inflammation and coagulation were analyzed (cell signaling: CD14, toll-like receptor (TLR)-2, TLR-4, IL-1 receptorassociated kinase (IRAK)-1, IRAK-3, IKB $\alpha$, and protease activated receptor-1 (PAR-1); coagulation: TF, tissue factor pathway inhibitor (TFPI), plasminogen activator inhibitor-1 (PAI-1), urokinase-type plasminogen activator receptor (UPAR), tissue-type plasminogen activator receptor (t-PA), and protein $\mathrm{C}$ receptor; inflammation: interleukin (IL)-6, IL-4, IL-10, IL-1 $\beta$, tumor necrosis factor (TNF)- $\alpha$, interferon (IFN) $-\gamma$, hypoxia-inducible factor (HIF)-1 $\alpha$, ICAM-1, macrophage inflammatory protein (MIP)- $1 \alpha, \mathrm{CxCl} 1, \mathrm{CCl} 3$, and eNOS. Only the genes that showed detectable expression levels are depicted in the results. 


\section{RESULTS}

Amount of myocardial I/R injury. Infarct sizes were determined using the Evans Blue/TTC staining. The percentage area of infarction (AOI) to area at risk (AAR) was determined and a $31.2 \%$ reduction in infarct size was revealed upon ASIS administration in a single dose during the ischemic phase (I), a $42.9 \%$ reduction when administered during the ischemia and reperfusion time $(I+R)$ and a $51.3 \%$ reduction when administered only during the reperfusion phase ( $R$ ) compared to placebo. Infarct size decreased when ASIS was given during the ischemia and reperfusion phase or only during the reperfusion phase compared to when ASIS was given only during ischemia (Figure $1 \mathrm{~A}$ ). Myocardial injury was also assessed by $\mathrm{H}$-FABP determination in plasma as FABP is released from the cardiomyocytes into the bloodstream upon myocardial infarction ${ }^{8}$. H-FABP levels increased upon $I / R$ injury compared to sham animals for all three administration time points. Upon ASIS administration, H-FABP levels were not altered compared to their corresponding placebo treated animals (Figure 1B).
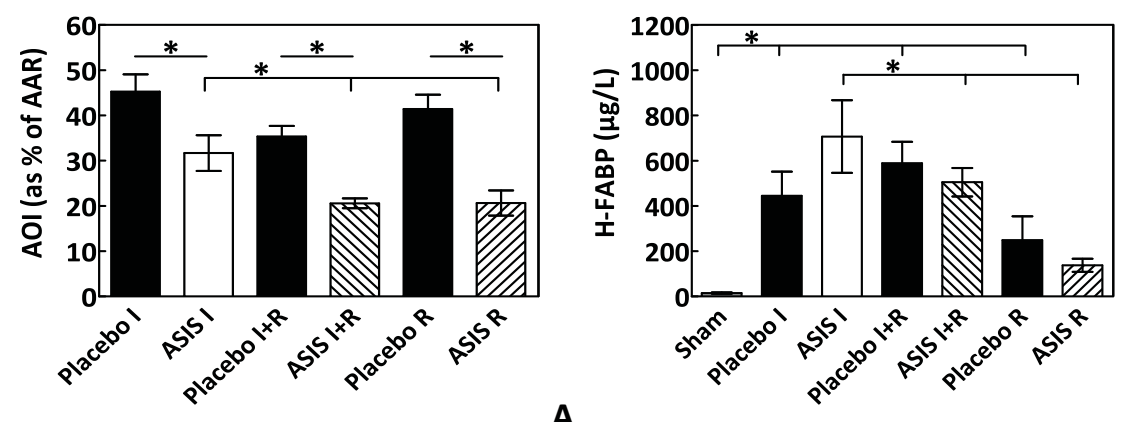

A

B

Figure 1: Panel A: Myocardial injury after I/R as assessed by Evans Blue/TTC staining. Panel B: FABP measurement in plasma. $n=6,{ }^{*} p<0.05$.

Coagulation. To determine the effect of ASIS on coagulation parameters, TF activity levels and thrombin generation were determined in the left ventricle tissue homogenates and paraffin sections were stained for fibrin. TF activity levels increased upon I/R injury compared to sham animals. Upon ASIS administration, TF activity levels decreased when administered during ischemia or during ischemia and reperfusion compared to placebo treatment. Administration of ASIS during the reperfusion phase did not influence TF activity levels compared to placebo (Figure 2). Thrombin generation as 
determined by CAT analysis revealed increased ETP values upon I/R compared to placebo. ETP values decreased upon ASIS administration with a maximal decrease when administered during ischemia and reperfusion or during reperfusion alone compared to when ASIS is administered during ischemia (Figure 2). Immunohistochemical staining revealed fibrin deposition in the heart after I/R but showed no influence of ASIS administration on fibrin deposition (data not shown).
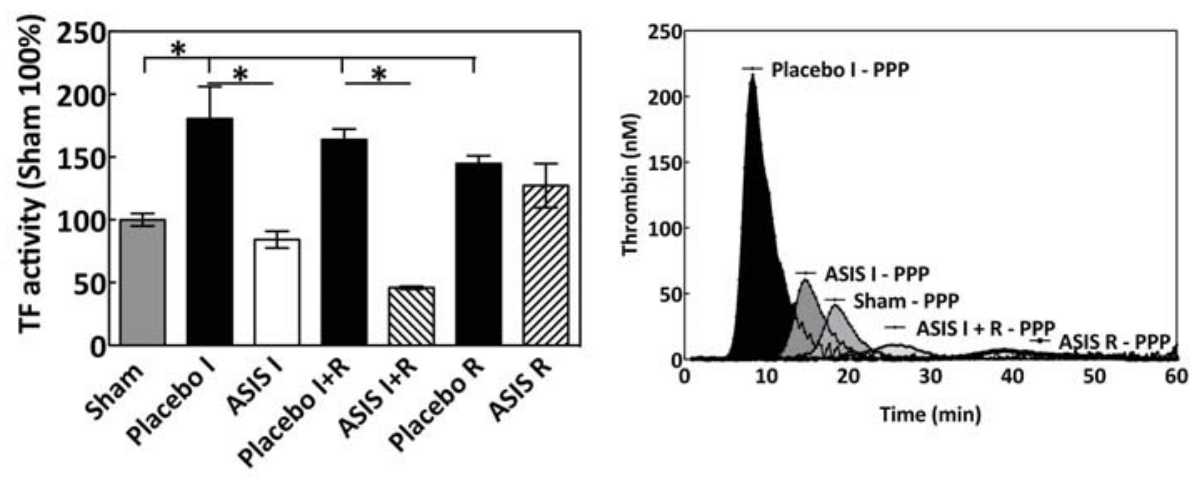

Figure 2: Effect of ASIS on coagulation as determined by TF activity (left panel), and thrombin generation (right panel). $n=6, p<0.05$.

MLPA (coagulation). RNA expression levels of several genes involved in coagulation were determined using MLPA. Neither TF nor TFPI levels were influenced upon I/R compared to sham. Administration of ASIS during ischemia increased TF and TFPI mRNA levels compared to placebo but an effect of ASIS was no longer visible when ASIS was given during reperfusion or during ischemia and reperfusion (Figure $1 \mathrm{~A}$ and $1 \mathrm{~B}$ ). PAI-1 mRNA expression levels increased upon I/R compared to sham and were decreased when ASIS was given during the ischemic as well as the reperfusion phase (Figure 1C). TPA levels were not influenced upon I/R and ASIS administration did not alter TPA levels (Figure 1D). 
TF

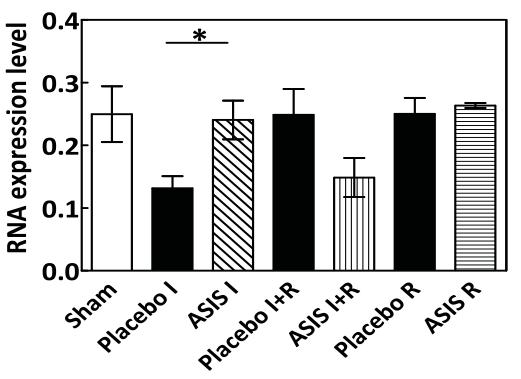

A

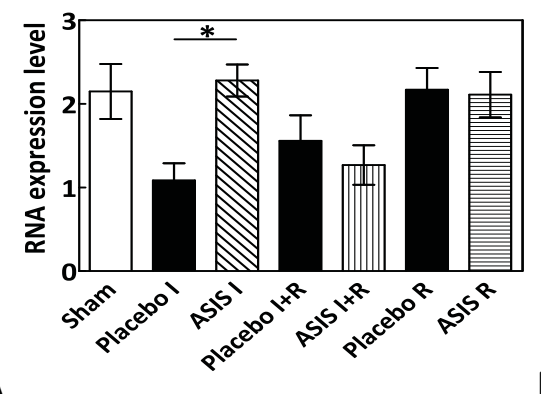

TFPI

B
PAI-1

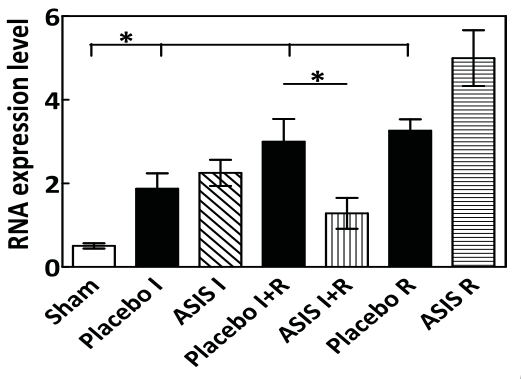

tPA

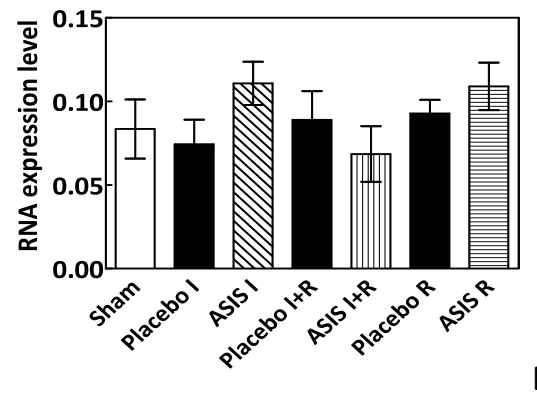

Figure 3: Effect of ASIS on RNA expression levels of coagulation related genes. Panel A: TF gene expression, Panel B: TFPI gene expression, Panel C: PAI-1 gene expression, Panel D: tPA gene expression. $n=6, p<0.05$.

MLPA (inflammation). IL-6, IL-1 $\beta$, and MIP-1 $\alpha$ levels increased upon I/R compared to sham animals. Administration of ASIS reduced IL-6, IL-1 $\beta$, and MIP-1 $\alpha$ mRNA expression levels when administered during both the ischemic as well as the reperfusion phase. IL-1 $\beta$ levels decreased upon ASIS administration when given during ischemia alone, but not when ASIS was administered during reperfusion in a single dose. ASIS administration during reperfusion alone did not influence IL-6 or MIP-1 $\alpha$ levels (Figure 4A, 4B, and 4C). ICAM1 levels increased upon I/R but were not influenced upon ASIS administration (Figure 4D). eNOS and HIF-1 $\alpha$ levels were not increased upon I/R compared to sham. eNOS mRNA expression levels decreased upon ASIS administration during ischemia and reperfusion. eNOS and HIF-1 $\alpha$ levels increased when ASIS was administered during ischemia and remained equal compared to placebo when ASIS was administered during reperfusion (Figure 4E and 4F). 
IL-6

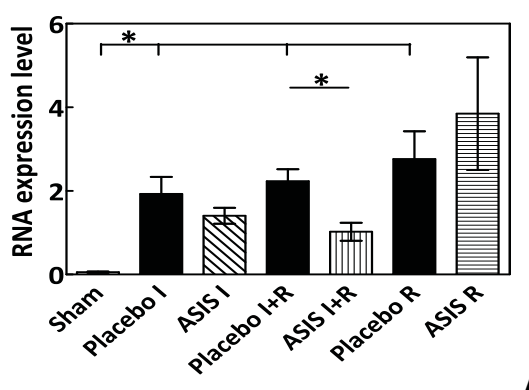

A

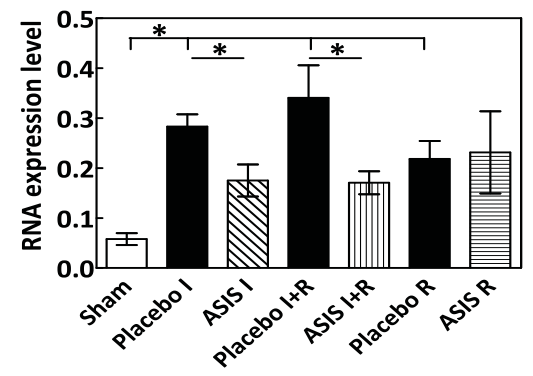

B

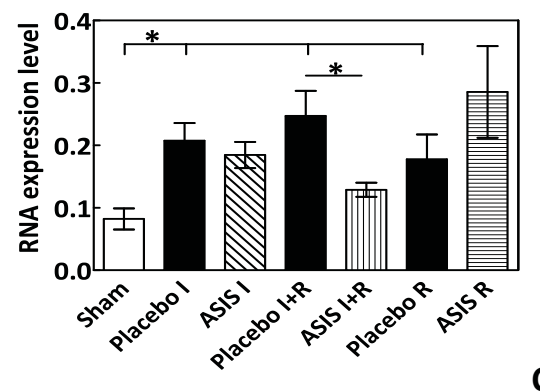

ICAM1

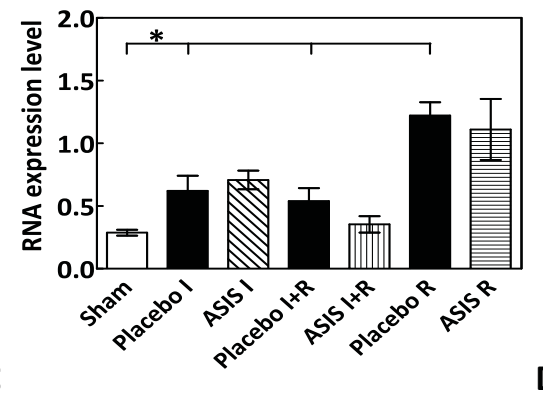

eNOS

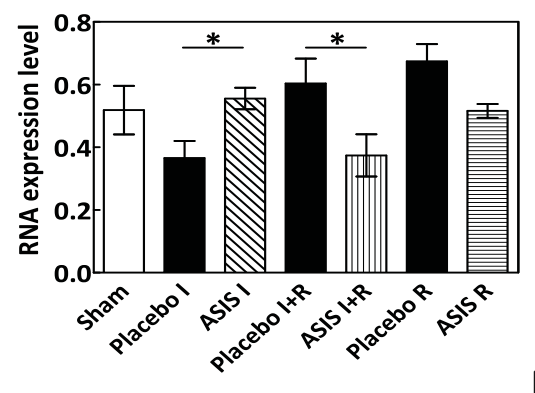

E

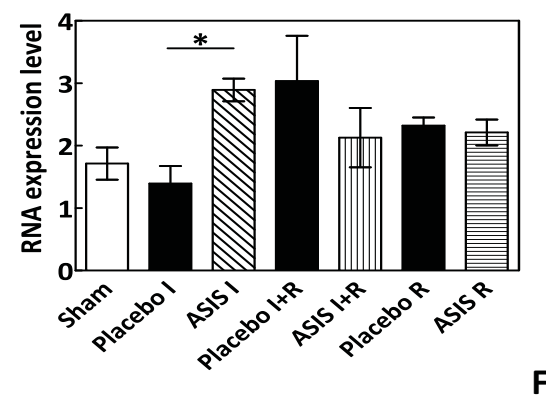

Figure 4: Effect of ASIS on RNA expression levels of inflammation related genes. Panel A: IL-6 gene expression, Panel B: IL-1 $\beta$ gene expression, Panel C: MIP-1 $\alpha$ gene expression, Panel D: ICAM-1 gene expression, Panel E: eNOS gene expression, Panel F: HIF-1 $\alpha$ gene expression. $n=6, p<0.05$. 
MLPA (cell signaling).TLR-4 mRNA expression levels were not influenced on I/R compared to sham nor did ASIS administration have an effect on TLR-4 levels (Figure 5A). IRAK1 levels decreased upon I/R compared to sham and increased upon ASIS administration when given during ischemia compared to placebo (Figure $5 B$ ). IKB $\alpha$ levels increased upon $\mathrm{I} / \mathrm{R}$ and decreased when ASIS was administered during ischemia and reperfusion. Administration of ASIS during ischemia however increased $1 \mathrm{~KB} \alpha$ expression levels compared to placebo (Figure 5C). PAR-1 levels were not influenced upon I/R but increased when ASIS was administered during ischemia when compared to placebo animals (Figure $5 D)$.

TLR-4

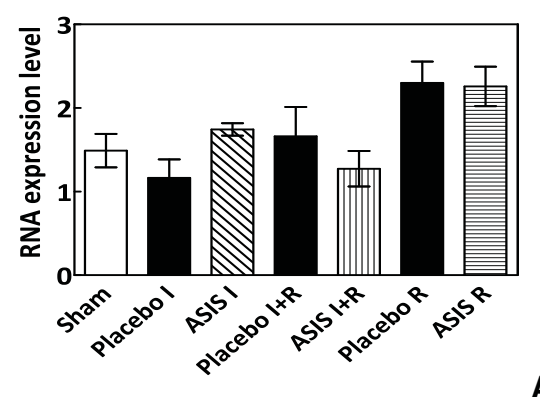

$\mathrm{IKB} \alpha$

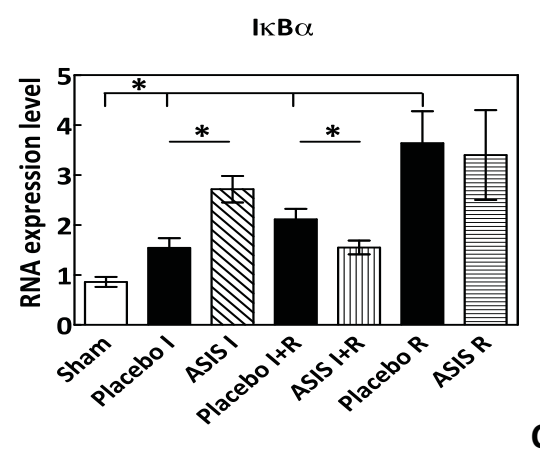

IRAK1

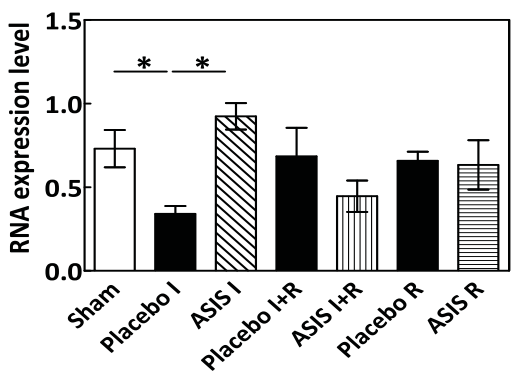

B

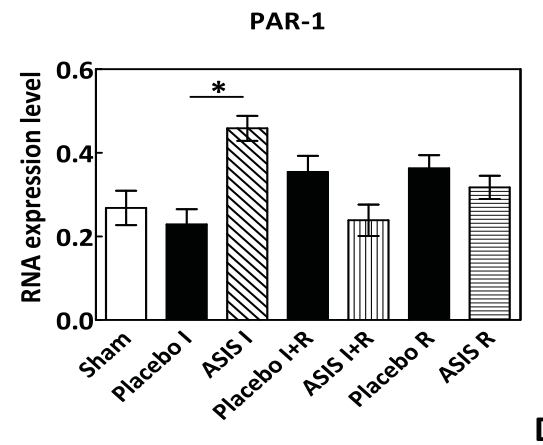

Figure 5: Effect of ASIS on RNA expression levels of cell signaling related genes. Panel A: TLR-4 gene expression, Panel B: IRAK1 gene expression, Panel $\mathrm{C}$ : IאB $\alpha$ gene expression, Panel D: PAR-1 gene expression. $n=6, p<0.05$. 


\section{DiscuSSION}

In this study, ASIS was administered at 3 different time points during myocardial ischemia and reperfusion to determine the optimal time point of ASIS administration in order to obtain a maximal effect of the intervention. Analysis of myocardial injury by means of Evans Blue/TTC staining showed a decreasing effect of myocardial infarct size upon ASIS administration, revealing a maximal effect when ASIS was administered during ischemia and reperfusion or only during the reperfusion phase compared to when ASIS was administered during ischemia. Analysis of coagulation revealed an attenuating effect of ASIS on TF activity in the heart, showing a maximal effect when ASIS was given during ischemia and reperfusion. Thrombin generation was reduced upon ASIS administration and a maximal effect was obtained when ASIS was given during ischemia and reperfusion or only during the reperfusion phase. Fibrin deposition, however, was not influenced upon ASIS administration. Analysis of gene expression levels involved in coagulation, inflammation, and cell signaling revealed the most profound effect of ASIS when administered during ischemia and reperfusion.

Active site inhibited factor VIla or ASIS is a synthetically developed anticoagulant which is a recombinant FVIla, blocked at its catalytic site by the tripeptide (Phe-Phe-Arg) chloromethyl ketone and a competitive inhibitor of TF. Pharmacokinetic studies showed that human ASIS was cleared from the circulation with a mean retention time of 2.7 hours when a dose of $10 \mathrm{mg} / \mathrm{kg}$ b.w. was administered to $\mathrm{C} 57 \mathrm{BI} / 6$ mice. The peak value was obtained after about 5 min. Experiments comparing 125-I labelled mouse and human FVIla showed no significant difference in pharmacokinetic parameters when administered to these mice, just as clearance of FVIla was not affected by active site blockage (unpublished data). Administration (i.v.) of $1 \mathrm{mg} / \mathrm{kg}$ b.w. resulted in a peak value of about $80 \mathrm{nM}$ (unpublished data) which is about 6 fold higher than the FVII plasma level of $14 \mathrm{nM}$ in mice. Also, ASIS binds to TF with an approximately 3 fold higher affinity than FVII. Taken together, this suggests that ASIS is effective as a competitive inhibitor of endogenous FVIla for its binding to TF.

Myocardial injury as assessed by Evans Blue/TTC staining revealed an infarct decreasing effect upon ASIS administration, whereas remarkably H-FABP levels were not influenced upon ASIS administration. H-FABP is a small cytoplasmic 
protein that is present in cardiomyocytes and is released into the bloodstream upon myocardial injury ${ }^{8}$. Therefore it can be used as an early marker for acute myocardial infarction ${ }^{9,10}$. In this study H-FABP levels were increased upon I/R but were not affected upon ASIS administration. In part, this may be explained by large variations in the H-FABP plasma levels among the different groups. Moreover, the absence of an attenuating effect of ASIS on FABP levels may indicate that indeed the protective effect is not primarily on limiting early ischemic damage, but on recovery from ischemia during the reperfusion phase. In this study we did not assess markers of later myocardial injury to confirm this.

To which extent the anti-coagulant function of ASIS contributes to the limitations in myocardial injury still remains disputable. The anti-coagulant effect of ASIS in this study was shown by reduced TF activity levels and thrombin generation but fibrin deposition remained unaffected by ASIS administration. These data suggest a cell signaling effect of the TF/FVIla pathway in the heart, rather than an anti-coagulant effect. To exclude the possibility that the observed inhibition of TF by ASIS was primarily due to direct inhibition of TF in the assay, ASIS was added into the measurement in varying concentrations ranging from 0.18 to $11.52 \mathrm{nM}$. These analyses showed that ASIS at concentrations up to $1.4 \mathrm{nM}$ did not interfere in the assay (data not shown). Based on calculated concentrations, considering blood volume, organ size of the mouse and the half life of ASIS, we estimated that a maximum amount of $4 \mathrm{fM}$ would be retained in the heart. This amount is well below the concentration that would compete with the FVIla added in the assay. To confirm this, ASIS was administered to sham animals and TF activity levels in their hearts were comparable to sham animals that did not receive ASIS (data not shown). Hence, we concluded that ASIS directly decreased TF activity through attenuated TF antigen levels. It is also unknown why fibrin levels were not affected by the anti-coagulant in spite of an inhibitory activity of ASIS on systemic thrombin generation. Either diffusion of fibrin(ogen) from the blood into the damaged myocardium, or local formation of fibrin, uninhibited by the low local concentrations of ASIS could be involved. The staining for fibrin is not sufficiently specific to eliminate this question and additional studies to characterize the nature of the fibrin products in the heart would be needed to settle this issue. 
Besides its role in coagulation, FVIla and subsequently ASIS also play an important role in cell signaling involved in apoptosis and inflammation through activation of G-protein coupled protease activated receptors (PARs). Four types of PARs are known which are activated by serine proteases such as thrombin. Despite their similar mechanisms of action, PARs have different functions and tissue distribution but all play a role in the cardiovascular system by their presence on endothelial cells, on cardiomyocytes, and on vascular smooth muscle cells ${ }^{11}$. Involvement of ASIS in cell signaling related inflammation was shown in this study as administration of ASIS during ischemia and reperfusion decreased IL-6, IL-1 $\beta$, MIP-1 $\alpha$, and eNOS mRNA expression levels. Speculations regarding the involvement of PAR-1 or PAR-2 can be made but were not elucidated in this study.

Previous studies revealed a decrease in infarct size upon ASIS administration or blockage of TF in a rabbit model of myocardial I/R injury but the underlying mechanisms were not fully elucidated ${ }^{3,4}$. In this study we showed that administration of ASIS during the ischemic as well as the reperfusion phase is most effective in the protection against myocardial $I / R$ injury as is shown by a reduction in myocardial infarct size upon ASIS administration as well as a reduction in inflammatory markers. Based on these data, we planned a more detailed intervention study (Chapter 3) with ASIS administration during the ischemic and reperfusion phase in a myocardial I/R model to reveal its working mechanism in relation to coagulation, inflammation, apoptosis, and cell signaling. 


\section{REFERENCES}

1. Girard TJ, Warren LA, Novotny WF, Likert KM, Brown SG, Miletich JP, Broze GJ, Jr. Functional significance of the Kunitz-type inhibitory domains of lipoproteinassociated coagulation inhibitor. Nature. 1989;338:518-520.

2. Baugh RJ, Broze GJ, Jr., Krishnaswamy S. Regulation of extrinsic pathway factor Xa formation by tissue factor pathway inhibitor. J Biol Chem. 1998;273:4378-4386.

3. Erlich JH, Boyle EM, Labriola J, Kovacich JC, Santucci RA, Fearns C, Morgan EN, Yun W, Luther T, Kojikawa O, Martin TR, Pohlman TH, Verrier ED, Mackman N. Inhibition of the tissue factor-thrombin pathway limits infarct size after myocardial ischemiareperfusion injury by reducing inflammation. Am J Pathol. 2000;157:1849-1862.

4. Golino P, Ragni M, Cirillo P, Scognamiglio A, Ravera A, Buono C, Guarino A, Piro O, Lambiase C, Botticella F, Ezban M, Condorelli M, Chiariello M. Recombinant human, active site-blocked factor VIla reduces infarct size and no-reflow phenomenon in rabbits. Am J Physiol Heart Circ Physiol. 2000;278:H1507-1516.

5. Jong WM, Reitsma PH, ten Cate $\mathrm{H}$, de Winter RJ. Modified two-step model for studying the inflammatory response during myocardial ischemia and reperfusion in mice. Comp Med. 2003;53:522-526.

6. Frederix K, Kooter IM, van Oerle R, Fens D, Hamulyak K, Gerlofs-Nijland ME, Ten Cate $\mathrm{H}$, Spronk HM. A new method to determine tissue specific tissue factor thrombomodulin activities: endotoxin and particulate air pollution induced disbalance. Thromb J. 2008;6:14.

7. Spek CA, Verbon A, Aberson H, Pribble JP, McElgunn CJ, Turner T, Axtelle T, Schouten J, Van Der Poll T, Reitsma PH. Treatment with an anti-CD14 monoclonal antibody delays and inhibits lipopolysaccharide-induced gene expression in humans in vivo. J Clin Immunol. 2003;23:132-140.

8. Glatz JF, Kleine AH, van Nieuwenhoven FA, Hermens WT, van Dieijen-Visser MP, van der Vusse GJ. Fatty-acid-binding protein as a plasma marker for the estimation of myocardial infarct size in humans. Br Heart J. 1994;71:135-140.

9. Knowlton AA, Apstein CS, Saouf R, Brecher P. Leakage of heart fatty acid binding protein with ischemia and reperfusion in the rat. J Mol Cell Cardiol. 1989;21:577-583.

10. Kleine AH, Glatz JF, Van Nieuwenhoven FA, Van der Vusse GJ. Release of heart fatty acid-binding protein into plasma after acute myocardial infarction in man. Mol Cell Biochem. 1992;116:155-162.

11. Barnes JA, Singh S, Gomes AV. Protease activated receptors in cardiovascular function and disease. Mol Cell Biochem. 2004;263:227-239. 




\section{Chapter 3}

\section{ASIS attenuates myocardial I/R injury}

\section{in mice}

STBG Loubele, CA Spek, P Leenders, R van Oerle, HL Aberson, D van der Voort, $\mathrm{K}$ Hamulyák, LC Petersen, HMH Spronk, $\mathrm{H}$ ten Cate.

Active site inhibited factor VIla attenuates myocardial ischemia/reperfusion injury in mice.

J Thromb Haemost 2009; 7: 290-298

Commentary: Pawlinski R, Mackman N. Tissue factor and heart inflammation. J Thromb Haemost 2009; 7: 288-289. 


\section{AbSTRACT}

Inhibition of specific coagulation pathways such as the factor (F)VIla-tissue factor (TF) complex by active site inhibited FVIla (ASIS) has been shown to attenuate ischemia/reperfusion (I/R) injury, but the cellular mechanisms have not been explored. This study aimed at determining the cellular mechanisms involved in the working mechanism of ASIS in the protection against myocardial I/R injury.

We investigated the effects of a specific mouse recombinant ASIS in a mouse model of myocardial I/R injury. One hour of ischemia was followed by 2, 6, or $24 \mathrm{hrs}$ of reperfusion. Mouse ASIS or placebo was administered before and after induction of reperfusion.

ASIS administration reduced myocardial I/R injury by more than $40 \%$ at 3 reperfusion times. Multiplex ligation dependent probe amplification (MLPA) analysis showed reduced mRNA expression in the ischemic myocardium of CD14, toll-like receptor (TLR)-4, interleukin-1 (IL-1) receptor-associated kinase (IRAK) and IKB $\alpha$ upon ASIS administration, indicative of inhibition of toll-like receptor-4 (TLR-4) and subsequent nuclear factor-KB (NF-KB) mediated cell signaling. Levels of nuclear activated NF-KB and proteins influenced by the NFKB pathway including TF and IL- 6 that were increased after I/R, were attenuated upon ASIS administration. After 6 and $24 \mathrm{hrs}$ of reperfusion, neutrophil infiltration into the area of infarction was decreased upon ASIS administration. There was, however, no evidence of an effect of ASIS on apoptosis (apoptosis staining and MLPA analysis).

We conclude that the diminished amount of myocardial I/R injury after ASIS administration is primarily due to attenuated inflammation-related lethal $I / R$ injury, probably mediated through the NF-KB mechanism. 


\section{INTRODUCTION}

Coronary heart disease remains the most important cause of death worldwide. While acute myocardial infarction is still associated with a near $10 \%$ death rate, chronic morbidity, particularly heart failure develops in $25 \%$ of the survivors ${ }^{1}$. The salvage of ischemic myocardium is dependent on rapid reperfusion; however, the recovery in blood flow is accompanied by $I / R$ injury ${ }^{2,3}$. Clinically, reperfusion strategies have been optimized over the past decades, but the paradox of I/R damage due to accelerated restoration of perfusion, cannot yet be specifically prevented in spite of promising pre-clinical studies ${ }^{4}$. Recent studies indicate that coagulation proteases affect I/R injury. One of these proteases is FVIla, which in complex with the cell membrane bound TF not only triggers the generation of thrombin, but also affects intra-cellular signaling properties $^{5,6}$.

A study in a rabbit model of myocardial $I / R$ injury showed that myocardial damage could be diminished with a specific inhibiting antibody against TF. This inhibition of infarction was associated with reduced infiltration of neutrophils in the heart and with a trend towards lower levels of pro-inflammatory cytokines. Similar protection was obtained by infusion of a human recombinant ASIS in a rabbit myocardial I/R model via inhibition of the pro-coagulant activity of TF ${ }^{8}$. These studies suggested a potential therapeutic intervention, but the spectrum of the cell protective effects remained largely unexplored. In addition, the duration of the protective effects was not addressed, which is relevant to assess the long term impact of intervention in the acute phase of the I/R process. To characterize the protective mechanisms of TF/FVIla inhibition, we used recombinant mouse ASIS in an experimental mouse model of myocardial I/R. This study was the first to use species specific ASIS in a myocardial I/R model. We investigated the effects of mouse ASIS on early myocardial I/R injury, particularly related to anticoagulant, anti-inflammatory and anti-apoptotic mechanisms and this in relation to cellular signaling. 


\section{MATERIALS AND METHODS}

Mouse Myocardial Ischemia/Reperfusion Model. Myocardial I/R was induced according to the method of Jong et al. ${ }^{9}$. A detailed protocol is provided in addendum 1.

Intervention. Recombinant mouse ASIS (Novo, Denmark) in a dose of $1 \mathrm{mg} / \mathrm{kg}$ $(100 \mu \mathrm{l})$ or placebo $(0.9 \% \mathrm{NaCl})$ was administered i.v. as a repeated i.v. dose 15 min after induction of ischemia and 5 min after induction of reperfusion.

Plasma and tissue collection. A detailed protocol is provided in addendum 2.

Determination of myocardial I/R injury: Evans Blue/TTC staining. A detailed protocol is provided in addendum 3 .

TF activity. A detailed protocol is provided in addendum 4.

Oligo GEArray ${ }^{\circledast}$ Mouse Signal Transduction Pathway Finder ${ }^{\mathrm{TM}}$ Microarray. The microarray was used to analyze the expression of 113 genes representative of 18 signal transduction pathways. The technique is based on a side-by-side hybridization and was performed according to the manufacturer's instructions (Tebu-Bio, Superarray, MD, US). Data analysis was performed online using GEArray Expression Analysis Suite at www.SuperArray.com. Absolute and comparison analyses were conducted using the following settings: density with average, background with minimum value and normalization with interquartile.

Multiplex Ligation dependent Probe Amplification (MLPA). Coagulation, inflammation, cell signaling, and apoptosis related gene expression levels were determined in isolated RNA of the mouse hearts ( $n=6$ per group). $50 \mathrm{ng} / \mu$ I RNA was analyzed according to the method described previously by Spek et al. ${ }^{10}$. Several genes involved in cellular signaling, inflammation and coagulation were analyzed (cell signaling: CD14, TLR-2, TLR-4, IRAK-1, IRAK-3, IKB $\alpha$, and protease activated receptor-1 (PAR-1); coagulation: TF, tissue factor pathway inhibitor (TFPI), plasminogen activator inhibitor-1 (PAI-1), urokinase-type plasminogen activator receptor (UPAR), tissue-type plasminogen activator receptor (t-PA), and protein $C$ receptor; inflammation: IL-6, IL-4, IL-10, IL-1 $\beta$, tumor necrosis factor (TNF)- $\alpha$, interferon (IFN) $-\gamma$, hypoxia-inducible factor (HIF)- $1 \alpha$, ICAM-1, macrophage inflammatory protein (MIP)-1 $\alpha, \mathrm{CxCl} 1, \mathrm{CCl} 3$, and eNOS; apoptosis: Bcl-W, Bcl-Xl, Bcl-2, Mcl1, Bak, Bax, Bcl-Rambo, Bad, Bid, Bik, Bim, Map-1, Niap, 
AIF, Apaf-1, Smac/Diablo, Flip, Miap, Bruce, and p21. Only the genes that showed detectable expression levels are depicted in the results.

Activated NF-KB. Activated NF-kB levels (p50 and p105) were determined in the nuclear extract isolated according to Davis et al. ${ }^{11}$. Activated NF-KB levels were determined in nuclear extracts of $1 \mathrm{mg} / \mathrm{ml}$ protein content according to the manufacturer's instructions (Colorimetric Enzyme Immunoassay for NF-kB, Oxford Biomedical Research, MI, US).

IL-6, TNF- $\alpha$ and IL-1B antigen. IL-6, TNF- $\alpha$ and IL-1 $\beta$ antigen levels were determined in tissue homogenates containing $1 \mathrm{mg} / \mathrm{ml}$ protein using an ELISA reagent set. All analysis were performed according to the manufacturer's manual (eBioscience, CA, US). PAI-1 antigen. Total PAI-1 antigen levels were determined in tissue homogenates $(1 \mathrm{mg} / \mathrm{ml}$ protein content) according to the manufacturer's instructions (Innovative Research, MI, US).

CD 45 staining. Mouse heart paraffin sections were depariffinized and underwent microwave pretreatment. After washing 3 times for 5 minutes in TBS, the sections were treated with $\mathrm{H}_{2} \mathrm{O}_{2}$ /methanol and then washed again. The slides were blocked and incubated overnight with rat anti-mouse CD 45 antibody (BD, Pharmingen, San Jose, USA) at RT. After washing 3 times for 5 minutes in TBS, the slides were incubated with a rabbit anti-rat biotinylated antibody (Dako, Glostrup, Denmark) for 30 minutes at RT and then washed again. The slides were treated with the TSA biotin system according to the manufacturer's instruction (Perkin Elmer, Wellesly, USA). After washing 3 times for 5 minutes with TBS, streptavidine-ABC-alkaline phosphatase antibody (Dako, Glostrup, Denmark) was administered for 30 minutes at RT. After washing 3 times for 5 minutes with TBS, the slides were stained with Vector Red (Vector, Burlingame, CA) and counterstained with haematoxylin (Klinipath, Duiven, the Netherlands). Finally, sections were mounted with Imsol and Entellan.

Apoptosis staining. Mouse heart paraffin sections were stained for apoptosis using the ApopTag Plus Peroxidase In Situ Apoptosis Detection Kit. Sections were stained according the manufacturers manual (Chemicon, Billerica, USA).

Statistical analyses. Data analysis was performed with Prism for Windows, version 5.00 (GraphPad Software Inc., San Diego, California, USA). Values are means \pm SEM. Differences between groups were tested using a Mann-Whitney $U$ test and $P$ values $<0.05$ were considered statistically significant. 


\section{RESULTS}

Determination of the optimal time point of administration. Mouse ASIS was administered at three different time points during $I / R$ to determine the optimal administration time. Ischemia was induced for 60 minutes followed by a $2 \mathrm{hrs}$ reperfusion period and ASIS was administered only during the ischemic phase (I), during the ischemic and reperfusion phase $(I+R)$, or only during the reperfusion phase (R). Analysis on myocardial I/R injury by means of Evans Blue/TTC staining (focusing on $\mathrm{LDH}$ release) (Figure $1 \mathrm{~A}$ ) and coagulation by means of TF activity (Figure $1 \mathrm{~B}$ ) revealed that ASIS administration during both the ischemic and the reperfusion phase was the optimal time point of administration.

Effects of mouse ASIS on cellular signaling pathways. To explore cell signaling effects affected by ASIS, a pathway finder microarray was employed. Different pathways were affected by ASIS as demonstrated by alterations in different RNA expression levels after 2 hrs of reperfusion (only the pathways with a minimum of 3 genes detectable, are mentioned; gene expression was defined as different compared to placebo when the expression values were more than $50 \%$ deviating): the NF-kB pathway (involved genes: Cxcl1, NF-kB, ІкB $\alpha$, and TANK), the WNT signaling pathway (Jun, Myc, and Ppary), the stress pathway (Atf2, Fos, and Hsp25) and the phospholipase $C$ pathway (Egr1, Fos, and Jun). As an example, 2 spots of the NF-kB pathway are highlighted in Figure 1C. RNA expression of NF-kB-p50 was increased threefold upon ASIS administration, whereas ASIS administration reduced the RNA levels of $1 \kappa B \alpha$ with only $32 \%$. The variation in RNA expression levels of differentially expressed genes involved in several pathways, upon ASIS vs. placebo administration is depicted in Figure 1D.

All further experiments are carried out with a $1 \mathrm{hr}$ ischemia period, followed by a 2,6 , or $24 \mathrm{hrs}$ reperfusion period. ASIS was administered during both the ischemic and the reperfusion period.

Effects of mouse ASIS on myocardial I/R injury. Myocardial I/R injury decreased after prolonged reperfusion times upon administration of placebo: the \% area of infarction (AOI)/area at risk (AAR) decreased by $20 \%$ after $6 \mathrm{hrs}$ of reperfusion and further by $43 \%$ after $24 \mathrm{hrs}$ of reperfusion. Administration of ASIS decreased I/R injury at all reperfusion times compared to placebo treated animals. After $2 \mathrm{hrs}$ reperfusion, ASIS decreased I/R injury by $40 \%$, whereas the \% AOI/AAR decreased by 64 and $44 \%$ after 6 and 24 hrs reperfusion upon ASIS administration (Figure 2A). A representative picture of the Evans Blue/TTC stained hearts is given in Figure 2B. 

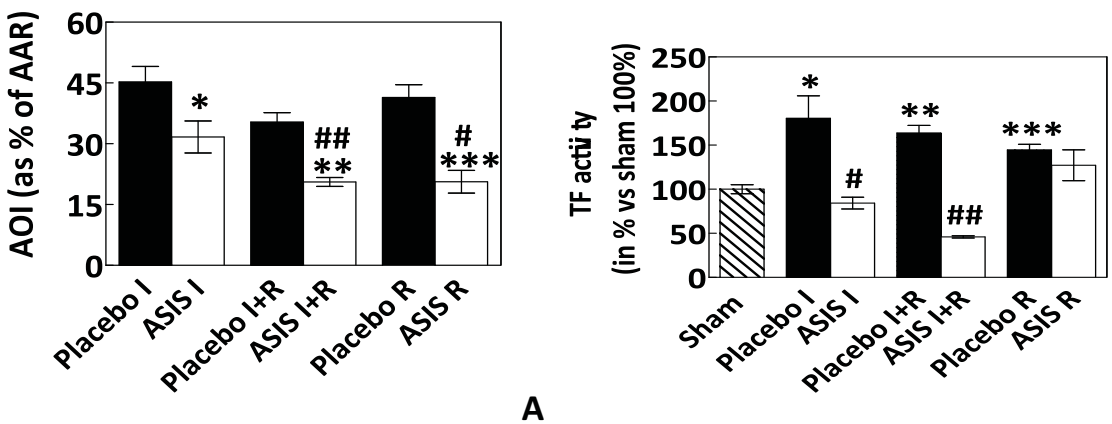

A
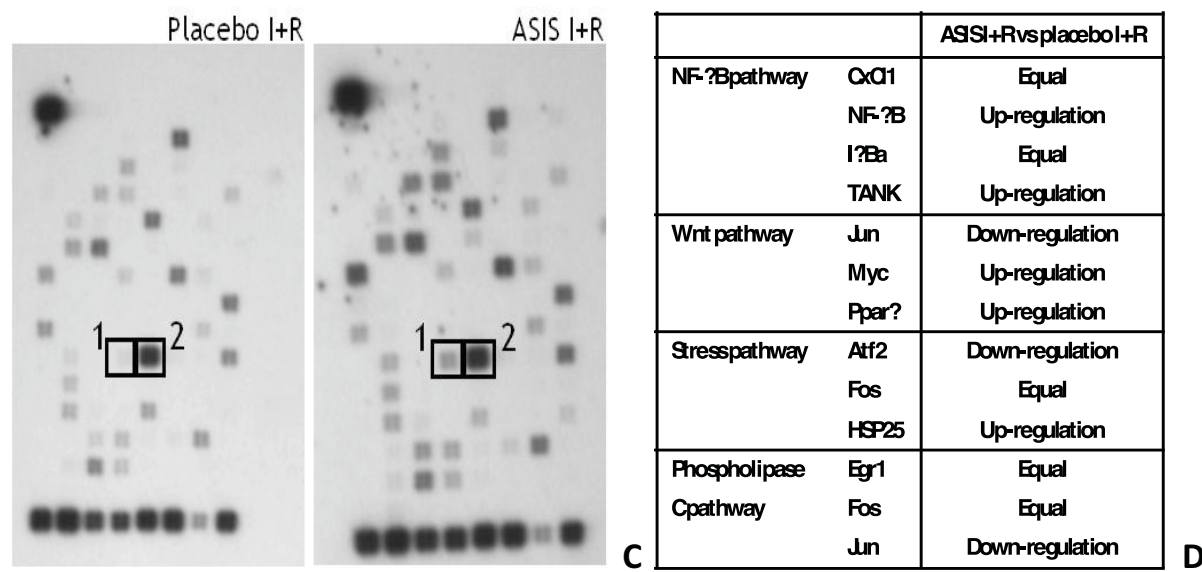

Figure 1: Panel A: AOI as a percentage of the $A A R$ after myocardial $I / R$ injury in 3 treatment groups. ASIS was administered during the ischemic phase (I), during the ischemic and reperfusion phase (I+R) or during the reperfusion phase (R). Values are means \pm SEM, $n=6 . *$ difference between ASIS and their corresponding placebo group $\left(* \mathrm{I},{ }^{* *} \mathrm{I}+\mathrm{R}, * * * \mathrm{R}\right), \mathrm{p}<0.05$. \# difference between different ASIS groups (\# ASIS I vs ASIS R; \#\# ASIS I vs ASIS I+R), $\mathrm{p}<0.05$. Panel B: TF activities in the left ventricles of hearts. TF activity levels are depicted as $\%$ of the sham group which is set at $100 \%$. Values are mean \pm SEM, $\mathrm{n}=6$. ${ }^{*}$ difference between sham and placebo groups $\left({ }^{*} \mathrm{I},{ }^{*} \mathrm{I}+\mathrm{R}, * * * \mathrm{R}\right), \mathrm{p}<0.05$. \# difference between ASIS treatment and the corresponding placebo (\# I, \#\# I+R), $\mathrm{p}<0.05$. Panel C: Mouse Signal Transduction Pathway Finder Microarray. 2

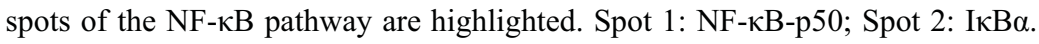
Panel D: The effect of ASIS administration on the expression of a number of genes involved in several pathways. 
Effects of mouse ASIS on myocardial I/R injury. Myocardial I/R injury decreased after prolonged reperfusion times upon administration of placebo: the $\%$ area of infarction (AOI)/area at risk (AAR) decreased by $20 \%$ after $6 \mathrm{hrs}$ of reperfusion and further by $43 \%$ after 24 hrs of reperfusion. Administration of ASIS decreased I/R injury at all reperfusion times compared to placebo treated animals. After 2 hrs reperfusion, ASIS decreased I/R injury by $40 \%$, whereas the $\%$ AOI/AAR decreased by 64 and $44 \%$ after 6 and 24 hrs reperfusion upon ASIS administration (Figure 2A). A representative picture of the Evans Blue/TTC stained hearts is given in Figure 2B.
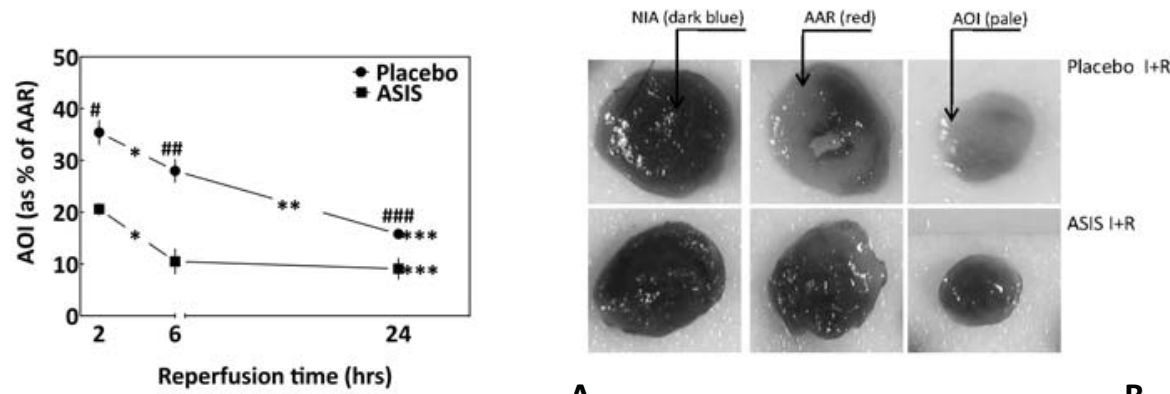

A

Figure 2: Panel A: AOI as a percentage of the AAR after myocardial I/R injury at varying reperfusion times. All values are mean $\pm \mathrm{SEM}, \mathrm{n}=6$. *differences between different reperfusion times after placebo or ASIS administration $(* 2 \mathrm{hrs}$ vs 6 hrs, ** 6 hrs vs $24 \mathrm{hrs,} * * * 2 \mathrm{hrs}$ vs $24 \mathrm{hrs}), \mathrm{n}=6, \mathrm{p}<0.05$. \# difference between placebo and ASIS treatment (\# 2 hrs R, \#\# 6 hrs R, \#\# 24 hrs R), n=6, $\mathrm{p}<0,05)$. Panel B: A representative picture of the Evans Blue/TTC staining after $2 \mathrm{hrs}$ of reperfusion. The normal tissue is stained dark blue, whereas the ischemic area is stained brick red. The non-viable infarct area did not stain and remained pale. NIA: non infarcted area (dark blue), AAR: area at risk (brick red), and AOI: area of infarction (pale). See addendum for color figure.

\section{Effect of mouse ASIS on cellular signaling pathways with varying reperfusion}

times. Based on the results of the signal transduction pathway finder, the NF-KB pathway was analyzed by MLPA. In Figure 3, the mRNA expression levels of 4 different genes involved in cell signaling are shown. The expression levels of NF$\mathrm{KB}$ related genes TLR-4 (Figure 3A) and IKB $\alpha$ (Figure 3C) were increased upon I/ $R$ with varying reperfusion times, whereas IRAK-1 (Figure 3B) levels were not influenced. 
TLR-4

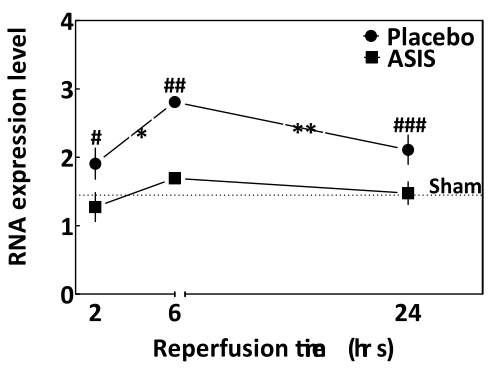

$\mathrm{I} \mathrm{B} \boldsymbol{\mathrm { C }} \alpha$

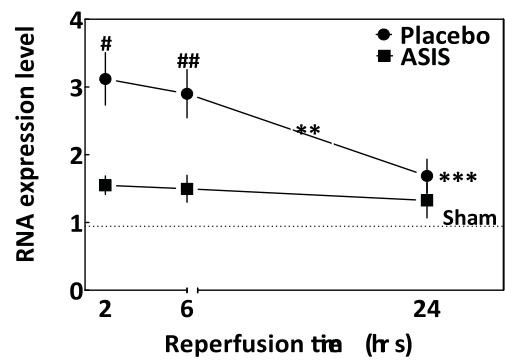

CD14

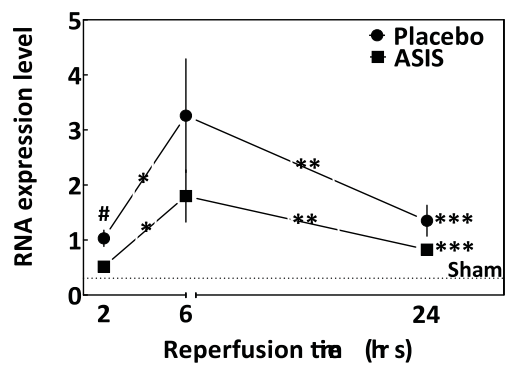

IRAK-1

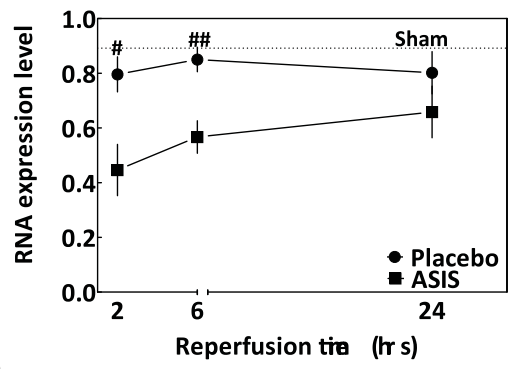

PAR-1

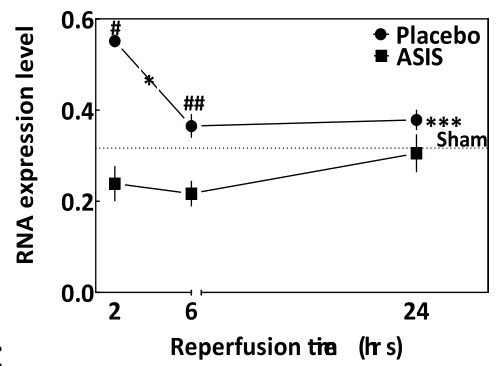

IRAK-3

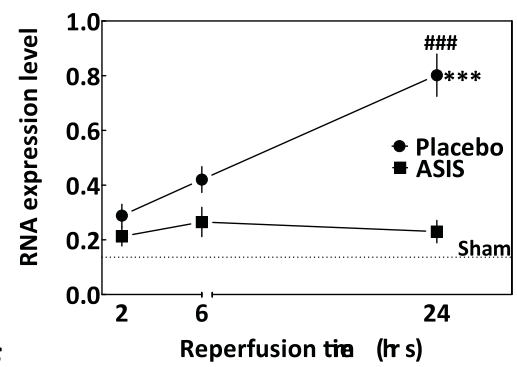

$\mathbf{F}$

Figure 3: mRNA expression levels of cellular signaling related genes determined by MLPA analysis. All values are mean $\pm \mathrm{SEM}, \mathrm{n}=6$. *differences between different reperfusion times after placebo or ASIS administration $(* 2 \mathrm{hrs}$ vs $6 \mathrm{hrs}$, ** $6 \mathrm{hrs}$ vs $24 \mathrm{hrs,} * * * 2 \mathrm{hrs}$ vs $24 \mathrm{hrs}), \mathrm{n}=6, \mathrm{p}<0.05$. \# difference between placebo and ASIS treatment (\# 2 hrs R, \#\# 6 hrs R, \#\#\# 24 hrs R), n=6, $\mathrm{p}<0,05)$. 
The expression levels of TLR-4 were decreased to sham baseline levels when ASIS was administered after 2, 6 and 24 hrs of reperfusion, while IRAK-1 expression levels decreased after 2 and $6 \mathrm{hrs}$ of reperfusion. ASIS administration decreased IKB $\alpha$ levels after 2 and 6 hrs of reperfusion. PAR-1 expression in the placebo group temporally increased after $2 \mathrm{hrs}$ of reperfusion compared to the sham group; ASIS administration lowered PAR-1 expression after 2 and 6 hrs of reperfusion (Figure 3D). The expression levels of CD14 and IRAK-3 were decreased upon ASIS administration upon a 2 and $24 \mathrm{hrs}$ reperfusion period respectively (Figure $3 \mathrm{E}$ and $3 \mathrm{~F}$ ).

TF

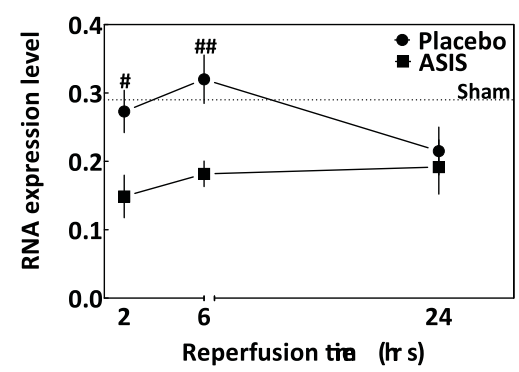

PAl-1

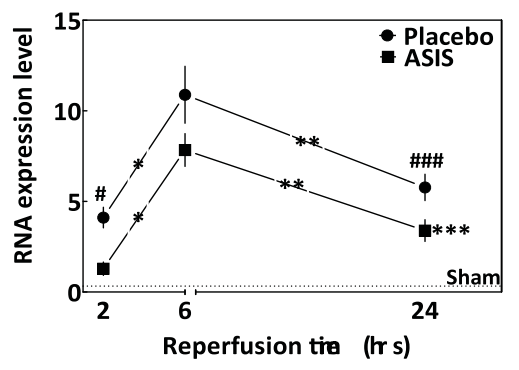

TFPI

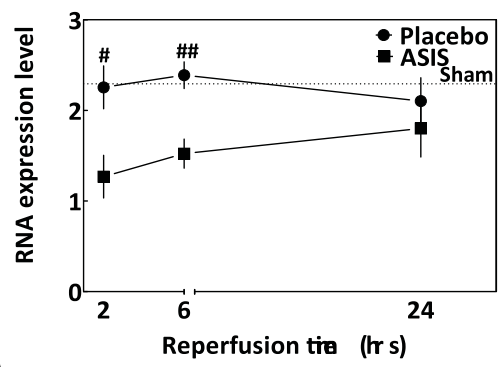

UPAR

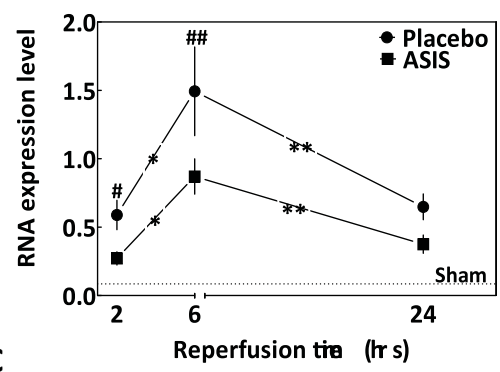

Figure 4: mRNA expression levels of inflammation and coagulation related genes determined by MLPA analysis. All values are mean \pm SEM, $n=6$. $*$ differences between different reperfusion times after placebo or ASIS $(* 2 \mathrm{hrs}$ vs $6 \mathrm{hrs}, * * 6 \mathrm{hrs}$ vs $24 \mathrm{hrs}, * * * 2 \mathrm{hrs}$ vs $24 \mathrm{hrs}), \mathrm{n}=6, \mathrm{p}<0.05$. \# difference between placebo and ASIS treatment (\# 2 hrs R, \#\# 6 hrs R, \#\#\# 24 hrs R), n=6, p<0,05). 
Results on the expression levels of inflammation and coagulation related genes are summarized in Figure 4 and 5. TF mRNA expression levels were not influenced by I/R but were decreased by ASIS administration after 2 and 6 hrs of reperfusion (Figure 4A). TFPI, PAI-1, and UPAR levels were decreased upon ASIS administration (Figure 4B, 4C, and 4D).

Inflammation-related genes IL-6 (Figure 5A) and IL-1 $\beta$ (Figure 5B) showed increased expression levels after 2, 6 and $24 \mathrm{hrs}$ of reperfusion compared to sham animals. ASIS administration lowered IL- 6 levels but did not affect IL-1 $\beta$ expression. ICAM-1 levels increased after I/R, which was reversed upon ASIS administration (Figure $5 \mathrm{C}$ ). The expression levels of HIF-1 $\alpha$ and eNOS were decreased upon ASIS administration as compared to placebo (Figure 5D and 5E).

\section{Effects of mouse ASIS on activated NF-KB and NF-KB regulated proteins.}

Regarding the strong indications from the MLPA data for involvement of the NFKB pathway in the mode of action of ASIS, nuclear activated NF-KB and a number NF-KB regulated proteins was measured.

Nuclear activated NF-KB levels decreased upon ASIS administration after 2 and $24 \mathrm{hrs}$ of reperfusion $(1.1 \pm 1.1 \mathrm{pg} / \mathrm{ml}$ and $6.9 \pm 1.8 \mathrm{pg} / \mathrm{ml}$, respectively) compared to placebo treatment $(7.5 \pm 2.2 \mathrm{pg} / \mathrm{ml}$ and $39.0 \pm 9.4 \mathrm{pg} / \mathrm{ml}$, respectively, $p<0.05)$. ASIS administration upon $6 \mathrm{hrs}$ of reperfusion showed a trend towards decreased activated NF-KB levels, but the results showed no statistically significant effect (Figure 6A).

IL-6 antigen levels were increased after 2 and $6 \mathrm{hrs}$ of reperfusion (19.5 \pm 6.7 and $9.0 \pm 3.6 \mathrm{pg} / \mathrm{ml})$ compared to the sham animals $(0.8 \pm 0.3 \mathrm{pg} / \mathrm{ml})$ but remained equal after $24 \mathrm{hrs}$ of reperfusion $(3.0 \pm 2.2 \mathrm{pg} / \mathrm{ml})$. IL- 6 antigen levels were diminished by the administration of ASIS after a $2 \mathrm{hrs}$ reperfusion period $(4.5 \pm 1.1 \mathrm{pg} / \mathrm{ml}, \mathrm{p}<0.05)$ but remained equal after 6 and $24 \mathrm{hrs}$ of reperfusion (9.9 \pm 2.9 and $3.7 \pm 2.0 \mathrm{pg} / \mathrm{ml}$, respectively) (Figure 6B).

TNF- $\alpha$ and IL-1 $\beta$ protein levels were not detectable. TF activity levels increased after 2,6 , and $24 \mathrm{hrs}$ of reperfusion $(6.2 \pm 0.2 \mathrm{pM}, 9.1 \pm 1.0 \mathrm{pM}$, and $11.1 \pm 1.2$ $\mathrm{pM}$, respectively) compared to the sham animals ( $4.1 \pm 0.6 \mathrm{pM})$, while ASIS administration decreased TF activity for 2,6 , and $24 \mathrm{hrs}$ of reperfusion (1.0 \pm 
$0.08 \mathrm{pM}, 3.4 \pm 0.6 \mathrm{pM}$, and $7.0 \pm 1.0 \mathrm{pM}$ respectively, $\mathrm{p}<0.05)$ compared to the placebo treated animals (Figure 6C).

IL-6

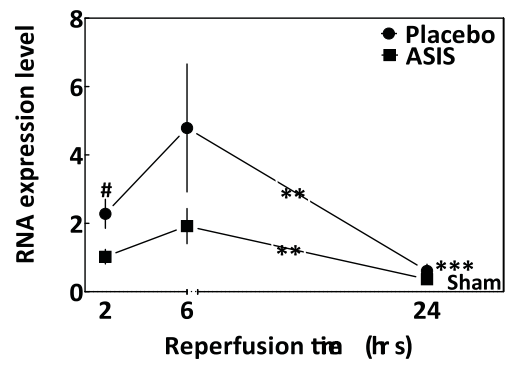

ICAM-1

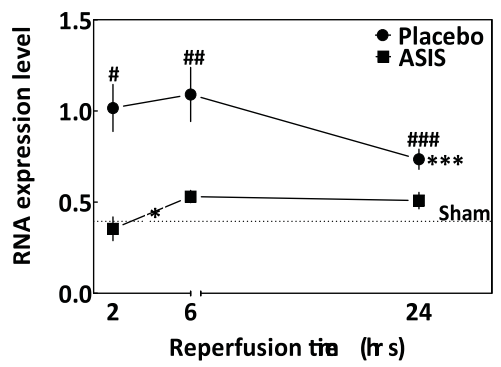

eNOS

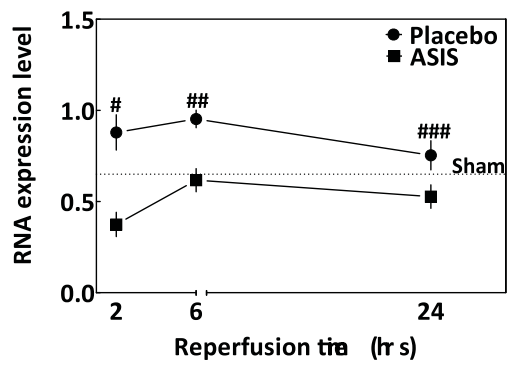

IL-1 $\beta$

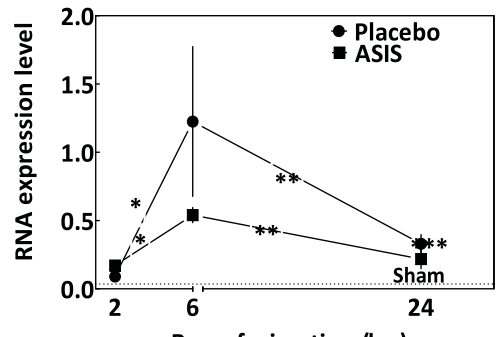

A

Reperfusion tire (tr s)

B

HIF-1 $\alpha$

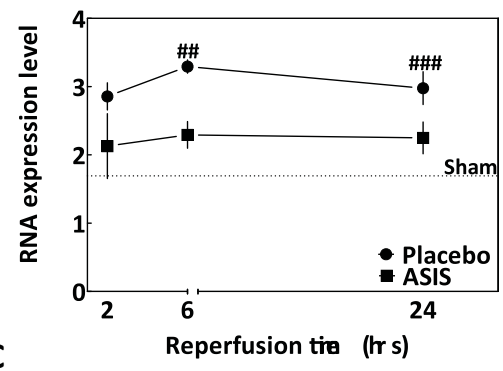

D

E

Figure 5: mRNA expression levels of inflammation and coagulation related genes determined by MLPA analysis. All values are mean \pm SEM, $n=6$. *differences between different reperfusion times after placebo or ASIS $(* 2 \mathrm{hrs}$ vs $6 \mathrm{hrs}, * * 6 \mathrm{hrs}$ vs $24 \mathrm{hrs}, * * * 2 \mathrm{hrs}$ vs $24 \mathrm{hrs}), \mathrm{n}=6, \mathrm{p}<0.05$. \# difference between placebo and ASIS treatment (\# 2 hrs R, \#\# 6 hrs R, \#\#\# 24 hrs R), n=6, p<0,05). 
PAl-antigen levels were increased in a time-dependent way after I/R ( $2 \mathrm{hrs} R$ : $7.1 \pm 2.4 \mathrm{ng} / \mathrm{ml} ; 6 \mathrm{hrs} \mathrm{R:} 33.7 \pm 4.0 \mathrm{ng} / \mathrm{ml} ; 24 \mathrm{hrs} \mathrm{R}: 57.8 \pm 2.0 \mathrm{ng} / \mathrm{ml}$ ) compared to sham animals $(0.2 \pm 0.05 \mathrm{ng} / \mathrm{ml}, \mathrm{p}<0.05)$. Administration of ASIS diminished PAl-1 antigen levels after $24 \mathrm{hrs}$ of reperfusion $(38.4 \pm 8.5 \mathrm{ng} / \mathrm{ml}$ ) but not after 2 and 6 hrs of reperfusion ( $4.1 \pm 0.8$ and $27.1 \pm 3.4 \mathrm{ng} / \mathrm{ml}$, respectively) (Figure 6D).
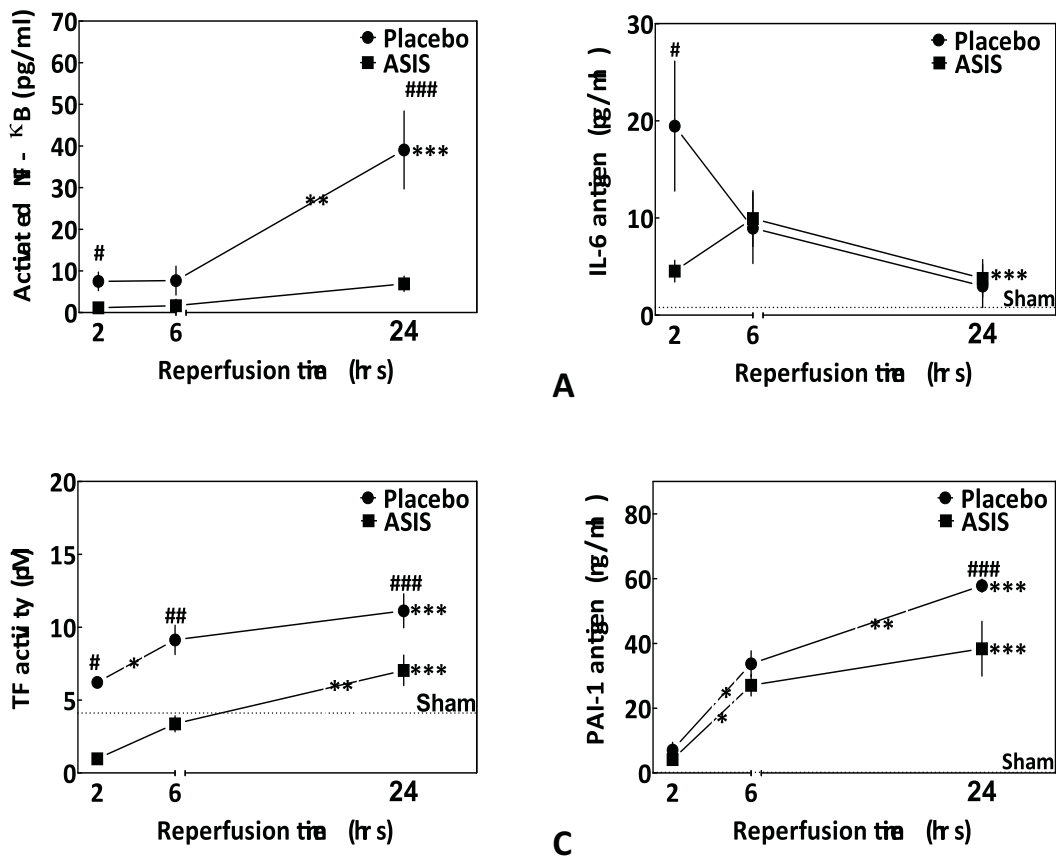

Figure 6: Activated NF- $\kappa$ B, TF activity, PAI-1 and IL-6 antigen levels in the left ventricles of sham mice and animals after ischemia/reperfusion injury mice. Panel A: Nuclear activated NF-kB. Panel B: Il-6 antigen levels. Panel C: TF activity. Panel D: PAI-1 antigen levels. Values are mean \pm SEM, $n=6$. * differences between different reperfusion times after placebo or ASIS administration (* $2 \mathrm{hrs}$ vs $6 \mathrm{hrs}, * * 6 \mathrm{hrs}$ vs $24 \mathrm{hrs}$, *** 2 hrs vs $24 \mathrm{hrs}$ ), $\mathrm{n}=6$, $\mathrm{p}<0.05$. \# difference between placebo and ASIS treatment (\# $2 \mathrm{hrs} \mathrm{R}$, \#\# $6 \mathrm{hrs} \mathrm{R}$, \#\#\# 24 hrs R), n=6, p<0,05). 
The influence of mouse ASIS on leukocyte infiltration. To determine the effect of ASIS on leukocyte infiltration, paraffin sections were stained for CD45 and the number of CD45-positive cells per $\mathrm{cm}^{2}$ was determined. A representative picture of placebo and ASIS treatment after $24 \mathrm{hrs}$ of reperfusion is depicted in Figure 7A (20x magnification). The number of CD45-positive cells increased after $6\left(334.0 \pm 26.9\right.$ cells $\left./ \mathrm{cm}^{2}\right)$ and $24 \mathrm{hrs}\left(323.9 \pm 36.9 \mathrm{cells} / \mathrm{cm}^{2}\right)$ of reperfusion compared to a 2 hrs reperfusion period $\left(32.0 \pm 14.4\right.$ cells $\left./ \mathrm{cm}^{2}\right)$. Administration of ASIS attenuated the infiltration of CD45-positive cells after 6 and $24 \mathrm{hrs}$ of reperfusion (164.1 \pm 35.4 and $109 \pm 23.2$ cells $/ \mathrm{cm}^{2}$, respectively), whereas the number of CD45+ cells was not altered by ASIS after 2 hrs of reperfusion ( $61.5 \pm 5.9$ cells $/ \mathrm{cm}^{2}$ ) compared to the placebo (Figure 7B).

Influences of mouse ASIS on apoptosis. Apoptosis staining and MLPA analysis was performed to determine the possible effect of ASIS on apoptosis. ASIS neither influenced the number of cells that stained positive for apoptosis, nor affected the area size stained positive within the left ventricle (data not shown). MLPA analysis revealed no significant differences in Bcl-2-family related gene expression levels upon ASIS administration. The expression levels of Bcl-W, Bcl$\mathrm{Xl}, \mathrm{Bcl}-2$, Bak, Bax, Bcl-Rambo, Bad, Bik and Bid remained equal upon ASIS administration compared to placebo administration (data not shown). These data indicate no significant contribution of an anti-apoptotic effect of ASIS in limiting myocardial I/R injury. 
Placebo $24 \mathrm{hrs}$

ASIS 24 hrs
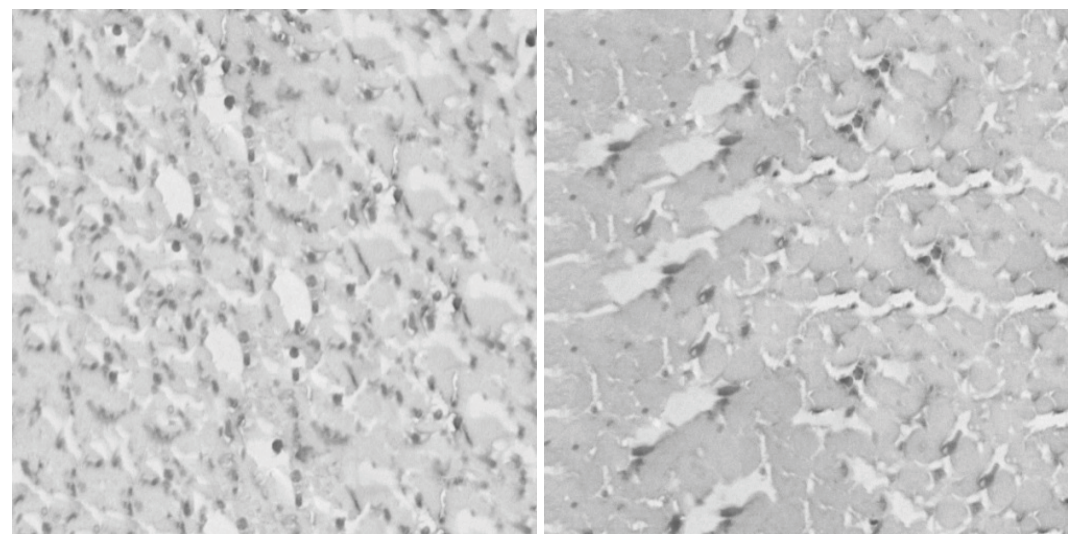

A

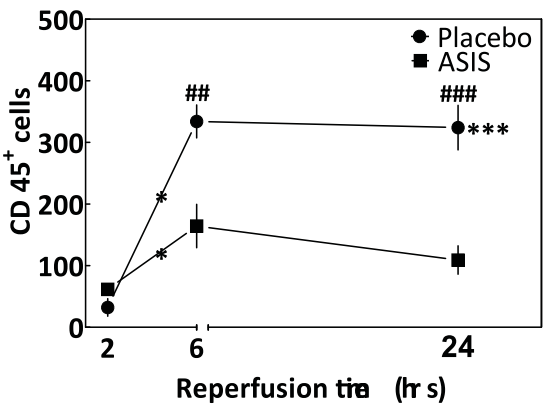

B

Figure 7: Representative example of CD 45 infiltration into the left ventricles of hearts after $24 \mathrm{hrs}$ of reperfusion. Panel A left: placebo $24 \mathrm{hrs}$ R; panel A right: ASIS 24 hrs R. Panel B: number of CD45-positive cells per $\mathrm{cm}^{2}$. Values are mean \pm SEM, $\mathrm{n}=4$. *differences between different reperfusion times after placebo or ASIS administration (*2hrs vs $6 \mathrm{hrs},{ }^{* *} 6 \mathrm{hrs}$ vs $24 \mathrm{hrs}, * * * 2 \mathrm{hrs}$ vs $24 \mathrm{hrs}$ ), $\mathrm{n}=6, \mathrm{p}<0.05$. \# difference between placebo and ASIS treatment (\# $2 \mathrm{hrs}$ $\mathrm{R}$, \#\# 6 hrs R, \#\#\# 24 hrs R), n=6, p<0,05). See addendum for color figure. 


\section{Discussion}

Myocardial I/R is a complex disease process and the ultimate process of lethal reperfusion injury is of major importance for the absolute infarct size as it offsets the beneficial effects of reperfusion after myocardial ischemia through the induction of cardiomyocyte death. Several cellular processes contribute to lethal reperfusion injury and intervention in these processes has shown a reduction of up to $50 \%$ of myocardial infarct size within several animal models ${ }^{1}$. Previous experimental animal studies showed that intervention in the TF/FVIIa complex yielded smaller myocardial infarcts in rabbits. These data also suggested an anti-inflammatory effect of inhibition of the TF mechanism in myocardial I/R injury but the exact mechanisms were not investigated ${ }^{7,8}$.

Our study provides several new insights. First, we used mouse ASIS in a mouse myocardial I/R model, excluding species specific differences in TF/FVIla binding, which were previously shown to be relevant ${ }^{12}$. Utilizing mouse specific ASIS, we show that inhibition of the TF/FVIla pathway provides a substantial reduction in myocardial $\mathrm{I} / \mathrm{R}$ injury and that this effect was sustained up to $24 \mathrm{hrs}$ of reperfusion. Second, we show that intervention in the TF/FVIla complex is associated with anti-inflammatory effects in the sense that there was a marked reduction in leukocyte influx, also shown in previous studies ${ }^{7,8}$, as well as attenuation in the pro-inflammatory cytokine IL-6 and this at varying reperfusion times. In contrast, we do not show any overt effect on apoptosis as a possible protective mechanism. Third, we explored the pathways involved in these anti-inflammatory effects and show a number of changes in the NF-KB (mediated) genes and proteins upon administration of ASIS.

In this study, administration of the anticoagulant ASIS reduced myocardial I/R injury based on LDH release (Evans Blue/TTC staining), revealing the most profound effect when administered during ischemia and reperfusion, suggesting that ASIS diminishes lethal reperfusion injury already after a short reperfusion period. Remarkably, upon prolonged reperfusion time, I/R injury decreased both in placebo and ASIS treated mice, although this effect was significantly more pronounced in ASIS treated animals, suggesting a sustained protective effect of FVIla-TF inhibition on cardiomyocytes after I/R. As the \% $A A R /$ whole heart remained equal over time (data not shown), technical issues regarding the model were excluded. The decrease of $I / R$ injury within time observed in the placebo treated animals is an unexpected finding. Previous 
studies suggest an equal infarct size or even an increase in infarct size after a prolonged reperfusion time rather than a decrease observed in this study. However, the exact time points used in this study were not previously investigated $^{13,14}$. The observed apparent reduction in infarct size in all animals might be explained by the phenomenon of cell shrinkage which is considered the onset of apoptotic cell death ${ }^{15}$. From this study, however, we did not obtain any convincing evidence for a reduction in apoptosis by ASIS, indicated by a lack of change in the number of apoptotic cells and MLPA analysis.

Based on the previous notion of reduced inflammation ${ }^{7,8}$ and the fact that the NF-KB pathway plays a significant role in I/R injury related cell signaling in the cardiac myocyte we further explored NF-kB related gene function. Our results reveal a coherent association of cell signaling related genes CD14, TLR-4 and IRAK-1 in the down-regulation of $1 \mathrm{~KB} \alpha$ under the influence of ASIS administration. TLR-4, one of the regulators of NF-KB signaling, is best known to be activated by LPS ${ }^{16}$ but can also be regulated by other proteins and requires CD14 and MD2. TLR-4 is expressed in cardiomyocytes and its expression is increased after myocardial I/R injury most likely due to oxidative stress ${ }^{17}$. TLR-4 expression leads to the recruitment of IRAK-1 causing activation of inhibitor $\mathrm{KB}$ $(\mathrm{I} B \mathrm{~B})$ kinases which regulatess NF-KB translocation to the nucleus ${ }^{18,19}$. NF-KB in turn activates the transcription of $1 \kappa B \alpha$, regulating its own inactivation ${ }^{20}$. As is shown in human and animal studies, the process of myocardial I/R activates the phosphorylation of $1 \kappa B \alpha$ resulting in NF-KB translocation and subsequent activation of inflammation ${ }^{21,22}$. Several factors involved in NF-kB signaling contribute to I/R injury. Deficiency in TLR-4 protects against myocardial I/R injury $^{23}$, as well as ischemic renal damage, showing a diminished inflammatory response ${ }^{24}$. Inhibition of IKK $\beta$, responsible for the IKB $\alpha$ phosphorylation, yielded smaller myocardial infarcts and an improved cardiac function ${ }^{25}$, while mice depleted in the p50 subunit of the NF-KB gene, also showed less myocardial I/R injury accompanied by reduced neutrophil infiltration ${ }^{26}$. Hence, the observed effects of ASIS on NF-kB related pathways may indeed be compatible with known protective effects related to specific alterations in this mechanism.

Whether the down regulation of TF is directly affecting these pathways, or that the signaling pathways directly influence TF levels still remains an important question. TF gene expression is known to be regulated by transcriptional factors including NF-KB ${ }^{27}$. The TF/FVIla complex is, however, also able to activate PAR-2 or can via thrombin formation activate PAR $-1^{28}$. A recent study has shown an 
important role for TF within the cardiac myocytes in heart hemostasis ${ }^{29}$. In this study, TF activity increased after $\mathrm{I} / \mathrm{R}$, showing increasing levels after a prolonged reperfusion time. The administration of ASIS decreased TF activity levels as well as TF mRNA levels within the myocardial tissue possibly via cellular signaling mechanisms through the influence of ASIS on NF-KB signaling. A possible link between TF and the TLR-4 pathway could be explained by this PAR-2 signaling as the PAR-2 receptor, which is activated by the TF/FVIla complex, is possibly able to activate TLR-4 as is shown in an inflammation model ${ }^{30}$. However, research involving the interactions between those signaling pathways need to be expanded. Recently, also a role for PAR-1, activated by thrombin, was determined in myocardial as well as renal $1 / R$ injury ${ }^{31,32}$. NF-KB regulation is also linked to PAR-1 as shown in a cancer cell line ${ }^{33}$. In our experiments PAR-1 showed an increased expression after $2 \mathrm{hrs}$ of reperfusion, and this was attenuated by ASIS administration. Longer reperfusion times had no effect on PAR-1 expression, suggesting an early effect of PAR-1 on I/R injury. TLR-4 on the other hand was activated after 6 and $24 \mathrm{hrs}$ of reperfusion and decreased by the administration of ASIS. Those data suggest a possible role for TLR-4 signaling in the later stages of the reperfusion process.

Having observed significant changes in the NF-kB gene complex we studied activated NF-KB levels and several downstream proteins that may be involved in myocardial I/R injury. Activated NF-KB levels were decreased upon ASIS administration. IL-6, a typical downstream effector of the NF-KB pathway is an important regulator of inflammation and is known to be increased in patients with myocardial infarction, heralding a poor outcome ${ }^{34,35}$. Upon I/R injury the levels of the pro-inflammatory genes for IL-6, IL-1 $\beta$ and MIP- $1 \alpha$ were increased compared to sham operated animals. Importantly, IL-6 mRNA expression levels were decreased by ASIS administration after $2 \mathrm{hrs}$ of reperfusion and the same pattern was seen in heart specific IL-6 protein levels.

Both PAI-1 mRNA and protein levels were decreased by ASIS administration after a $24 \mathrm{hrs}$ reperfusion period. However, the specific contribution of PAI-1 in myocardial $\mathrm{I} / \mathrm{R}$ is controversial ${ }^{36,37}$.

The beneficial effect of ASIS on myocardial infarction was associated with reduced inflammation, indicated by reduced neutrophil influx as well as reduced expression of pro-inflammatory genes and proteins in the left ventricle. Gene array analysis showed that the NF-KB pathway is involved in the 
ASIS induced effects on the heart and it may be surmised that the observed reduction in inflammation is in part related to the effects on the NF-kB system, although this will require further experimental studies.

From a clinical perspective, the favorable effects of ASIS on I/R injury after myocardial infarction may ultimately pave the way for clinical studies with such specific anticoagulants in situations of critical ischemic organ damage.

\section{ACKNOWLEDGEMENTS}

We kindly acknowledge Dr. J. Cleutjens, department of Pathology, for critical comments.

This project was funded by the Netherlands Heart Foundation (grant no. 2003B065). 


\section{REFERENCES}

1. Yellon DM, Hausenloy DJ. Myocardial reperfusion injury. $N$ Engl J Med. 2007;357:1121-1135.

2. Jennings RB, Sommers HM, Smyth GA, Flack HA, Linn H. Myocardial necrosis induced by temporary occlusion of a coronary artery in the dog. Arch Pathol. 1960;70:68-78.

3. Birdsall HH, Green DM, Trial J, Youker KA, Burns AR, MacKay CR, LaRosa GJ, Hawkins HK, Smith CW, Michael LH, Entman ML, Rossen RD. Complement C5a, TGF-beta 1, and MCP-1, in sequence, induce migration of monocytes into ischemic canine myocardium within the first one to five hours after reperfusion. Circulation. 1997;95:684-692.

4. Bolli R, Becker L, Gross G, Mentzer R, Jr., Balshaw D, Lathrop DA. Myocardial protection at a crossroads: the need for translation into clinical therapy. Circ Res. 2004;95:125-134.

5. Strukova S. Blood coagulation-dependent inflammation. Coagulation-dependent inflammation and inflammation-dependent thrombosis. Front Biosci. 2006;11:59-80.

6. Chu AJ. Role of tissue factor in thrombosis. Coagulation-inflammation-thrombosis circuit. Front Biosci. 2006;11:256-271.

7. Erlich JH, Boyle EM, Labriola J, Kovacich JC, Santucci RA, Fearns C, Morgan EN, Yun W, Luther T, Kojikawa O, Martin TR, Pohlman TH, Verrier ED, Mackman N. Inhibition of the tissue factor-thrombin pathway limits infarct size after myocardial ischemiareperfusion injury by reducing inflammation. Am J Pathol. 2000;157:1849-1862.

8. Golino P, Ragni M, Cirillo P, Scognamiglio A, Ravera A, Buono C, Guarino A, Piro O, Lambiase C, Botticella F, Ezban M, Condorelli M, Chiariello M. Recombinant human, active site-blocked factor VIla reduces infarct size and no-reflow phenomenon in rabbits. Am J Physiol Heart Circ Physiol. 2000;278:H1507-1516.

9. Jong WM, Reitsma PH, ten Cate $\mathrm{H}$, de Winter RJ. Modified two-step model for studying the inflammatory response during myocardial ischemia and reperfusion in mice. Comp Med. 2003;53:522-526.

10. Spek CA, Verbon A, Aberson H, Pribble JP, McElgunn CJ, Turner T, Axtelle T, Schouten J, Van Der Poll T, Reitsma PH. Treatment with an anti-CD14 monoclonal antibody delays and inhibits lipopolysaccharide-induced gene expression in humans in vivo. J Clin Immunol. 2003;23:132-140.

11. Davis JN, Kucuk O, Djuric Z, Sarkar FH. Soy isoflavone supplementation in healthy men prevents NF-kappa B activation by TNF-alpha in blood lymphocytes. Free Radic Biol Med. 2001;30:1293-1302.

12. Petersen LC, Norby PL, Branner S, Sorensen BB, Elm T, Stennicke HR, Persson E, Bjorn $\mathrm{SE}$. Characterization of recombinant murine factor VIla and recombinant murine tissue factor: a human-murine species compatibility study. Thromb Res. 2005;116:75-85.

13. Ojha N, Roy S, Radtke J, Simonetti O, Gnyawali S, Zweier JL, Kuppusamy P, Sen CK. Characterization of the structural and functional changes in the myocardium following focal ischemia-reperfusion injury. Am J Physiol Heart Circ Physiol. 2008;294:H2435-2443.

14. Redel A, Jazbutyte V, Smul TM, Lange M, Eckle T, Eltzschig H, Roewer N, Kehl F. Impact of ischemia and reperfusion times on myocardial infarct size in mice in vivo. Exp Biol Med (Maywood). 2008;233:84-93. 
15. Maeno E, Ishizaki Y, Kanaseki T, Hazama A, Okada Y. Normotonic cell shrinkage because of disordered volume regulation is an early prerequisite to apoptosis. Proc Natl Acad Sci U S A. 2000;97:9487-9492.

16. Qureshi ST, Lariviere L, Leveque G, Clermont S, Moore KJ, Gros P, Malo D. Endotoxintolerant mice have mutations in Toll-like receptor 4 (TIr4). J Exp Med. 1999;189:615-625.

17. Frantz S, Kobzik L, Kim YD, Fukazawa R, Medzhitov R, Lee RT, Kelly RA. Toll4 (TLR4) expression in cardiac myocytes in normal and failing myocardium. J Clin Invest. 1999;104:271-280.

18. Karin M, Ben-Neriah Y. Phosphorylation meets ubiquitination: the control of NF[kappa]B activity. Annu Rev Immunol. 2000;18:621-663.

19. DiDonato JA, Hayakawa M, Rothwarf DM, Zandi E, Karin M. A cytokine-responsive IkappaB kinase that activates the transcription factor NF-kappaB. Nature. 1997;388:548-554.

20. Johnson C, Van Antwerp D, Hope TJ. An N-terminal nuclear export signal is required for the nucleocytoplasmic shuttling of IkappaBalpha. EMBO J. 1999;18:6682-6693.

21. Li C, Browder W, Kao RL. Early activation of transcription factor NF-kappaB during ischemia in perfused rat heart. Am J Physiol. 1999;276:H543-552.

22. Valen $G$, Paulsson $G$, Vaage J. Induction of inflammatory mediators during reperfusion of the human heart. Ann Thorac Surg. 2001;71:226-232.

23. Oyama J, Blais C, Jr., Liu X, Pu M, Kobzik L, Kelly RA, Bourcier T. Reduced myocardial ischemia-reperfusion injury in toll-like receptor 4-deficient mice. Circulation. 2004;109:784-789.

24. Wu H, Chen G, Wyburn KR, Yin J, Bertolino P, Eris JM, Alexander SI, Sharland AF, Chadban SJ. TLR4 activation mediates kidney ischemia/reperfusion injury. J Clin Invest. 2007;117:2847-2859.

25. Moss NC, Stansfield WE, Willis MS, Tang RH, Selzman CH. IKKbeta inhibition attenuates myocardial injury and dysfunction following acute ischemia-reperfusion injury. Am J Physiol Heart Circ Physiol. 2007;293:H2248-2253.

26. Frantz S, Tillmanns J, Kuhlencordt PJ, Schmidt I, Adamek A, Dienesch C, Thum T, Gerondakis S, Ertl G, Bauersachs J. Tissue-specific effects of the nuclear factor kappaB subunit p50 on myocardial ischemia-reperfusion injury. Am J Pathol. 2007;171:507-512.

27. Mackman N. Regulation of the tissue factor gene. FASEB J. 1995;9:883-889.

28. Versteeg HH, Ruf W. Emerging insights in tissue factor-dependent signaling events. Semin Thromb Hemost. 2006;32:24-32.

29. Pawlinski R, Tencati M, Holscher T, Pedersen B, Voet T, Tilley RE, Marynen P, Mackman N. Role of cardiac myocyte tissue factor in heart hemostasis. J Thromb Haemost. 2007;5:1693-1700.

30. Matsuda N, Nishihira J, Takahashi Y, Kemmotsu O, Hattori Y. Role of macrophage migration inhibitory factor in acute lung injury in mice with acute pancreatitis complicated by endotoxemia. Am J Respir Cell Mol Biol. 2006;35:198-205.

31. Pawlinski R, Tencati M, Hampton CR, Shishido T, Bullard TA, Casey LM, AndradeGordon P, Kotzsch M, Spring D, Luther T, Abe J, Pohlman TH, Verrier ED, Blaxall BC, Mackman N. Protease-activated receptor-1 contributes to cardiac remodeling and hypertrophy. Circulation. 2007;116:2298-2306.

32. Sevastos J, Kennedy SE, Davis DR, Sam M, Peake PW, Charlesworth JA, Mackman N, Erlich $\mathrm{JH}$. Tissue factor deficiency and PAR-1 deficiency are protective against renal ischemia reperfusion injury. Blood. 2007;109:577-583. 
33. Tantivejkul K, Loberg RD, Mawocha SC, Day LL, John LS, Pienta BA, Rubin MA, Pienta KJ. PAR1-mediated NFkappaB activation promotes survival of prostate cancer cells through a Bcl-xL-dependent mechanism. J Cell Biochem. 2005;96:641-652.

34. Shu J, Ren N, Du JB, Zhang M, Cong HL, Huang TG. Increased levels of interleukin-6 and matrix metalloproteinase- 9 are of cardiac origin in acute coronary syndrome. Scand Cardiovasc J. 2007;41:149-154.

35. Manten A, de Winter RJ, Minnema MC, ten Cate H, Lijmer JG, Adams R, Peters RJ, van Deventer SJ. Procoagulant and proinflammatory activity in acute coronary syndromes. Cardiovasc Res. 1998;40:389-395.

36. Moriwaki H, Stempien-Otero A, Kremen M, Cozen AE, Dichek DA. Overexpression of urokinase by macrophages or deficiency of plasminogen activator inhibitor type 1 causes cardiac fibrosis in mice. Circ Res. 2004;95:637-644.

37. Takeshita K, Hayashi M, lino S, Kondo T, Inden $\mathrm{Y}$, Iwase $\mathrm{M}$, Kojima T, Hirai $\mathrm{M}$, Ito $\mathrm{M}$, Loskutoff DJ, Saito H, Murohara T, Yamamoto K. Increased expression of plasminogen activator inhibitor-1 in cardiomyocytes contributes to cardiac fibrosis after myocardial infarction. Am J Pathol. 2004;164:449-456. 




\section{Chapter 4}

\section{APC protects against myocardial $I / R$ injury via inhibition of apoptosis and inflammation}

STBG Loubele, CA Spek, P Leenders, R van Oerle, HL Aberson, K Hamulyák, G Ferrell, CT Esmon, HMH Spronk, $\mathrm{H}$ ten Cate.

Activated protein C protects against myocardial ischemia/reperfusion injury via inhibition of apoptosis and inflammation.

Arterioscler Thromb Vasc Biol 2009:Apr. 16 (epub ahead of print) 


\section{AbStract}

In spite of major advances in reperfusion therapy for patients presenting with an acute coronary syndrome, long term morbidity is still substantial. A limitation of initial treatment of myocardial ischemia is the lack of prevention of ischemia/reperfusion (I/R) injury, mainly recognized by apoptosis and inflammation. Activated protein C (APC), a crucial mediator in the coagulation process, plays a prominent role in the crosstalk between coagulation and inflammation and provides cytoprotective effects via inhibition of apoptosis and inflammation in several human and animal studies.

APC was administered during the ischemic as well as the reperfusion phase in a mouse model for myocardial I/R.

APC largely inhibited early myocardial I/R injury after varying reperfusion times, an effect that was absent upon administration of heparin, a non specific anticoagulant agent. The protective effects of APC were absent in case of absence or blockade of protease activated receptor-1 (PAR-1), indicating a critical role for PAR-1 in this process. Furthermore, we showed a strong antiapoptotic effect of APC in the early phase of reperfusion combined with an antiinflammatory effect at an early stage (interleukine (IL)-6), as well as at a later stage (leukocyte infiltration).

APC exerts strong protective effects on early myocardial I/R injury, primarily via inhibition of apoptosis and inflammation, which are regulated via PAR-1. 


\section{INTRODUCTION}

Acute myocardial infarction (AMI) is an important contributor to cardiovascular mortality. Although mortality attributable to to the acute coronary event has declined substantially with current improved reperfusion therapies, long term morbidity is increased because of secondary heart failure in survivors of AMI. Unfortunately, the shift from acute to long-term morbidity after acute ischemic injury of the heart reveals other therapeutic shortcomings. While revascularization in the acute phase of ischemia or thrombolysis has caused a major improvement in survival, there are no agents that limit $I / R$ injury, contributing to apoptosis, inflammation and subsequent heart failure ${ }^{1}$.

The natural anti-coagulant protein $\mathrm{C}$, which is converted by thrombin into activated protein $\mathrm{C}$ or $\mathrm{APC}^{2}$, plays a crucial role in the process of coagulation but is also prominent in the crosstalk between coagulation and inflammation ${ }^{3}$. The anti-inflammatory role of APC emerged from the PROWESS study where APC was shown to reduce mortality in patients with severe sepsis ${ }^{4}$. Animal studies indicate that $A P C$ offers protection against $\mathrm{I} / \mathrm{R}$ injury in in vivo models of ischemic stroke, spinal cord ischemia, and renal injurys-8. Hence, we hypothesized that APC might also reduce myocardial injury after ischemic damage of the heart.

To explore the potential beneficial effects of APC on myocardial I/R injury, we applied mouse APC in an experimental mouse model of myocardial I/R. The effects of APC on myocardial I/R injury, inflammation as well as apoptosis were explored to gain a better insight into the specific mechanisms of APC on cardiac myocytes. We especially focused on the cell signaling pathways on several time points of reperfusion and the effects on coagulation, inflammation, and apoptosis related processes. 


\section{Materials AND Methods}

Mouse Myocardial Ischemia/Reperfusion Model. Myocardial I/R was induced according to the method of Jong et al. ${ }^{9}$. A detailed protocol is provided in addendum 1.

Intervention. Mouse APC in a dose of $0.4 \mathrm{mg} / \mathrm{kg}$, or placebo $(0.9 \% \mathrm{NaCl})$ was administered (i.v. via the vena jugularis) 15 min after induction of ischemia and a second time $5 \mathrm{~min}$ after induction of reperfusion. Unfractionated heparin (Heparin Leo, Leo Pharma BV, Breda, The Netherlands) was administered (i.v. via the vena jugularis) twice at the same time points in a dose of $5 \mathrm{U}$ each. The PAR-1 inhibitor P1pal12 was administered $30 \mathrm{~min}$ before induction of reperfusion in a $10 \mu \mathrm{M}$ dose $\left(200 \mu\right.$ i.p.) according to Slofstra et al. ${ }^{10}$.

Plasma and tissue collection. A detailed protocol is provided in addendum 2.

Determination of myocardial I/R injury: Evans Blue/TTC staining. A detailed protocol is provided in addendum 3.

Calibrated Automated Thrombogram (CAT). Thrombin generation was determined using the Calibrated Automated Thrombogram (CAT). The CAT was obtained from Thrombinoscope BV (Maastricht, The Netherlands) and all samples were analyzed according to the manufacturer's instructions in a 96well plate fluorometer (Ascent Reader, THermolabsystems OY, Helsinki, Finland). APC was added in varying concentrations of 0 to $250 \mathrm{nM}$ and heparin was added in concentrations of 0 to $5 \mathrm{U} / \mathrm{ml}$ to mouse plasma. Lag time, time to peak, peak height, ETP and time to tail were determined.

TF activity. A detailed protocol is provided in addendum 4.

Plasminogen activator inhibitor (PAI)-1 antigen. Total PAI-1 antigen levels were determined in tissue homogenates ( $1 \mathrm{mg} / \mathrm{ml}$ protein content) according to the manufacturer`s instructions (Innovative Research, MI, US).

Gene expression. Apoptosis and cell signaling related gene expression levels were determined in isolated RNA of the mouse hearts ( $n=6$ per group). $50 \mathrm{ng} / \mu \mathrm{l}$ RNA was analyzed according to the method described by spek et al. ${ }^{11}$. The following genes were analyzed: Bcl-2-like anti-apoptotic genes $\mathrm{Bcl}-2, \mathrm{Bfl}-1, \mathrm{Bcl}-$ $\mathrm{W}$, and Bcl-xl; Bax-like pro-apoptotic genes Bak1, Bax, Bcl-Rambo, and Mcl-1; BH3-only pro-apoptotic genes Bad, Bid, Bik, Bim, and Map-1, and other apoptosis-related genes NIAP, AIF, Apaf-1, Diablo, Flip, and p21. Only the genes 
related to the Bcl-2 family are discussed in the results as they showed the most striking differences upon APC administration. The difference in RNA expression levels between APC or placebo treated animals of other apoptosis related genes are shown in table 1 . Several genes involved in cellular signaling, inflammation and coagulation were analyzed (cell signaling: CD14, toll-like receptor (TLR)-2, TLR-4, IL-1 receptor associated kinase (IRAK)-1, IRAK-3, IKB $\alpha$, and PAR-1; coagulation: tissue factor (TF), tissue factor pathway inhibitor (TFPI), PAI-1, tPA, endothelial protein $C$ receptor and UPAR; inflammation: IL-6, IL-4, IL-10, IL-1 $\beta$, tumor necrosis factor (TNF)- $\alpha$, interferon (IFN)- $\gamma$, hypoxia inducible factor (HIF)-1 $\alpha$, ICAM-1, macrophage inflammatory protein (MIP)-1 $\alpha, \mathrm{CXCl} 1$, $\mathrm{CCl} 3$, and eNOS).

Inflammation. IL-6, TNF- $\alpha$, and IL-1 $\beta$ antigen levels were determined in tissue homogenates containing $1 \mathrm{mg} / \mathrm{ml}$ protein using an ELISA reagent set. All analyses were performed according to the manufacturer's manual (eBioscience, CA, US). Paraffin sections were stained for CD 45 using a rat anti-mouse CD 45 antibody (BD Pharmingen, San Jose, USA). The number of CD 45 positive cells per surface area was determined in 3 fields within the infarcted area using a 40x magnification.

Apoptosis. Mouse heart paraffin sections were stained for apoptosis using the ApopTag Plus Peroxidase In Situ Apoptosis Detection Kit and the In Situ Cell Death Detection Kit TMR red. Sections were stained according the manufacturer's manual (Chemicon, Billerica, USA and Roche Diagnostics, Indianapolis, USA). Analyses of all sections were done blinded for treatment allocation (APC, placebo, or sham). The amount of apoptosis was estimated by counting the number of cells in 3 fields within the infarcted area using a $40 \mathrm{x}$ magnification. Data are represented as the number of positive cells per surface area.

Statistical analysis. Data analysis was performed with GraphPad Prism version 5.00. Values are means \pm SEM. Differences between groups were tested using a Mann-Whitney t-test and $\mathrm{P}$ values $<0.05$ were considered statistically significant. 


\section{RESULTS}

APC diminishes myocardial I/R injury via PAR-1. In a model of myocardial I/R injury, administration of mouse recombinant APC decreased, as compared to placebo, the amount of I/R injury (depicted as a percentage of area of infarction (AOI) to area at risk (AAR)) with a trend observed at $2 \mathrm{hrs}$ and obtaining a maximal and statistically significant protective effect after $6 \mathrm{hrs}$, which sustained after $24 \mathrm{hrs}$ of reperfusion (Figure $1 \mathrm{~A}$ ). As a control, AAR ratios to the whole heart were determined in the placebo treated animals and these remained equal over time (data not shown). To assess the effects of APC against an active comparator agent, the anti-coagulant unfractionated heparin was administered. Heparin administration at a peak level of 2.5 units/ml had no effect on myocardial I/R injury as the \% AOI/AAR after heparin administration was comparable to placebo administration after $6 \mathrm{hrs}$ of reperfusion, suggesting specific protective effects of APC not involving its anti-coagulant action (Figure 1B). PAR-1 was recently shown to influence cardiac remodeling, hypertrophy, and myocardial ischemia/reperfusion injury ${ }^{12,13}$. Furthermore, blocking PAR-1 reversed the protective effects of APC on apoptosis in hypoxic cells ${ }^{6}$. To reveal the role of PAR-1 in the protective mechanism of APC in the myocardium, APC was administered in combination with the specific PAR-1 blocker P1Pal12 and was administered to PAR-1\% mice. P1Pal12 reversed the protective effects of APC on myocardial I/R injury since the $\%$ AOI/AAR remained equal to placebo administration after a $6 \mathrm{hrs}$ reperfusion period (Figure $1 \mathrm{C}$ ). Furthermore administration of APC to PAR-1\% mice confirmed these results as no protective effect of APC was observed in PAR-1/- mice (Figure 1C).

To compare the anti-coagulant effects of both heparin and APC, both anticoagulants were added in a thrombin generation measurement in a dose varying around the dose administered to the mice. Both APC and heparin already inhibited thrombin generation at a dose (Heparin: $0.052 \mathrm{U} / \mathrm{ml}$; APC: 10 $\mathrm{nM}$ ) that was much lower than the dose administered in the mice (Heparin: 5 $\mathrm{U} / \mathrm{ml}$; APC: $214 \mathrm{nM}$ ), indicating that both heparin and APC exert an equally strong anti-coagulant function within the experiment, suggesting that other functions of APC besides its anti-coagulant function are necessary for its protective effect in myocardial I/R injury (Figure 2A). 

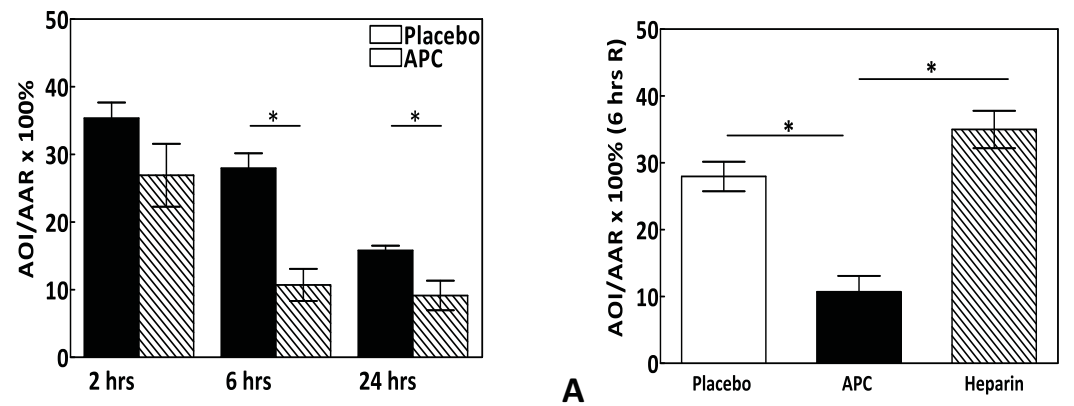

B

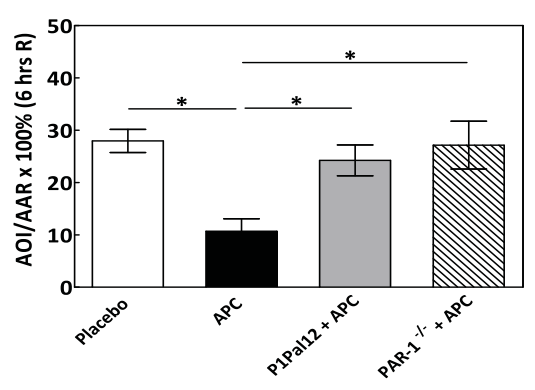

C

Figure 1: Panel A: \%AOI/AAR of APC treatment compared to placebo. APC reduces the AOI as a percentage of the AAR after myocardial ischemia/ reperfusion injury at varying reperfusion times. Panel B: The administration of heparin did not influence the amount of $\mathrm{I} / \mathrm{R}$ injury. Panel $\mathrm{C}$ : The absence or blockage of PAR-1 reversed the protective mechanisms of APC on the \%AOI/ AAR. All values are mean $\pm \mathrm{SEM}, \mathrm{n}=6,{ }^{*} \mathrm{p}<0.05$.

Because APC has been shown to inhibit the NF-KB transcription complex in specific cells including mononuclear cells ${ }^{14}$, we determined whether the administration of APC would also diminish protein levels that result from immediate gene translation of the NF-KB pathway, including TF and PAI-1. Both TF activity and PAI-1 antigen levels in heart tissue homogenates increased upon I/R after 2, 6 or 24 hrs of reperfusion compared to the sham group. Remarkably, APC administration increased TF activity levels as well as PAI-1 antigen concentrations after $2 \mathrm{hrs}$ of reperfusion compared to the placebo treated animals. TF activity levels were no longer increased upon APC administration in combination with P1Pal12. After 6 and 24 hrs of reperfusion neither TF activity nor PAl-1 antigen levels were different between APC and placebo treated animals (Figure 2B and 2C). 

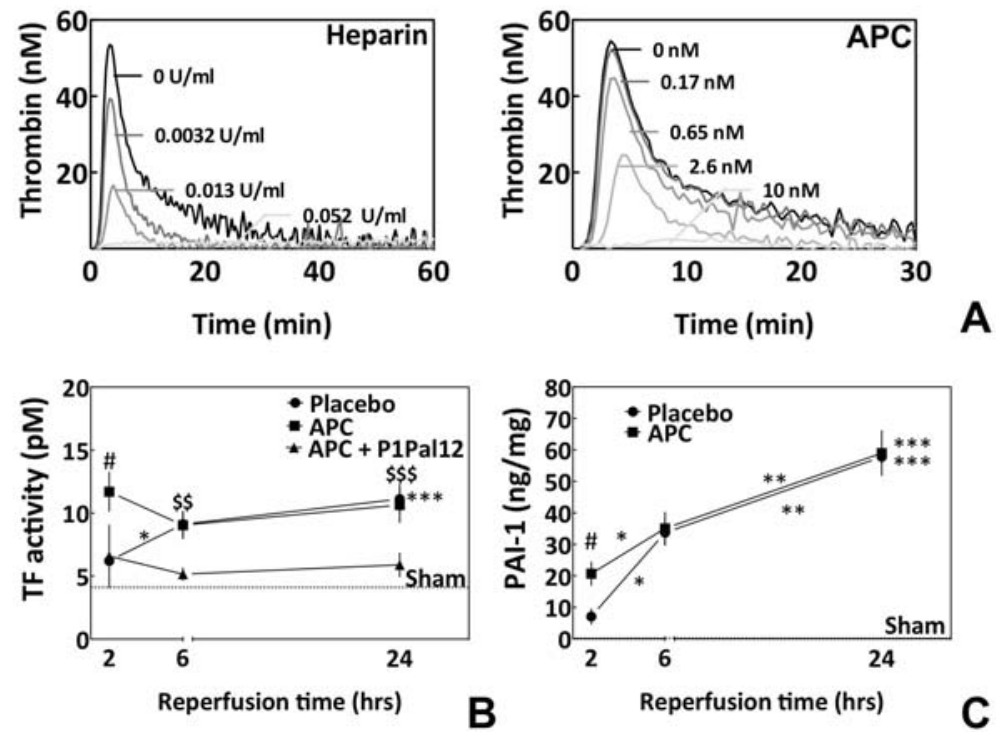

Figure 2: Panel A: APC as well as heparin has a strong anti-coagulant effect when added in a thrombin generation assay. Panel B: APC administration increased TF activity levels after 2 hrs of reperfusion, but no longer influenced TF activity levels after prolonged reperfusion times. Panel B: PAI-1 antigen levels were increased upon APC administration after $2 \mathrm{hrs}$ of reperfusion, whereas PAI-1 antigen levels were no longer influenced with APC after longer reperfusion times. All values are mean $\pm \mathrm{SEM}, \mathrm{n}=6$. *differences between different reperfusion times after placebo or APC administration (*2hrs vs 6 hrs, ** $6 \mathrm{hrs}$ vs $24 \mathrm{hrs}, * * * 2 \mathrm{hrs}$ vs $24 \mathrm{hrs}$ ), $\mathrm{p}<0.05$. \# difference between placebo and APC treatment (\# 2 hrs R, \#\# 6 hrs R, \#\#\# 24 hrs R), p<0,05. \$ difference between placebo and APC+P1Pal12 treatment ( $\$ 2 \mathrm{hrs}$ R, \$\$ $6 \mathrm{hrs}$ R, \$\$ $\$ 24 \mathrm{hrs}$ $\mathrm{R}), \mathrm{p}<0,05$.

APC attenuates apoptosis. APC was previously shown to reduce apoptosis in hypoxic cells and to be neuroprotective in a mouse stroke mode ${ }^{5,6}$, as well as to reduce apoptosis in the heart in a I/R model in rats ${ }^{15}$. To assess the effects of mouse specific APC on I/R-induced apoptosis, cell death was analyzed by means of apoptosis staining. Staining for apoptosis with a chromogenic as well as a fluorogenic detection method revealed a reduced number of positive cells upon APC administration, showing the most pronounced effect after 2 and 24 hrs of 
reperfusion (Figure $3 \mathrm{~A})$. Scoring of the stained sections for the number of apoptotic cells revealed a decrease after 2 and $24 \mathrm{hrs}$ of reperfusion upon APC administration compared to placebo, a trend which was also visible after $6 \mathrm{hrs}$ of reperfusion (Figure $3 \mathrm{~B}$ ). Thus, APC has a strong anti-apoptotic effect on myocardial I/R injury at an early onset in the reperfusion phase.
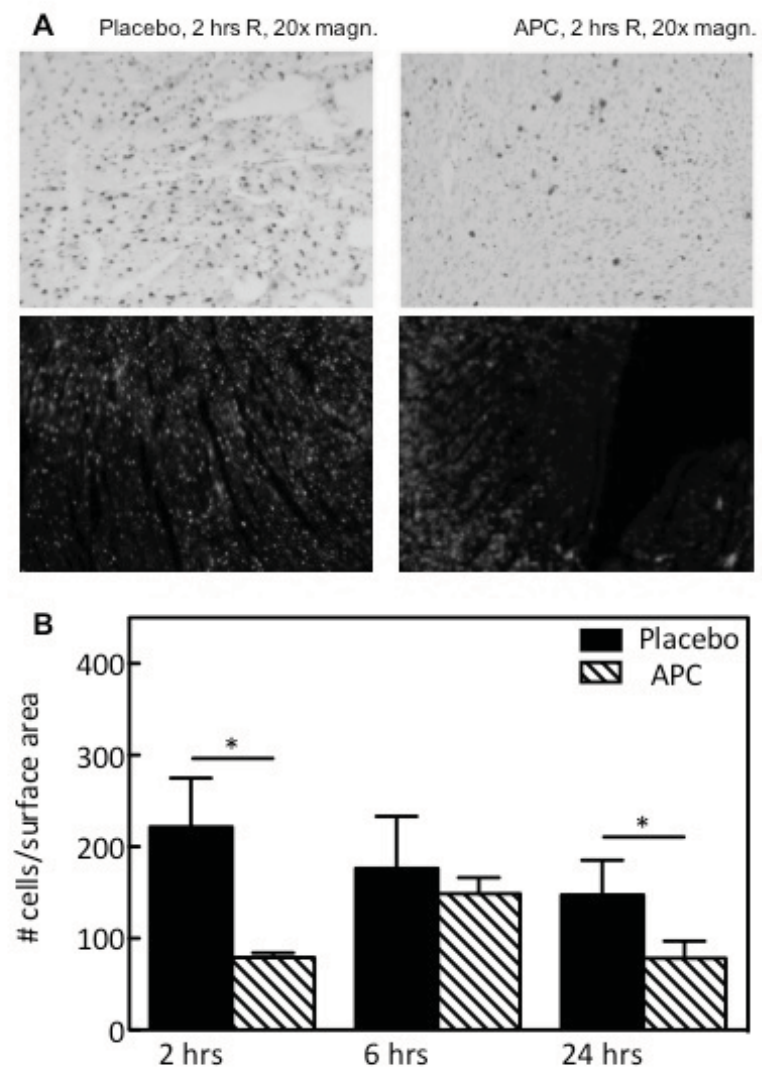

Figure 3: APC has strong anti-apoptotic effects as evident from reduced apoptosis staining. Panel A: Representative pictures of stained paraffin sections for apoptosis with as well a chromogenic as a fluorogenic detection method $(20 \mathrm{x}$ magnification). In the chromogenic method, the positive cells are stained dark brown. The fluorogenic method shows positive cells in red and nuclei in blue. Panel B: Slides were scored for the number of positive cells within 3 fields of the infarcted area using a 40x magnification. The scoring revealed a reduction in positively stained cells after APC administration at a 2 and $24 \mathrm{hrs}$ reperfusion period, $n=4, * p<0.05$. See addendum for color figure. 
APC reduces inflammation regulated via PAR-1. Besides its anti-apoptotic effects, APC also exerts anti-inflammatory properties in patients with sepsis as well as in experimental animal studies ${ }^{4-8}$. Within the placebo group, IL-6 levels increased compared to the sham group showing maximal levels at $2 \mathrm{hrs}$ of reperfusion. IL-6 levels remained slightly increased after $6 \mathrm{hrs}$ of reperfusion, and returned to baseline sham levels after $24 \mathrm{hrs}$ of reperfusion. Administration of APC caused an early reduction in IL-6 protein levels at $2 \mathrm{hrs}$ of reperfusion (Figure 4A). Blocking PAR-1 counteracts the anti-inflammatory effect of APC as IL-6 levels remained equal to placebo administration (Figure $4 A$ ). IL-1 $\beta$ and TNF- $\alpha$ values in the left ventricle remained below the detection limit at all reperfusion times. As an important hallmark of I/R injury, leukocyte infiltration was determined by means of CD 45 staining. Leukocyte infiltration was attenuated upon APC administration after a prolonged reperfusion time (Figure $4 B)$. The number of CD 45+ cells per surface area increased after 6 and $24 \mathrm{hrs}$ of reperfusion compared to a 2 hrs reperfusion period in placebo treated mice, while upon APC administration the number of infiltrating leukocytes decreased after 6 and 24 hrs of reperfusion (Figure 4C).

These results show marked anti-inflammatory properties of APC in association with a diminished myocardial I/R injury, primarily by inhibition of leukocyte influx and IL-6 levels, probably mediated via PAR-1. However, proteins transcribed in a NF-KB dependent manner including TF and PAI-1 do not seem to contribute to the protective effect of APC.

APC reduces apoptotic related gene expression. The effect of APC on gene expression relating apoptosis and NF-KB mediated genes were analyzed using Multiplex Ligation Dependent Probe Amplification (MLPA). From the apoptosis gene panel, $\mathrm{Bfl}-1$ and $\mathrm{BCl}-\mathrm{xl}$ expression levels were increased upon I/R compared to the sham animals. Administration of APC decreased Bfl-1 and $\mathrm{Bcl}-2$ expression levels after $6 \mathrm{hrs}$ of reperfusion. Bcl-w and $\mathrm{Bcl}-\mathrm{xl}$ were not influenced upon APC administration. The Bax-like pro-apoptotic related genes Bak1, Bax, and Mcl-1 increased upon I/R whereas the expression level of BclRambo decreased upon I/R compared to sham. The RNA expression levels of Bax, Bcl-Rambo, and $\mathrm{Mcl}-1$ decreased upon APC administration. The expression level of Bak1 showed a trend towards a decreased expression upon APC administration after $6 \mathrm{hrs}$ of reperfusion but the results were not significantly different. The BH3-only pro-apoptotic related gene Bid was increased after I/R at 6 and $24 \mathrm{hrs}$ of reperfusion, whereas Bik expression levels were decreased 
after I/R at 2 hrs of reperfusion. Administration of APC decreased Bik, Bim, and Map-1 levels after 2 and 6 hrs of reperfusion, whereas the expression level of Bid was increased after APC administration upon $2 \mathrm{hrs}$ of reperfusion. The expression levels of Bad were not influenced by the administration of APC (Figure 5). These results showed a down-regulating effect of APC on a number of pro-apoptotic genes, indicating an early effect on the $\mathrm{BH} 3$-only related genes at early reperfusion times and a down-regulating effect of Bax-like related genes at later stages of reperfusion.

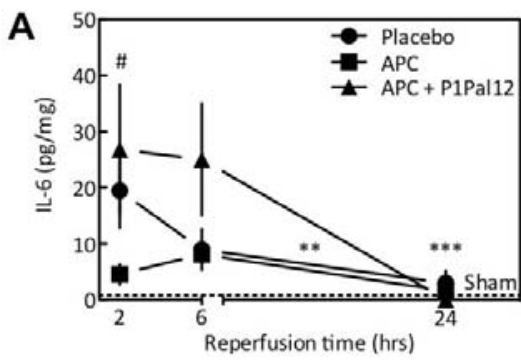

\section{B Placebo, 6 hrs R, 20x magn.}
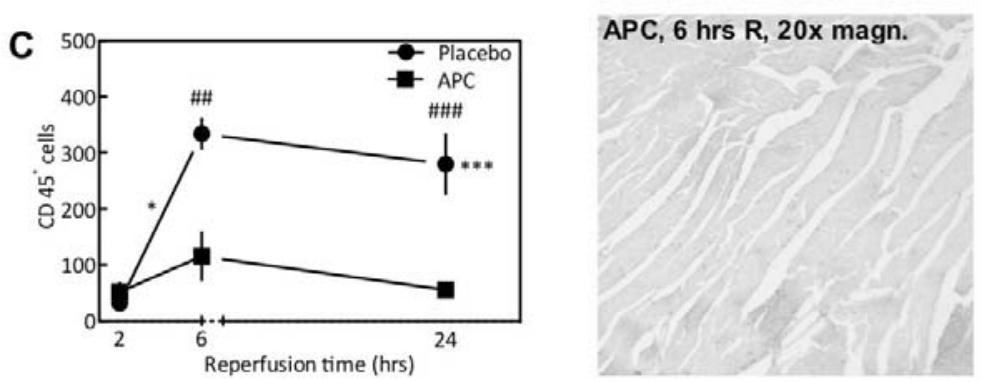

Figure 4: The anti-inflammatory properties of APC contribute to the myocardial protection. Panel A: IL-6 protein levels decreased after 2 hrs of reperfusion upon APC administration. Panel B: Representative pictures of the CD45 staining for leukocytes (20x magnification). Panel C: Counting the numbers of CD45 positively stained cells per surface area within the infarcted area revealed reduced leukocytes within the infarcted area upon APC administration. All values are mean $\pm \mathrm{SEM}, \mathrm{n}=6$. *differences between different $\mathrm{R}$ times after placebo or APC administration (*2hrs vs 6 hrs, ** $6 \mathrm{hrs}$ vs $24 \mathrm{hrs}$, *** $2 \mathrm{hrs}$ vs $24 \mathrm{hrs}$ ), $\mathrm{p}<0.05$. \# difference between placebo and APC treatment (\# $2 \mathrm{hrs} \mathrm{R}$, \#\# 6 hrs R, \#\#\# 24 hrs R), p $<0,05$. \$ difference between placebo and APC+P1Pal12 treatment ( $\$ 2$ hrs R, \$\$ 6 hrs R, \$\$ 24 hrs R), p<0,05. 


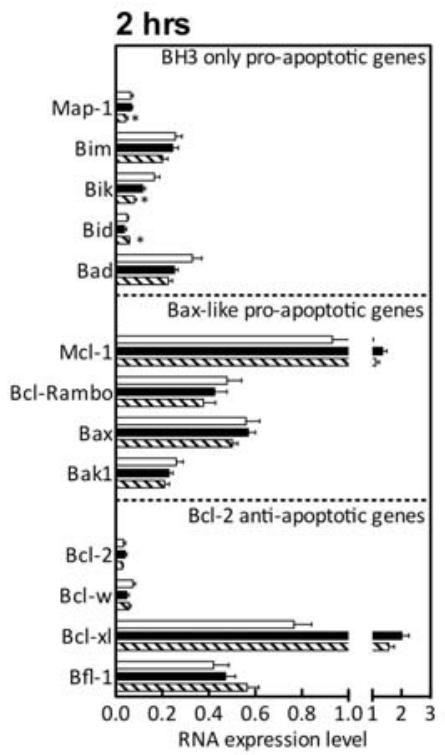

$6 \mathrm{hrs}$

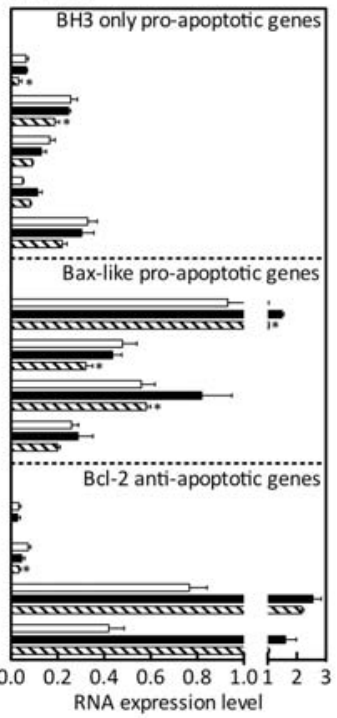

$24 \mathrm{hrs}$

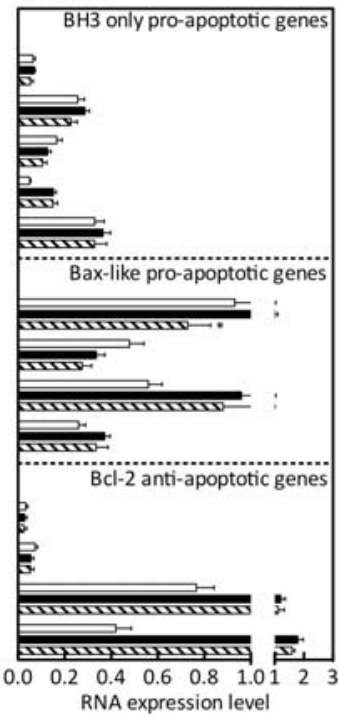

Figure 5: RNA expression levels of apoptosis related genes determined by MLPA analysis were influenced upon APC administration. The RNA expression levels of a number of Bcl-2 anti-apoptotic, Bax-like pro-apoptotic, and $\mathrm{BH} 3$ only pro-apoptotic genes were up- or down regulated upon APC administration. *difference between placebo and APC administration, $n=6, p<0.05$.

The difference in expression levels between placebo and APC treatment of several apoptosis related genes not involved in the $\mathrm{Bcl}-2$ family are depicted in table 1. MLPA analysis on NF-KB related cell signaling proteins did not reveal a contributing effect of APC on these pathways (data not shown).

\begin{tabular}{cccc}
\hline & APC vs placebo 2 hrs R & APC vs placebo 6 hrs R & APC vs placebo 24 hrs R \\
\hline NIAP & $\uparrow$ & $=$ & $=$ \\
AIF & $=$ & $=$ & $=$ \\
Apaf-1 & $\uparrow$ & $=$ & $=$ \\
Diablo & $=$ & $=$ & $=$ \\
Flip & $=$ & $\downarrow$ & $=$ \\
P21 & $=$ & $=$ & \\
\hline
\end{tabular}

Table 1: The difference in RNA expression level between placebo or APC treated animals of several apoptosis related genes not involved in the Bcl-2 family. 


\section{DiscusSiON}

This study reveals a role for APC in the protection against myocardial I/R injury via a combined effect on inflammation and apoptosis and mediated via PAR-1. Although the absence of PAR-1 was previously shown to be protective against myocardial I/R injury ${ }^{12,13}$, the current study highlights the need for PAR-1 in the protective actions of APC in myocardial I/R injury, consistent with results in an ischemic stroke model ${ }^{6}$. A great part of cardiomyocyte cell death occurs via the process of apoptosis ${ }^{16}$, which is preceded by cell shrinkage leading to cell fragmentation ${ }^{17}$. Whether apoptosis is induced during the ischemic or the reperfusion phase remains contradictory ${ }^{18-20}$. Several pathways are shown to be involved in the induction of I/R in the heart, including: activation of TNF- $\alpha, p 53$, $\mathrm{Bcl}-2$, Bax up-, or down regulation and infiltration of neutrophils ${ }^{21}$. Here we show a strong anti-apoptotic effect of APC on apoptosis staining at an early time point of reperfusion combined with an effect on $\mathrm{BH} 3$ only and Bax-like pro-apoptotic genes at early and later stages of reperfusion. The most striking effects of APC were visible upon genes involved in the Bcl-2 family, which was also revealed in brain endothelial cells ${ }^{22}$. A study by Pirat et al. also revealed an anti-apoptotic effect of APC after 20 min of ischemia and 2 hrs of reperfusion but an anti-inflammatory effect on C-reactive protein or TNF- $\alpha$ levels was not visible possibly due to the short ischemic period used ${ }^{15}$. Direct effects of APC on neutrophil migration have been demonstrated in experimental models under conditions of inflammation ${ }^{23}$. In I/R injury the process of apoptosis is thought to trigger an inflammatory response, including the influx of leukocytes, a process which is confirmed in the kidney but likely also applies to other organs ${ }^{24}$. Excess inflammatory activity is also thought to contribute to lethal cardiomyocyte injury and inhibition of this pathway by APC may in part explain the protective effect of this agent. The latter is also illustrated by an early inhibitory effect of APC on IL-6 production in the heart. It is unknown whether APC inhibits IL-6 production by infiltrating leukocytes or by cardiomyocytes, but the latter is more likely given that leukocyte influx occurs beyond $2 \mathrm{hrs}$, the time point when the anti-IL 6 effect of APC is evident.

Thrombin generation analysis in plasma revealed reduced thrombin levels on APC administration in a dose comparable to the dose administered in mice. Remarkably, TF activity and PAI-1 antigen levels in the heart increased on APC administration after a $2 \mathrm{hrs}$ reperfusion time. Given the temporary reduction in IL- 6 levels in the heart, a link between the increased TF and PAI-1 antigen levels 
to an unexpected pro-inflammatory effects of APC, such as described in endothelial cells in vitro ${ }^{27}$ could not be made, leaving it rather difficult to explain this observation.Our gene analysis data do not provide evidence for additional NF-KB mediated effects of APC in this model.

Based on the above data we propose that intervention with APC could indicate a new and important pharmacological tool in the prevention of early myocardial I/R injury. This might ultimately provide an intervention that would reduce heart failure arising from $\mathrm{MI}$.

\section{ACKNOWLEDGEMENTS}

We kindly acknowledge dr. Theo Lindhout (Department of Biochemistry, Maastricht University Medical Center+) for providing the P1Pal12.

This project was funded by the Netherlands Heart Foundation (grant no. 2003B065). 


\section{REFERENCES}

1. Yellon DM, Hausenloy DJ. Myocardial reperfusion injury. $N$ Engl $J$ Med. 2007;357:1121-1135.

2. Esmon CT. The protein C pathway. Chest. 2003;124:26S-32S.

3. Esmon CT. Crosstalk between inflammation and thrombosis. Maturitas. 2004;47:305-314.

4. Bernard GR, Vincent JL, Laterre PF, LaRosa SP, Dhainaut JF, Lopez-Rodriguez A, Steingrub JS, Garber GE, Helterbrand JD, Ely EW, Fisher CJ, Jr. Efficacy and safety of recombinant human activated protein $\mathrm{C}$ for severe sepsis. $N$ Engl J Med. 2001;344:699-709.

5. Shibata M, Kumar SR, Amar A, Fernandez JA, Hofman F, Griffin JH, Zlokovic BV. Antiinflammatory, antithrombotic, and neuroprotective effects of activated protein $\mathrm{C}$ in a murine model of focal ischemic stroke. Circulation. 2001;103:1799-1805.

6. Cheng T, Liu D, Griffin JH, Fernandez JA, Castellino F, Rosen ED, Fukudome K, Zlokovic BV. Activated protein C blocks p53-mediated apoptosis in ischemic human brain endothelium and is neuroprotective Nat Med; 2003.

7. Hirose K, Okajima K, Taoka Y, Uchiba M, Tagami H, Nakano K, Utoh J, Okabe H, Kitamura N. Activated protein $\mathrm{C}$ reduces the ischemia/reperfusion-induced spinal cord injury in rats by inhibiting neutrophil activation. Ann Surg. 2000;232:272-280.

8. Mizutani A, Okajima K, Uchiba M, Noguchi T. Activated protein C reduces ischemia/ reperfusion-induced renal injury in rats by inhibiting leukocyte activation. Blood. 2000;95:3781-3787.

9. Jong WM, Reitsma $\mathrm{PH}$, ten Cate $\mathrm{H}$, de Winter RJ. Modified two-step model for studying the inflammatory response during myocardial ischemia and reperfusion in mice. Comp Med. 2003;53:522-526.

10. Slofstra SH, Bijlsma MF, Groot AP, Reitsma PH, Lindhout T, ten Cate H, Spek CA. Protease-activated receptor-4 inhibition protects from multiorgan failure in a murine model of systemic inflammation. Blood. 2007;110:3176-3182.

11. Spek CA, Verbon A, Aberson H, Pribble JP, McElgunn CJ, Turner T, Axtelle T, Schouten J, Van Der Poll T, Reitsma PH. Treatment with an anti-CD14 monoclonal antibody delays and inhibits lipopolysaccharide-induced gene expression in humans in vivo. J Clin Immunol. 2003;23:132-140.

12. Pawlinski R, Tencati M, Hampton CR, Shishido T, Bullard TA, Casey LM, AndradeGordon P, Kotzsch M, Spring D, Luther T, Abe J, PohIman TH, Verrier ED, Blaxall BC, Mackman N. Protease-activated receptor-1 contributes to cardiac remodeling and hypertrophy. Circulation. 2007;116:2298-2306.

13. Strande JL, Hsu A, Su J, Fu X, Gross GJ, Baker JE. SCH 79797, a selective PAR1 antagonist, limits myocardial ischemia/reperfusion injury in rat hearts. Basic Res Cardiol. 2007;102:350-358.

14. Pirat B, Muderrisoglu H, Unal MT, Ozdemir H, Yildirir A, Yucel M, Turkoglu S. Recombinant human-activated protein $\mathrm{C}$ inhibits cardiomyocyte apoptosis in a rat model of myocardial ischemia-reperfusion. Coron Artery Dis. 2007;18:61-66.

15. Joyce DE, Grinnell BW. Recombinant human activated protein $C$ attenuates the inflammatory response in endothelium and monocytes by modulating nuclear factorkappaB. Crit Care Med. 2002;30:S288-293.

16. Kajstura J, Cheng W, Reiss K, Clark WA, Sonnenblick EH, Krajewski S, Reed JC, Olivetti G, Anversa P. Apoptotic and necrotic myocyte cell deaths are independent contributing variables of infarct size in rats. Lab Invest. 1996;74:86-107. 
17. Maeno E, Ishizaki Y, Kanaseki T, Hazama A, Okada Y. Normotonic cell shrinkage because of disordered volume regulation is an early prerequisite to apoptosis. Proc Natl Acad Sci U S A. 2000;97:9487-9492.

18. Gottlieb RA, Burleson KO, Kloner RA, Babior BM, Engler RL. Reperfusion injury induces apoptosis in rabbit cardiomyocytes. J Clin Invest. 1994;94:1621-1628.

19. Bialik S, Cryns VL, Drincic A, Miyata S, Wollowick AL, Srinivasan A, Kitsis RN. The mitochondrial apoptotic pathway is activated by serum and glucose deprivation in cardiac myocytes. Circ Res. 1999;85:403-414.

20. Black SC, Huang JQ, Rezaiefar P, Radinovic S, Eberhart A, Nicholson DW, Rodger IW. Co-localization of the cysteine protease caspase- 3 with apoptotic myocytes after in vivo myocardial ischemia and reperfusion in the rat. J Mol Cell Cardiol. 1998;30:733-742.

21. Borutaite $\mathrm{V}$, Brown GC. Mitochondria in apoptosis of ischemic heart. FEBS Lett. 2003;541:1-5.

22. Griffin JH, Fernandez JA, Liu D, Cheng T, Guo H, Zlokovic BV. Activated protein C and ischemic stroke. Crit Care Med. 2004;32:S247-253.

23. Slofstra SH, Groot AP, Maris NA, Reitsma PH, Ten Cate H, Spek CA. Inhalation of activated protein $\mathrm{C}$ inhibits endotoxin-induced pulmonary inflammation in mice independent of neutrophil recruitment. Br J Pharmacol. 2006;149:740-746.

24. Daemen MA, van 't Veer C, Denecker G, Heemskerk VH, Wolfs TG, Clauss M, Vandenabeele $\mathrm{P}$, Buurman WA. Inhibition of apoptosis induced by ischemiareperfusion prevents inflammation. J Clin Invest. 1999;104:541-549.

25. Hooper WC, Philips DJ, Renshaw MA, Evatt BL, Benson JM. The up-regulation of IL- 6 and IL-8 in human endothelial cells by activated protein C. J Immunol. 1998;161:2567-2573. 




\section{Chapter}

\section{The anti-coagulants ASIS and APC do not protect against renal $\mathrm{I} / \mathrm{R}$ injury}

STBG Loubele, CA Spek, P Leenders, K Hamulyák, RA Matthijsen, WA Buurman, CJ Peutz-Kootstra, HMH Spronk, $\mathrm{H}$ ten Cate.

The anti-coagulants ASIS or APC do not protect against renal ischemia/ reperfusion injury.

Submitted 


\section{AbSTRACT}

Renal ischemia/reperfusion (I/R) injury is the main cause of acute renal failure (ARF). The severity of the injury is determined by endothelial damage as well as inflammatory and apoptotic processes that require a number of cell signaling mediated pathways. The anti-coagulants active site inhibited factor VIIa (ASIS) and activated protein $C$ (APC) are besides their anti-coagulant function also known for their anti-inflammatory, anti-apoptotic, and endothelial barrier protection properties.

In this study the effect of ASIS and APC was assessed on renal I/R injury and this in relation to inflammation and apoptosis.

Our results showed no effect of ASIS or APC on renal injury as determined by histopathological scoring as well as by BUN and creatinin levels. Furthermore, no effect on fibrin staining was detected but ASIS did reduce tissue factor (TF) activity levels after a 2 hrs reperfusion period. ASIS nor APC administration influenced overall inflammation markers including interleukin (IL)-6, IL-1 $\beta$, tumor necrosis factor (TNF)- $\alpha$, and myeloperoxidase (MPO) but some inflammatory effects of ASIS on IL-1 $\beta$ and TNF- $\alpha$ were detectable after 2 hrs of reperfusion. Finally, neither APC nor ASIS had an influence on cell signaling pathways involved in NF-kB signaling or on the number of apoptotic cells within the kidneys.

We can conclude that the anti-coagulants ASIS and APC do not have protective effects in renal I/R injury in the experimental setup as used in this study which is in contrast to the protective effects of these anti-coagulants in other models of I/R injury. 


\section{INTRODUCTION}

Renal $\mathrm{I} / \mathrm{R}$ injury contributes in a large extent to kidney failure after organ transplantation ${ }^{1}$. The molecular mechanisms involved in the development of renal I/R injury are not yet completely understood but involve the generation of reactive oxygen species and an inflammatory response with the release of cytokines and the expression of adhesion molecules leading to the recruitment of leukocytes ${ }^{2}$. Furthermore, the process of renal I/R leads to cell death either via necrosis due to a loss of ATP, or apoptosis due to cell signaling mechanisms ${ }^{3}$. Whether the process of inflammation is involved in the development of cell death or the other way around still remains a matter of debate $e^{4-6}$.

Anti-coagulants may exert, beside their anti-coagulant function, also cell protective properties. APC is a natural anti-coagulant which in a clinical setting is used in the treatment of severe sepsis (PROWESS trial) ${ }^{7}$. Besides its anti-coagulant properties, APC exerts cytoprotective functions via inhibition of inflammation, prevention of apoptosis, and protection of the endothelial barrier function ${ }^{8}$. Administration of APC has shown to limit organ damage in several animal models including an ischemic stroke model, a lung injury model, and a spinal cord ischemia mode ${ }^{9-12}$. A recent study revealed a protective effect of APC against diabetic nephropathy. In this study, mice over expressing human APC were shown to have less nephropathy in long-term diabetes due to a modulating effect on apoptosis of endothelial cells and podocytes ${ }^{13}$. Furthermore, APC was shown to be protective in a rat renal I/R model ${ }^{13,14}$. The anti-coagulant ASIS is also known for its cytoprotective properties as it reduces myocardial $I / R$ injury via inhibition of inflammation ${ }^{15,16}$.

Hence, we hypothesized that administration of APC or ASIS would protect against renal I/R injury via apoptosis and inflammation regulated mechanisms. In the current study we used a mouse model for renal I/R injury in which either a $1 \mathrm{hr}$ ischemia time followed by $2 \mathrm{hrs}$ of reperfusion, or a 40 minutes ischemia time followed by 2 or 24 hrs of reperfusion was used. In contrast to previous studies $^{14,17-19}$, in our experimental model only one kidney was clamped instead of two, while reperfusion of the clamped kidney was allowed after removal of the contra lateral kidney. This approach is considered to be a good model for the clinical situation of ischemia reperfusion injury in a single transplanted kidney, which is one of the critical conditions related to renal I/R damage 4 .

We investigated the effects of mouse APC and ASIS on early renal I/R injury, particularly related to anticoagulant, anti-inflammatory and anti-apoptotic mechanisms and this in relation to cellular signaling. 


\section{Materials AND MethodS}

Experimental procedure. All animal experiments were approved by the Animal Ethics Committee of the Maastricht University. Male C57Black/6 mice of 8 weeks old and around $25 \mathrm{~g}$ were purchased from Charles River Laboratories (Sulzfeld, Germany) and were housed under normal conditions: temperature was kept constant at $20-24{ }^{\circ} \mathrm{C}$ and food and water were provided ad libitum. Mice were anesthetized with isoflurane (induced with 3-4 \% and maintained with 1.5-2.5\%) and were ventilated (frequency: $210 / \mathrm{min}$, volume: $250 \mu \mathrm{l}$ ). 30 min before the procedure, buprenorphine (Temgesic, $0.1 \mathrm{mg} / \mathrm{kg}$ ) was given subcutaneously. Body temperature was assessed using a rectal probe and was kept constant at $37^{\circ} \mathrm{C}$. Ischemia was induced by placing a clamp to the left renal pedicle either for 40 minutes or for $1 \mathrm{hr}$. After removal of the clamp, the collateral kidney was removed. The animals were sacrificed after $2 \mathrm{hrs}$ (for the 40 minutes and the $1 \mathrm{hr}$ ischemia period) of after $24 \mathrm{hrs}$ (only for the 40 minutes ischemia period). Animals undergoing a $1 \mathrm{hr}$ ischemia period did not survive a $24 \mathrm{hrs}$ reperfusion period; hence this group was not included in the study.

Intervention. Mouse APC (0.4 mg/kg), human ASIS $(10 \mathrm{mg} / \mathrm{kg})$, or placebo $(0.9 \% \mathrm{NaCl})$ was administered 2 minutes before induction of reperfusion and 15 minutes after induction of reperfusion. In an additional experiment mouse APC was administered in a $0.4 \mathrm{mg} / \mathrm{kg}$ or a $1 \mathrm{mg} / \mathrm{kg}$ dose, 5 minutes after the beginning of ischemia and 5 minutes after the induction of reperfusion. The rationale for the chosen doses is for APC based on a study by Cheng et al. ${ }^{20}$ and for ASIS the optimal dose was estimated based on a dose finding study suggesting reduced histological damage after the selected ASIS dose (data not shown). Furthermore, the systemic anti-coagulant activity was assessed by means of a thrombin generation assay in which the doses used revealed reduced thrombin levels when added to mouse plasma (data not shown).

Plasma and tissue collection. A detailed protocol is provided in addendum 2.

Renal function. In mice that underwent $24 \mathrm{hrs}$ of reperfusion blood urea nitrogen (BUN) and creatinine levels were determined in plasma with a Beckman/Coulter Synchron LX-20.

Renal histology. To determine renal injury, paraffin sections (5 $\mu \mathrm{m}$ ) were stained with PAS-D. A 5-point scale scoring system was used to determine a 
histopathological score as described by Leemans et al. ${ }^{21} .10$ fields within one section were scored for tubular dilatation, necrosis, cast deposition, and brush border loss using a $20 x$ magnification.

TF activity. A detailed protocol is provided in addendum 4.

Plasminogen activator inhibitor (PAI)-1 antigen. Total PAI-1 antigen levels were determined in tissue homogenates $(1 \mathrm{mg} / \mathrm{ml}$ protein content) according to the manufacturer's instructions (Innovative Research, MI, US).

Microwave PTAH (Phosphotungstic Acid Hematoxylin) staining. Tissues were stained for fibrin using the PTAH staining kit (American Master Tech Scientific Inc, CA, US). All experiments were performed according to the manufacturer's instructions. Tissues were scored using a 3 point scoring system; 1: mild fibrin deposition in $<20 \%$ of the cortex; 2 : moderate fibrin deposition in $20-50 \%$ of the cortex; 3 : high amount of fibrin deposition in $>50 \%$ of the cortex.

IL-6, TNF- $\alpha$ and IL-16 antigen. IL-6, TNF- $\alpha$ and IL-1 $\beta$ antigen levels were determined in tissue homogenates containing $1 \mathrm{mg} / \mathrm{ml}$ protein using an ELISA reagent set. All analyses were performed according to the manufacturer's manual (eBioscience, CA, US).

MPO. Mouse MPO was determined in tissue homogenates containing $1 \mathrm{mg} / \mathrm{ml}$ protein using an ELISA kit. All analyses were performed according to the manufacturer's manual (Hycult biotechnology b.v., Uden, The Netherlands).

Multiplex Ligation dependent Probe Amplification (MLPA). Coagulation, inflammation, cell signaling, and apoptosis related gene expression levels were determined in isolated RNA of the mouse kidneys ( $n=6$ per group). $50 \mathrm{ng} / \mu \mathrm{l}$ RNA was analyzed according to the method described previously ${ }^{22}$. Several genes involved in cellular signaling, inflammation and coagulation were analyzed (cell signaling: CD14, toll-like receptor (TLR)-2, TLR-4, IL-1 receptorassociated kinase (IRAK)-1, IRAK-3, IKB $\alpha$, and protease activated receptor-1 (PAR-1); coagulation: TF, tissue factor pathway inhibitor (TFPI), PAI-1, urokinasetype plasminogen activator receptor (UPAR), tissue-type plasminogen activator receptor (t-PA), and protein C receptor; inflammation: IL-6, IL-4, IL-10, IL-1 $\beta$, tumor necrosis factor (TNF)- $\alpha$, interferon (IFN)- - , hypoxia-inducible factor (HIF)-1 $\alpha$, ICAM-1, macrophage inflammatory protein (MIP)-1 $\alpha, \mathrm{CxCl} 1, \mathrm{CCl} 3$, and eNOS. Only the genes that showed detectable expression levels are depicted in the results. 
Apoptosis. Mouse heart paraffin sections were stained for apoptosis using the ApopTag Plus Peroxidase In Situ Apoptosis Detection Kit and the In Situ Cell Death Detection Kit TMR red. Sections were stained according the manufacturer's manual (Chemicon, Billerica, USA and Roch Diagnostics, Indianapolis, USA). Analyses of all sections were done blinded for treatment allocation (APC, placebo, or sham). The amount of apoptosis was estimated by counting the number of cells in 3 fields within the infarcted area using a 40x magnification. Data are represented as the number of positive cells per surface area.

Statistical analyses. Data analysis was performed with Prism for Windows, version 5.00 (GraphPad Software Inc., San Diego, California, USA). Values are means \pm SEM. Differences between groups were tested using a Mann-Whitney $\mathrm{U}$ test and $\mathrm{P}$ values $<0.05$ were considered statistically significant. 


\section{RESULTS}

Renal function. The effect of APC and ASIS on renal function was assessed measuring BUN and creatinine levels in plasma after a $24 \mathrm{hrs}$ reperfusion period. Renal function neither improved upon APC, nor upon ASIS administration, as both BUN (Figure 1A) and creatinine (Figure 1B) levels remained equal after APC $(50.4 \pm 1.6 \mathrm{mmol} / \mathrm{L}$ and $186.4 \pm 4.1 \mu \mathrm{mol} / \mathrm{L}$, respectively) or ASIS administration 2 min before induction of reperfusion and $15 \mathrm{~min}$ after induction of reperfusion $(53.1 \pm 1.5 \mathrm{mmol} / \mathrm{L}$ and $193.5 \pm 4.6 \mu \mathrm{mol} /$ L) compared to placebo administration $(54.0 \pm 1.3 \mathrm{mmol} / \mathrm{L}$ and $194.6 \pm 3.5$ $\mu \mathrm{mol} / \mathrm{L}$, respectively). In addition, APC was administered at the beginning of the ischemic period and at the beginning of the reperfusion period in both a 0.4 $\mathrm{mg} / \mathrm{kg}$ and a $1 \mathrm{mg} / \mathrm{kg}$ dose. BUN (Figure 1C), as well as creatinine (Figure 1D) levels were not influenced after the administration of APC early in the ischemia period and with a varying dose.
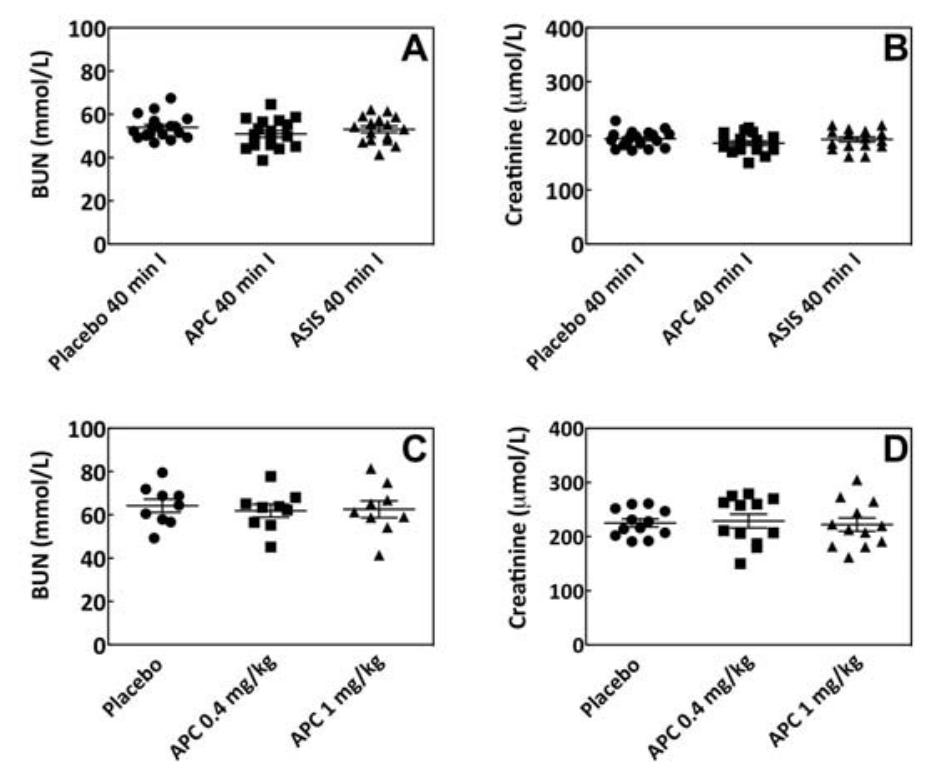

Figure 1: Panel A: BUN levels and Panel B: creatinine levels did not differ upon APC nor upon ASIS administration 2 min before induction of reperfusion and 15 min after induction of reperfusion compared to placebo after 40 minutes of ischemia followed by $24 \mathrm{hrs}$ of reperfusion. Administration of APC in a higher dose and at an earlier time point in the ischemia phase did not reveal changes in Panel C: BUN or Panel D: creatinin levels compared to placebo. Values are mean \pm SEM, $\mathrm{n}=18$ per group. 
Renal histology. Paraffin sections were scored for tubular dilatation, cast deposition, brush border loss, and necrosis after which an average histopathological score was obtained for a total of 10 mice per group. A representative picture is given in Figure 2A. APC administration did not improve the score after $1 \mathrm{hr}$ of ischemia and $2 \mathrm{hrs}$ of reperfusion compared to placebo administration (Figure 2B). Administration of ASIS revealed a decreased histopathological score compared to the placebo animals but the results were not significantly different. Renal injury increased after $24 \mathrm{hrs}$ of reperfusion compared to $2 \mathrm{hrs}$ of reperfusion after a 40 minutes ischemia period. Administration of APC or ASIS did however not decrease renal injury as the histopathological score of both placebo and APC or ASIS treated animals remained equal after 2 as well as $24 \mathrm{hrs}$ of reperfusion (Figure 2C). Administration of APC in a higher dose and at a different time point during ischemia also revealed no effect on the histopathological score (Figure 2D).
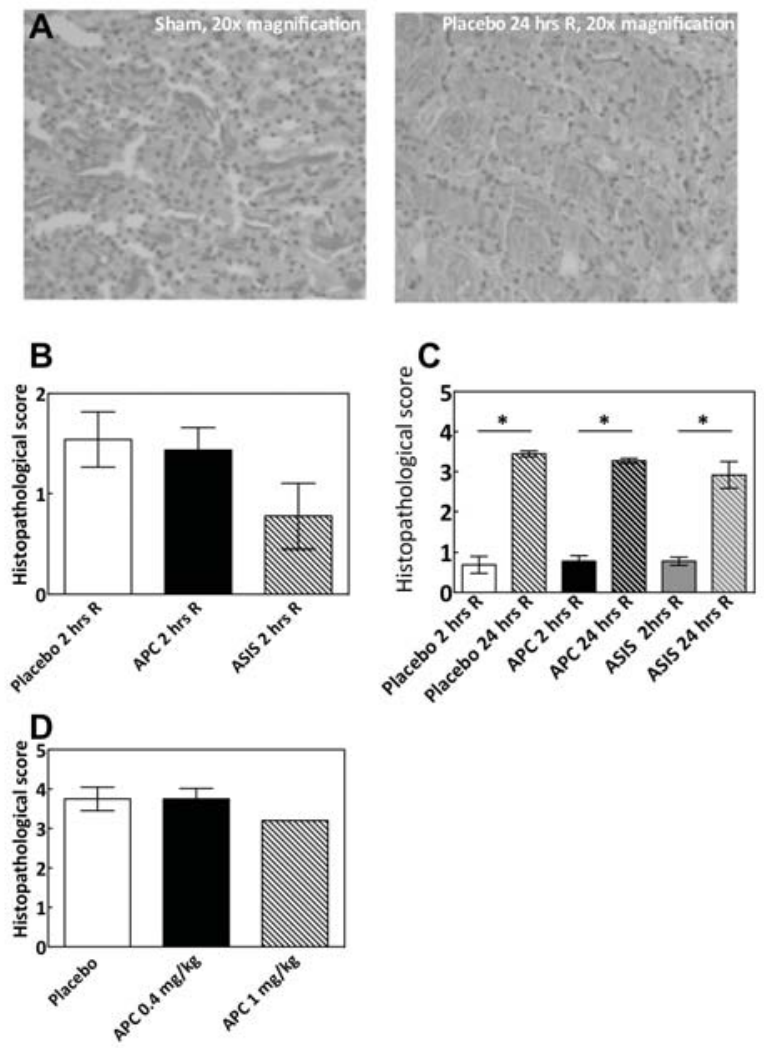

Figure 2: P a n e 1 A : Representative picture of a PAS stained sham kidney (left) and placebo $24 \mathrm{hrs} \mathrm{R}$ treatment (right) revealed increased injury upon renal $\mathrm{I} / \mathrm{R}$. Panel $\mathrm{B}$ : Histopathological scoring did not reveal an influence of APC on renal injury after $1 \mathrm{hr}$ of I followed by $2 \mathrm{hrs}$ of $\mathrm{R}$ but revealed a trend towards a decreased score upon ASIS administration compared to placebo. Panel C: APC nor ASIS administration influenced the histopathological score after $40 \mathrm{~min}$ of I followed by 2 or 24 hrs of R. Panel D: Administration of APC in a higher dose and at a different time point in the ischemia phase also showed no effect on the histopathological score compared to placebo. Values are mean \pm SEM, $n=10,{ }^{*} p<0,05$.

See addendum for color figure. 
Coagulation parameters. Kidney TF activity levels were increased after 40 min of ischemia and $24 \mathrm{hrs}$ of reperfusion compared to sham animals and animals with a 2 hrs reperfusion period. No differences could be detected upon APC administration compared to placebo after varying ischemia and reperfusion times (Figure 3A). Administration of ASIS did however, decrease TF activity levels after a $2 \mathrm{hrs}$ reperfusion period both for a $40 \mathrm{~min}$ as well as a $1 \mathrm{hr}$ ischemia period. No differences in TF activity were visible after a $24 \mathrm{hrs}$ reperfusion period. PAl-antigen levels were assessed after $1 \mathrm{hr}$ of ischemia and $2 \mathrm{hrs}$ of reperfusion and revealed increased PAI-1 levels upon I/R compared to sham animals. Administration of APC or ASIS did however not influence PAI-1 antigen levels (Figure $3 \mathrm{~B}$ ). Tissue scoring for fibrin deposition revealed an increase in fibrin deposition after $24 \mathrm{hrs}$ of ischemia compared to $2 \mathrm{hrs}$ of reperfusion. Administration of neither APC nor ASIS influenced fibrin deposition in the cortex of the kidneys (Figure $3 \mathrm{C}$ ).
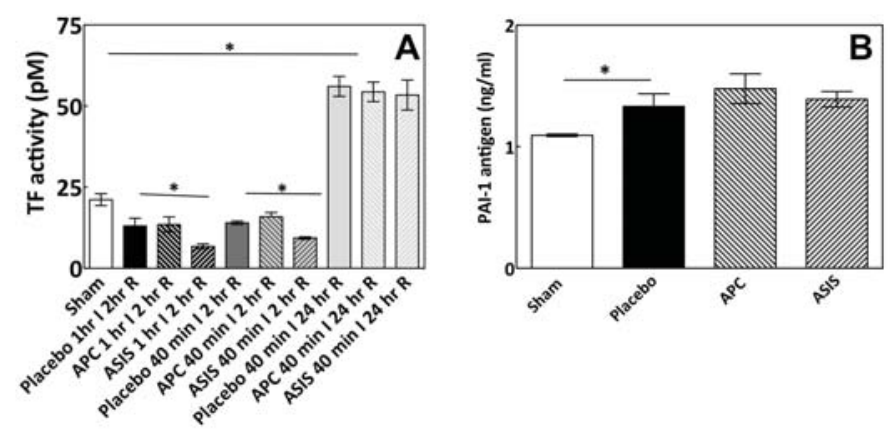

Figure 3: Panel A: TF activity levels decreased after ASIS administration but were not influenced upon APC administration. Panel B: PAI-1 antigen levels in kidney tissue homogenates remained equal upon APC or ASIS administration compared to placebo. Panel C: Fibrin deposition increased after $24 \mathrm{hrs}$ of reperfusion but was not influenced upon APC or ASIS administration. Values are mean \pm $\mathrm{SEM}, \mathrm{n}=10,{ }^{*} \mathrm{p}<0,05$. 
Inflammation markers. IL-6, IL-1 $\beta$, and TNF- $\alpha$ levels were determined in tissue homogenates of the left kidneys. IL- 6 levels increased upon I/R after both a $1 \mathrm{hr}$ reperfusion as well as a 40 min reperfusion time. APC nor ASIS administration revealed an anti-inflammatory effect in the ischemic kidneys and even increased IL- 6 levels after both a $1 \mathrm{hr}$ and a $40 \mathrm{~min}$ ischemic period followed by a $2 \mathrm{hrs}$ reperfusion time (Figure $4 \mathrm{~A}$ ). I/R increased IL-1 $\beta$ levels compared to sham animals for both the $1 \mathrm{hr}$ and the $40 \mathrm{~min}$ ischemia period. APC administration did not influence IL-1 $\beta$ levels for neither of the varying I/R times. Administration of ASIS did however decrease IL-1 $\beta$ after a $1 \mathrm{hr}$ ischemia and a 2 hrs reperfusion period compared to placebo (Figure 4B). TNF- $\alpha$ levels increased upon I/R compared to the sham group. TNF- $\alpha$ levels were not decreased upon APC administration after $2 \mathrm{hrs}$ or reperfusion with both a $1 \mathrm{hr}$ and a $40 \mathrm{~min}$ ischemic time. APC did however decrease TNF- $\alpha$ levels after a $40 \mathrm{~min}$ ischemic period followed by a $24 \mathrm{hrs}$ reperfusion phase. Administration of ASIS on the other hand decreased TNF- $\alpha$ levels after a $1 \mathrm{hr}$ ischemia and a $2 \mathrm{hrs}$ reperfusion period but increased TNF- $\alpha$ levels after a $40 \mathrm{~min}$ ischemia and $2 \mathrm{hrs}$ reperfusion period compared to placebo (Figure 4C). MPO levels increased upon I/R compared to sham animals. No down-regulating effect of APC or ASIS administration could be detected, and administration of both APC or ASIS even increased MPO levels after a $1 \mathrm{hr}$ ischemia and $2 \mathrm{hrs}$ reperfusion period compared to placebo administration (Figure 4D).

MLPA analysis cell signaling, coagulation and inflammation. Analysis of cell signaling related genes involved in the NF-KB pathway did not reveal an effect of APC or ASIS on this pathway as TLR-4, IRAK-1, and IKB $\alpha$ levels remained equal after APC or ASIS treatment compared to placebo administration (Figure 5A, 5B, and $5 \mathrm{C}$ ). PAR-1 expression levels increased after a $24 \mathrm{hrs}$ reperfusion period compared to a $2 \mathrm{hrs}$ reperfusion period and to non-ischemic kidneys (Figure 5D). However, no effect of APC or ASIS administration was detected on PAR-1 RNA expression levels. TF RNA expression levels were increased upon I/R compared to the sham animals showing the highest TF RNA levels after $24 \mathrm{hrs}$ of reperfusion (Figure 6A). Administration of APC showed a trend towards decreased TF RNA levels, but the results were only significant after a $40 \mathrm{~min}$ ischemia and a $2 \mathrm{hrs}$ reperfusion period. TF RNA levels were decreased after a $40 \mathrm{~min}$ ischemia and a $2 \mathrm{hr}$ reperfusion period upon ASIS administration. PAI-1 RNA expression levels also increased upon I/R compared to the sham group and revealed increasing levels of PAI-1 after 24 hrs of reperfusion (Figure 6B). 

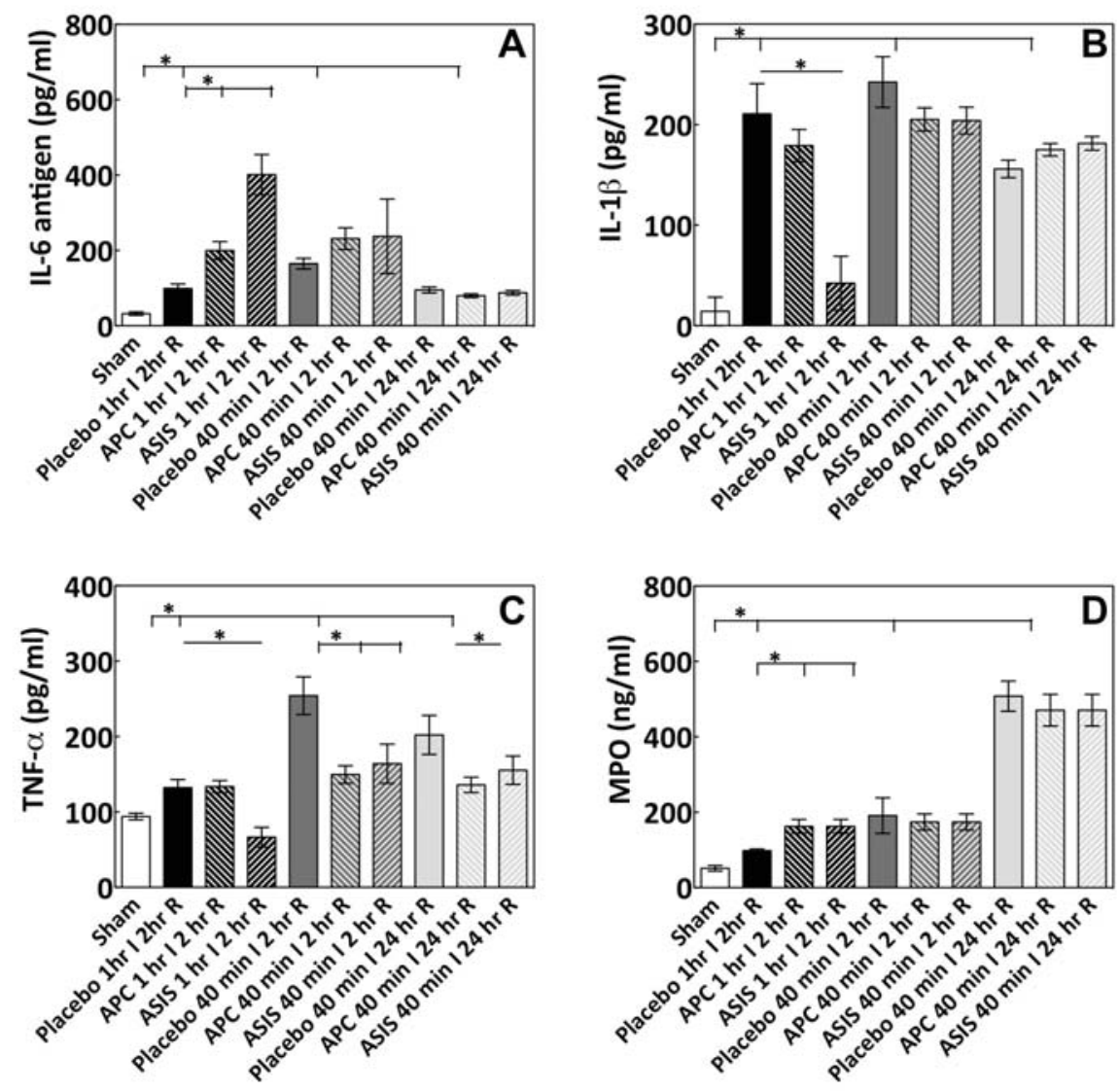

Figure 4: APC did not have an anti-inflammatory effect on ischemic kidneys as Panel A: IL-6, Panel B: IL-1 $\beta$, Panel C: TNF- $\alpha$, and Panel D: MPO levels did not decrease upon APC administration. Values are mean $\pm \mathrm{SEM}, \mathrm{n}=6,{ }^{*} \mathrm{p}<0,05$.

Neither APC nor ASIS administration did, however, influence PAI-1 expression levels. Inflammation markers IL-6 (Figure 6C) and IL-1 $\beta$ (Figure 6D) showed increased mRNA expression levels after I/R compared to sham animals. APC or ASIS administration showed no anti-inflammatory effect as APC as well as ASIS administration even increased IL- 6 and IL-1 $\beta$ levels compared to placebo administration after a $40 \mathrm{~min}$ ischemia period followed by $2 \mathrm{hrs}$ of reperfusion. A similar trend was observed after a $1 \mathrm{hr}$ ischemia and $2 \mathrm{hrs}$ reperfusion period. A small decrease in IL- 6 and IL- $1 \beta$ levels was observed after a 40 min ischemia and a 24 hrs reperfusion time but the results were not significant. 
TLR-4

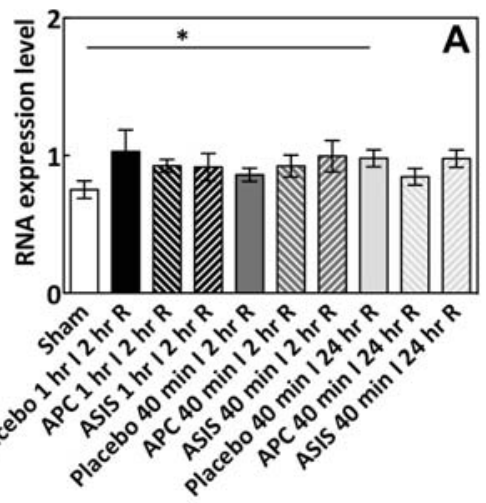

$\mathrm{I \kappa} B \alpha$

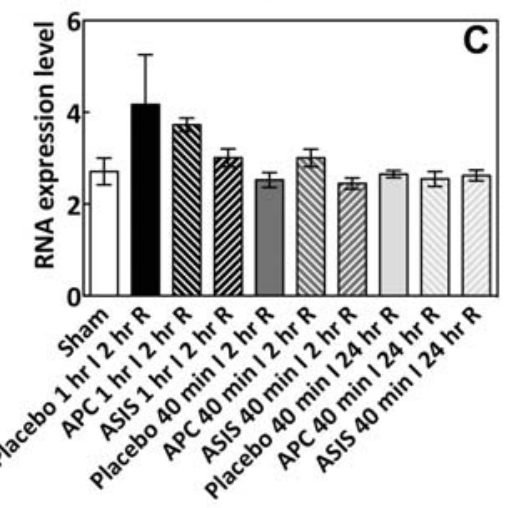

IRAK-1

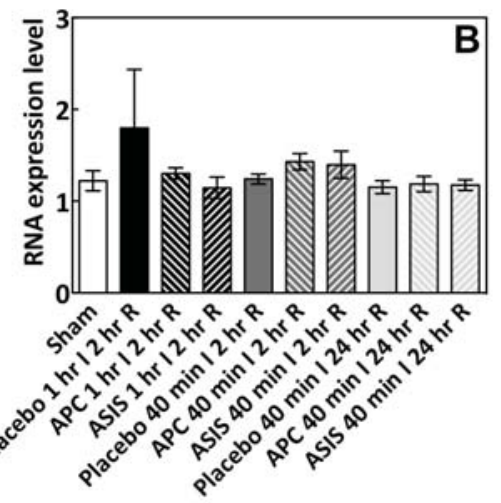

PAR-1

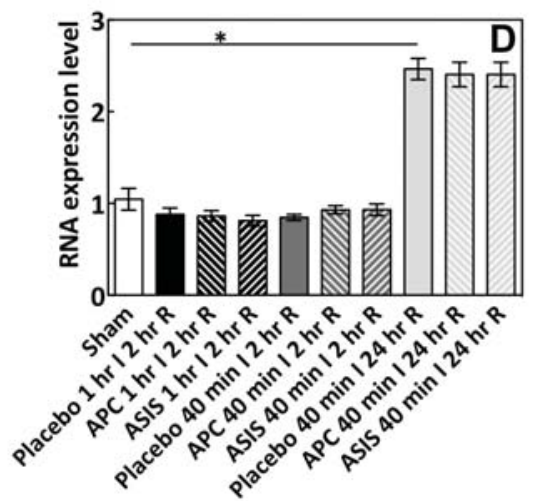

Figure 5: RNA expression levels of Panel A: TLR-4, Panel B: IRAK-1, Panel C: I $\kappa \mathrm{B} \alpha$, and Panel D: PAR-1 were not influenced upon APC or ASIS administration compared to placebo. Values are mean \pm SEM, $n=6,{ }^{*}<<0,05$.

Apoptosis. Kidney paraffin sections were stained for apoptosis. A representative picture is given in Figure 7A. Scoring of the sections by counting apoptotic cells per surface area did not reveal any statistically significant effects of ASIS or APC administration compared to placebo. Furthermore, no differences in apoptosis levels were detectable between a $2 \mathrm{hrs}$ and a $24 \mathrm{hrs}$ reperfusion period (Figure 7B). 
TF

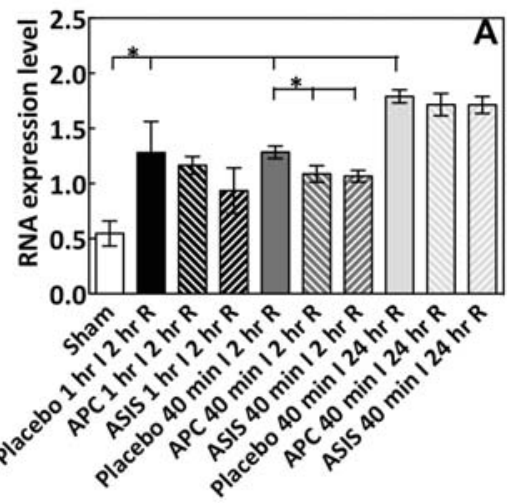

IL-6

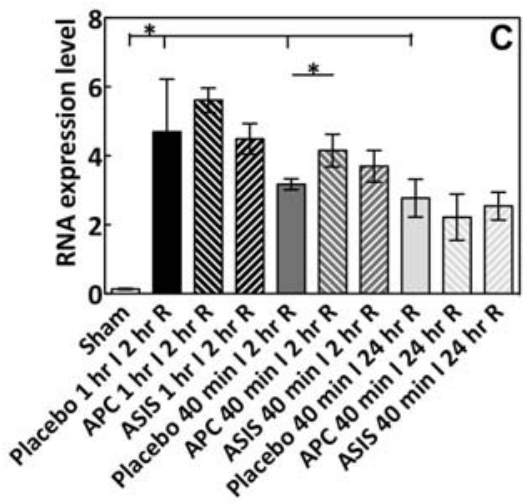

PAI-1

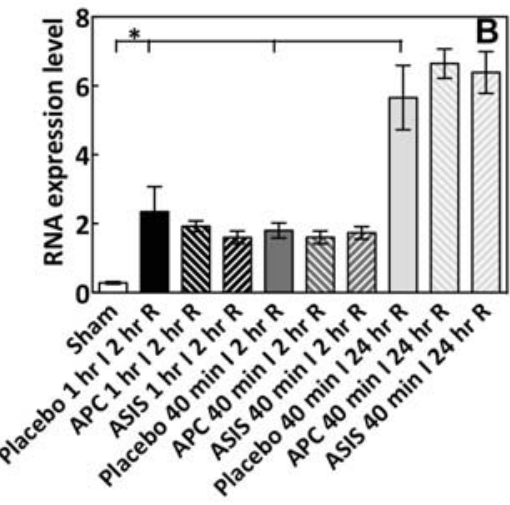

IL-1 $\beta$

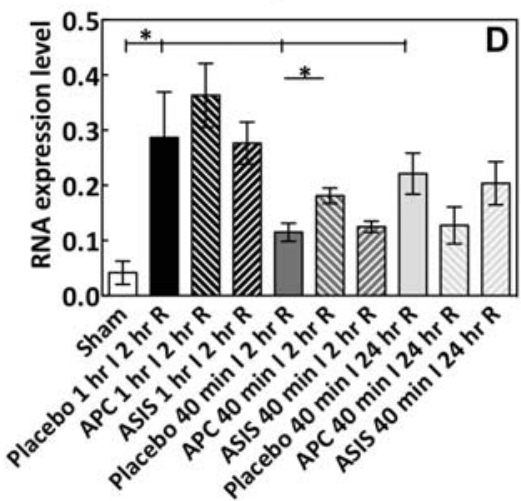

Figure 6: RNA expression levels of Panel A: TF and Panel B: PAI-1 increased upon I/R and TF activity levels were decreased upon APC as well as ASIS administration. Panel C: IL-6 and Panel D: IL-1 $\beta$ levels increased upon I/R but did not reveal an anti-inflammatory effect of APC. Values are mean \pm SEM, $n=6$, $* \mathrm{p}<0,05$. 

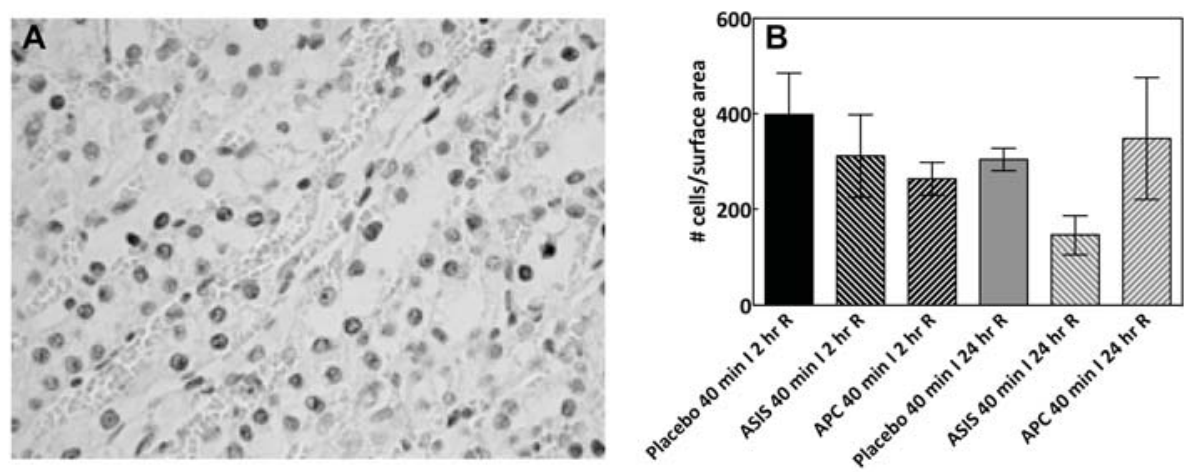

Figure 7: Panel A: Representative picture of paraffin section stained for apoptosis. Apoptotic cells are shown in brown, the cell nuclei are depicted in green. 40x magnification. Panel B: Slides were scored for the number of positive cells within 3 fields of the infarcted area using a 40x magnification. No difference in the number of apoptotic cells was observed upon ASIS or APC administration. $\mathrm{n}=4, * \mathrm{p}<0.05$. See addendum for color figure. 


\section{DISCUSSION}

In this study we aimed to address the protective mechanisms of the anticoagulants APC and ASIS in a model of renal I/R injury, based on previously studied protective effects of such interventions in renal $I / R$ injury but also in myocardial I/R and stroke.

Renal injury was evident in our model, as assessed by histopathological scoring for tubular dilatation, brush border loss, necrosis, and cast deposition showing increased renal injury after a prolonged reperfusion time of $24 \mathrm{hrs}$ compared to $2 \mathrm{hrs}$. This tubular injury is probably maximal after $24 \mathrm{hrs}$ of reperfusion as previous studies have shown a recovery of tubular injury after a few days of reperfusion compared to 1 day of reperfusion ${ }^{21,23}$.

In spite of the clearly evident renal injury, our study did not reveal any protective effects of APC or ASIS on renal I/R injury as indicated by BUN and creatinine levels, as well as histopathological scoring. Moreover, administration of APC at a different time point during ischemia or at an increased dose did not result in any measurable protective effects.

Renal I/R injury is of great importance in renal transplantation surgery and is an important cause of ARF. Activation of the coagulation cascade is associated with this disease process as fibrin deposition in the microvasculature and tubuli of ischemic kidneys is observed ${ }^{24,25}$. Activation of coagulation can via PARs in turn induce inflammatory pathways contributing to cell death. PAR-1, which is expressed in the kidney, can be activated by several coagulation proteases including FVIla, FXa, and most importantly thrombin and APC ${ }^{26,27}$. Several anticoagulants have been studied in injury models for their cytoprotective properties in addition to their anti-coagulant functions ${ }^{12-15}$ and a few of those were also investigated in kidney $\mathrm{I} / \mathrm{R}$ models. The anti-coagulant fondaparinux, as well as a non-anticoagulant synthetic pentasaccharide were protective against renal $\mathrm{I} / \mathrm{R}$ injury as shown by an increased survival rate, reduced creatinine levels after 48 hrs of reperfusion, reduced cytokine levels, and decreased neutrophil accumulation compared to placebo administration ${ }^{17,28}$. A rat kidney I/R model revealed a protective role for APC (100 ug/ $/ \mathrm{kg})$ as BUN, creatinine, TNF- $\alpha$, IL- 6 , and MPO levels were decreased upon APC administration 30 minutes prior to ischemia, compared to placebo and this was most likely regulated via an inhibition of leukocyte activation ${ }^{14}$. Furthermore, administration of antithrombin reduced $\mathrm{I} / \mathrm{R}$ induced renal injury in rats ${ }^{18}$. Also, 
low TF mice ( $1 \%$ human TF), as well as PAR-1 deficient mice were protected against renal $\mathrm{I} / \mathrm{R}$ injury as demonstrated by reduced mortality rates, tubular injury, and neutrophil infiltration compared to WT mice ${ }^{25}$. Thrombin inhibition via melagatran administration on the other hand did not protect against renal I/ $R$ injury as shown via determination of the glomerular filtration rate (GFR) and histological scoring of injury ${ }^{19}$. In a clinical setting, the presence of increased plasma levels of APC were associated with reduced neutrophil activation markers, a process which can be protective in renal transplantation surgery ${ }^{29}$.

Based on published data, as well as our own studies, showing an effective reduction of $I / R$ injury in the heart, associated with similar dose regimens of ASIS ${ }^{16}$ and APC (Loubele, chapter 2) we expected to find at least an indication of a protective effect in the renal I/R experiments. Surprisingly, our model did not reveal a protective role for the anti-coagulants APC and ASIS after a 2 or a 24 hrs reperfusion period.

Besides the general indices of renal function we studied several mechanisms that may be related to cell injury upon I/R. Although the anti-coagulant effects of ASIS and APC were shown in vitro (data not shown), net procoagulant activity was not attenuated by the interventions with APC and ASIS, as fibrin deposition was clearly increased after 24 hrs of reperfusion, but unaltered by ASIS or of APC administration. Furthermore, coagulation parameters including renal TF activity and mRNA levels were increased after $24 \mathrm{hrs}$ of reperfusion compared to $2 \mathrm{hrs}$. Administration of ASIS inhibited TF activity in the kidney, but TF levels remained equal upon APC administration. The lack of any protective effect of APC or ASIS on a long term reperfusion period could in part be related to a lack of attenuating effect on tissue TF concentrations, taking into account that Sevastos et al. showed that TF deficient mice were protected from renal failure and death ${ }^{25}$.

Inflammation markers IL-6, IL-1 $\beta$, TNF- $\alpha$, and MPO protein levels as well as IL-6 and IL-1 $\beta$ mRNA levels were up-regulated upon I/R injury. A number of antiinflammatory effects of ASIS and APC were observed, indicated by decreased IL-1 $\beta$ and TNF- $\alpha$ levels but this did not result in an improved outcome. In contrast, IL-6 and MPO levels were even increased upon ASIS and APC administration using a $1 \mathrm{hr}$ ischemia period. Furthermore, increased MPO levels were detected after $24 \mathrm{hrs}$ of reperfusion compared to $2 \mathrm{hrs}$. A lack of decrease in IL-6 levels by ASIS or APC can contribute to a lack in protective effects as mice 
deficient in IL-6 showed reduced renal injury as determined by creatinin levels and histological scoring in a study for ischemic renal failure ${ }^{30}$. Furthermore, MPO is shown to be a critical factor in determining renal ischemic injury as $\mathrm{MPO}^{-/}$mice had less renal function loss upon ischemia ${ }^{31}$. Therefore we postulate that the lack of protection by APC and ASIS is in part related to the absence of any clear anti-inflammatory effect. It should be noted that also in vitro, several pro-inflammatory effects of APC have been noted ${ }^{32}$ and it seems likely that many additional factors beyond those currently studied, modulate the net responses to APC and ASIS in vivo, including doses, timing and experimental model used. In this regard it is of importance to keep in mind that in the clinical setting, APC is only protective in patients with advanced sepsis and not in less diseased persons where it may even be detrimental ${ }^{7}$. For ASIS or anti-TF treatment, clinical studies in sepsis and other conditions remain equivocal.

To explain the results found in this study, several differences among the experimental models used in previous studies should be taken into account. An overview of the different mouse or rat models of $I / R$ injury in which anticoagulants are used as an intervention is given in Table 1.

\begin{tabular}{|c|c|c|c|c|}
\hline Study & Renal Clamping & I/R time & Intervention & Outcome \\
\hline $\begin{array}{l}\text { Loubele et al. } \\
\text { (this study) }\end{array}$ & $\begin{array}{l}\text { Clamping left kidney, } \\
\text { right nephrectomy after }\end{array}$ & $\begin{array}{l}40 \text { or } 60 \min I \\
12 \text { or } 24 \mathrm{hrs} \mathrm{R}\end{array}$ & $\begin{array}{l}\text { Human ASIS or mouse } \\
\text { APC } \\
\text { I.v. just prior to } \\
\text { declamping and } 5 \text { min } \\
\text { after declamping }\end{array}$ & No effect \\
\hline Frank et al. ${ }^{24}$ & $\begin{array}{l}\text { Clamping left and right } \\
\text { kidney }\end{array}$ & $\begin{array}{l}20,25, \text { or } 30 \mathrm{~min} \mathrm{I} \\
24 \text { or } 48 \text { hrs } \mathrm{R}\end{array}$ & $\begin{array}{l}\text { Fondaparinux } \\
\text { I.p. just prior to } \\
\text { declamping and } 5 \mathrm{~min} \\
\text { after declamping }\end{array}$ & Effect after 48 hrs R \\
\hline Mizutani et al. ${ }^{11}$ & $\begin{array}{l}\text { Left nephrectomy before } \\
\text { I Clamping right kidney }\end{array}$ & $\begin{array}{l}60 \mathrm{~min} I \\
3,6,12 \text {, or } 24 \mathrm{hrs} \mathrm{R}\end{array}$ & $\begin{array}{l}\text { Human APC } \\
\text { I.v. } 30 \text { min before } \\
\text { declamping }\end{array}$ & Protective effect \\
\hline Mizutani et $a .^{26}$ & $\begin{array}{l}\text { Left nephrectomy before } \\
\text { I Clamping right kidney }\end{array}$ & $\begin{array}{l}45 \min \mathrm{I} \\
3,6,12,24 \text {, or } 48 \mathrm{hrs} \mathrm{R}\end{array}$ & $\begin{array}{l}\text { Antithrombin } \\
\text { I.v. } 30 \text { min before } \\
\text { declamping }\end{array}$ & Protective effect \\
\hline Nitescu et al..$^{27}$ & $\begin{array}{l}\text { Clamping left and right } \\
\text { kidney }\end{array}$ & $\begin{array}{l}35 \mathrm{~min} \mathrm{I} \\
24 \mathrm{hrs} \mathrm{R}\end{array}$ & $\begin{array}{l}\text { Melagatran } \\
\text { Continuous injection }\end{array}$ & No effect \\
\hline
\end{tabular}

Table 1:

Overview of distinct studies on renal $\mathrm{I} / \mathrm{R}$ injury with anti-coagulant intervention. 
One important factor may be that our study is the only one in which one kidney was clamped and where, after the ischemia phase, the contralateral kidney was removed. We chose this model because it better represents the clinical situation in which a transplanted kidney in a functionally anephric individual, is failing due to I/R injury. Furthermore, this model was used in several studies showing beneficial outcomes ${ }^{31,33,34}$. When a kidney sparing effect of the interventions remained absent, we infused a higher dose of APC at a different time point earlier in the ischemia phase. Again, however, no beneficial effect on renal I/R injury was observed.

The study by Frank et al. also did not reveal an effect of fondaparinux until after $48 \mathrm{hrs}$ of reperfusion ${ }^{28}$ but a reperfusion time longer than $24 \mathrm{hrs}$ was not used in our study due to decreasing survival rates that were observed in the presented study when the reperfusion time was prolonged.

In conclusion, we did not reveal an effect of the anti-coagulants APC or ASIS on renal I/R injury. These results are not in accordance with data from previous studies, showing a protective effect of APC, or functional TF deficiency, on renal $I / R$ injury ${ }^{14,25}$. In the absence of major differences in doses used and timing of administration we assume that differences between the models used (clamping one or two kidneys, or the removal of one kidney before the collateral kidney was clamped) are major confounders of the effects of the anticoagulant proteins. The results of this study suggest that more research is needed to determine whether the use of specific anti-coagulants potentially be of clinical benefit in the protection against renal I/R injury.

\section{ACKNOWLEDGMENTS}

We kindly acknowledge Dr. CT Esmon (Howard Hughes Medical Institute, Oklahoma City, Oklahoma, USA) and Dr. LC Petersen (Novo Nordisk A/S, Måløv and Bagsværd, Denmark) for providing us with mouse APC and human ASIS.

This project was funded by the Netherlands Heart Foundation (grant no. 2003B065). 


\section{REFERENCES}

1. Thadhani R, Pascual $\mathrm{M}$, Bonventre JV. Acute renal failure. $N$ Engl J Med. 1996;334:1448-1460.

2. Thurman JM. Triggers of inflammation after renal ischemia/reperfusion. Clin Immunol. 2007;123:7-13.

3. Dagher PC. Apoptosis in ischemic renal injury: roles of GTP depletion and p53. Kidney Int. 2004;66:506-509.

4. Daemen MA, de Vries B, Buurman WA. Apoptosis and inflammation in renal reperfusion injury. Transplantation. 2002;73:1693-1700.

5. Daemen MA, de Vries B, van't Veer C, Wolfs TG, Buurman WA. Apoptosis and chemokine induction after renal ischemia-reperfusion. Transplantation. 2001;71:1007-1011.

6. Daemen MA, Denecker G, van't Veer C, Wolfs TG, Vandenabeele P, Buurman WA. Activated caspase-1 is not a central mediator of inflammation in the course of ischemia-reperfusion. Transplantation. 2001;71:778-784.

7. Bernard GR, Vincent JL, Laterre PF, LaRosa SP, Dhainaut JF, Lopez-Rodriguez A, Steingrub JS, Garber GE, Helterbrand JD, Ely EW, Fisher CJ, Jr. Efficacy and safety of recombinant human activated protein $\mathrm{C}$ for severe sepsis. $N$ Engl J Med. 2001;344:699-709.

8. Mosnier LO, Zlokovic BV, Griffin JH. The cytoprotective protein C pathway. Blood. 2007;109:3161-3172.

9. Shibata M, Kumar SR, Amar A, Fernandez JA, Hofman F, Griffin JH, Zlokovic BV. Antiinflammatory, antithrombotic, and neuroprotective effects of activated protein $\mathrm{C}$ in a murine model of focal ischemic stroke. Circulation. 2001;103:1799-1805.

10. Zlokovic BV, Zhang C, Liu D, Fernandez J, Griffin JH, Chopp M. Functional recovery after embolic stroke in rodents by activated protein C. Ann Neurol. 2005;58:474-477.

11. Slofstra SH, Groot AP, Maris NA, Reitsma PH, Cate HT, Spek CA. Inhalation of activated protein $C$ inhibits endotoxin-induced pulmonary inflammation in mice independent of neutrophil recruitment. Br J Pharmacol. 2006;149:740-746.

12. Hirose K, Okajima K, Taoka Y, Uchiba M, Tagami H, Nakano K, Utoh J, Okabe H, Kitamura N. Activated protein $\mathrm{C}$ reduces the ischemia/reperfusion-induced spinal cord injury in rats by inhibiting neutrophil activation. Ann Surg. 2000;232:272-280.

13. Isermann B, Vinnikov IA, Madhusudhan $T$, Herzog $S$, Kashif $M$, Blautzik J, Corat MA, Zeier M, Blessing E, Oh J, Gerlitz B, Berg DT, Grinnell BW, Chavakis T, Esmon CT, Weiler $\mathrm{H}$, Bierhaus A, Nawroth PP. Activated protein C protects against diabetic nephropathy by inhibiting endothelial and podocyte apoptosis. Nat Med. 2007;13:1349-1358.

14. Mizutani A, Okajima K, Uchiba M, Noguchi T. Activated protein C reduces ischemia/ reperfusion-induced renal injury in rats by inhibiting leukocyte activation. Blood. 2000;95:3781-3787.

15. Golino P, Ragni M, Cirillo P, Scognamiglio A, Ravera A, Buono C, Guarino A, Piro O, Lambiase C, Botticella F, Ezban M, Condorelli M, Chiariello M. Recombinant human, active site-blocked factor VIla reduces infarct size and no-reflow phenomenon in rabbits. Am J Physiol Heart Circ Physiol. 2000;278:H1507-1516.

16. Loubele ST, Spek CA, Leenders P, van Oerle R, Aberson HL, van der Voort D, Hamulyak $\mathrm{K}$, Petersen LC, Spronk HM, Ten Cate H. Active site inhibited factor VIla attenuates myocardial ischemia/reperfusion injury in mice. J Thromb Haemost. 2008. 
17. Frank RD, Holscher T, Schabbauer G, Tencati M, Pawlinski R, Weitz JI, Mackman N. A non-anticoagulant synthetic pentasaccharide reduces inflammation in a murine model of kidney ischemia-reperfusion injury. Thromb Haemost. 2006;96:802-806.

18. Mizutani A, Okajima K, Uchiba M, Isobe H, Harada N, Mizutani S, Noguchi T. Antithrombin reduces ischemia/reperfusion-induced renal injury in rats by inhibiting leukocyte activation through promotion of prostacyclin production. Blood. 2003;101:3029-3036.

19. Nitescu N, Grimberg E, Ricksten SE, Marcussen N, Guron G. Thrombin inhibition with melagatran does not attenuate renal ischaemia-reperfusion injury in rats. Nephrol Dial Transplant. 2007;22:2149-2155.

20. Cheng T, Liu D, Griffin JH, Fernandez JA, Castellino F, Rosen ED, Fukudome K, Zlokovic BV. Activated protein C blocks p53-mediated apoptosis in ischemic human brain endothelium and is neuroprotective. Nat Med. 2003;9:338-342.

21. Leemans JC, Stokman G, Claessen N, Rouschop KM, Teske GJ, Kirschning CJ, Akira S, van der Poll T, Weening JJ, Florquin S. Renal-associated TLR2 mediates ischemia/ reperfusion injury in the kidney. J Clin Invest. 2005;115:2894-2903.

22. Spek CA, Verbon A, Aberson H, Pribble JP, McElgunn CJ, Turner T, Axtelle T, Schouten J, Van Der Poll T, Reitsma PH. Treatment with an anti-CD14 monoclonal antibody delays and inhibits lipopolysaccharide-induced gene expression in humans in vivo. J Clin Immunol. 2003;23:132-140.

23. Wu H, Chen G, Wyburn KR, Yin J, Bertolino P, Eris JM, Alexander SI, Sharland AF, Chadban SJ. TLR4 activation mediates kidney ischemia/reperfusion injury. J Clin Invest. 2007;117:2847-2859.

24. Enestrom S, Druid H, Rammer L. Fibrin deposition in the kidney in post-ischaemic renal damage. Br J Exp Pathol. 1988;69:387-394.

25. Sevastos J, Kennedy SE, Davis DR, Sam M, Peake PW, Charlesworth JA, Mackman N, Erlich JH. Tissue factor deficiency and PAR-1 deficiency are protective against renal ischemia reperfusion injury. Blood. 2007;109:577-583.

26. Coughlin SR. Protease-activated receptors in hemostasis, thrombosis and vascular biology. J Thromb Haemost. 2005;3:1800-1814.

27. Rondeau E, Vigneau C, Berrou J. Role of thrombin receptors in the kidney: lessons from PAR1 knock-out mice. Nephrol Dial Transplant. 2001;16:1529-1531.

28. Frank RD, Schabbauer G, Holscher T, Sato Y, Tencati M, Pawlinski R, Mackman N. The synthetic pentasaccharide fondaparinux reduces coagulation, inflammation and neutrophil accumulation in kidney ischemia-reperfusion injury. J Thromb Haemost. 2005;3:531-540.

29. Turunen AJ, Fernandez JA, Lindgren L, Salmela KT, Kyllonen LE, Makisalo H, Griffin JH, Siitonen SM, Petaja J, Pesonen EJ. Activated protein C reduces graft neutrophil activation in clinical renal transplantation. Am J Transplant. 2005;5:2204-2212.

30. Kielar ML, John R, Bennett M, Richardson JA, Shelton JM, Chen L, Jeyarajah DR, Zhou XJ, Zhou H, Chiquett B, Nagami GT, Lu CY. Maladaptive role of IL-6 in ischemic acute renal failure. J Am Soc Nephrol. 2005;16:3315-3325.

31. Matthijsen RA, Huugen D, Hoebers NT, de Vries B, Peutz-Kootstra CJ, Aratani Y, Daha MR, Tervaert JW, Buurman WA, Heeringa P. Myeloperoxidase is critically involved in the induction of organ damage after renal ischemia reperfusion. Am J Pathol. 2007;171:1743-1752.

32. Baltch AL, Bopp LH, Ritz WJ, Michelsen PB, Yan SB, Um S, Smith RP. Effect of recombinant human activated protein $\mathrm{C}$ on the bactericidal activity of human monocytes and modulation of pro-inflammatory cytokines in the presence of antimicrobial agents. J Antimicrob Chemother. 2007;59:1177-1181. 
33. Daemen MA, van 't Veer C, Denecker G, Heemskerk VH, Wolfs TG, Clauss M, Vandenabeele $\mathrm{P}$, Buurman WA. Inhibition of apoptosis induced by ischemiareperfusion prevents inflammation. J Clin Invest. 1999;104:541-549.

34. Daemen MA, Heemskerk VH, van't Veer C, Denecker G, Wolfs TG, Vandenabeele P, Buurman WA. Functional protection by acute phase proteins alpha(1)-acid glycoprotein and alpha(1)-antitrypsin against ischemia/reperfusion injury by preventing apoptosis and inflammation. Circulation. 2000;102:1420-1426. 



\section{Chapter 6}

General discussion 



\section{GENERAL DISCUSSION}

For a number of years, cardiovascular disease is the leading cause of death worldwide. Cardiovascular disease includes coronary heart disease, cerebrovascular disease, deep vein thrombosis and pulmonary embolism, and peripheral artery disease. A myocardial infarction or stroke is usually the first indication for underlying atherosclerosis, of which the acute thromboembolic manifestation is causal to acute organ ischemia. This process of ischemia leads to cell death and inflammation. Opening the vessel to supply the ligated vessel with oxygen is, however, not without risks as reperfusion is accompanied by processes of inflammation and cell death, so called reperfusion injury. Although ischemia/reperfusion injury in distinct organs results in different pathologies, the cellular processes may in part share mechanisms. In the heart as well as in the kidney, as described in this thesis, inflammation and apoptosis play an important role in determining ischemia/reperfusion injury. Reactive oxygen species (ROS) are in both renal and myocardial ischemia important regulators of inflammation through their ability to induce cytokine production ${ }^{1,2}$. The upregulated production of cytokines interleukin (IL-6), IL-1 $\beta$, and tumor necrosis factor (TNF)- $\alpha$ plays an important role in ischemia/reperfusion injury, as those cytokines are increased upon both myocardial infarction and renal ischemic injury ${ }^{3,4}$. This reaction triggers subsequent inflammatory mechanisms via the activation of leukocyte adhesion molecules and the infiltration of neutrophils within the ischemic area, mediated via NF-KB signaling 5,6 . Inflammation can trigger apoptosis ${ }^{7}$ but the inflammatory process may also be caused by ischemic cell death ${ }^{8,9}$. The role of several apoptotic pathways involved in both heart and renal ischemia/reperfusion injury have been described extensively ${ }^{10-12}$.

The processes of renal and myocardial ischemia/reperfusion are discussed separately in this thesis. However, both organs are also shown to influence each other upon injury. Patients suffering from renal failure have increased mortality rates due to cardiovascular disease ${ }^{13}$ and there is an increased incidence of cardiovascular disease after renal transplantation ${ }^{14}$. Furthermore, less myocardial ischemia/reperfusion injury is observed upon pre-conditioning with brief ischemic periods in the kidney ${ }^{15,16}$, revealing interacting mechanisms between renal and myocardial injury. In the studies as described in this thesis, the link between myocardial and renal injury was not investigated. However, based on the results obtained from the experiments regarding the positive 
effects of the anti-coagulants active site inhibited FVIla (ASIS) and activated protein $C$ (APC) on myocardial ischemia/reperfusion injury but not on renal ischemia/reperfusion injury, a future study exploring the effect of these anticoagulants in the interaction between myocardial and renal injury could be useful to explain this phenomenon.

Blood coagulation plays an important role in cardiovascular disease as several coagulation factors are risk factors for either venous or arterial thrombosis. Coagulation factors fibrinogen, FVIII, FIX, FXI, and prothrombin are risk factors for venous thrombosis ${ }^{17}$, whereas tissue factor (TF) and FVII are predictive of mortality in patients with coronary artery disease or acute myocardial infarction as increased TF and FVII levels are independent predictors for mortality and reinfarction in patients with acute myocardial infarction ${ }^{18,19}$. The procoagulant pathway can be inhibited by several natural mechanisms, namely tissue factor pathway inhibitor (TFPI), APC and antithrombin (AT), that also form risk factors for thrombosis. TFPI is a serine protease inhibitor of the TF/FVIla complex and has been proven to be a risk factor for venous thrombosis ${ }^{20,21}$, but no correlation has been found between TFPI levels and arterial thrombosis. In patients with the acute coronary syndrome, however, blood TFPI levels were shown to be increased ${ }^{22}$. APC, another inhibitor of coagulation, is a protease which plays a major role in thrombosis and hemostasis via its negative feedback regulation of thrombin generation. Deficiencies in protein $\mathrm{C}$ significantly increase the risk of venous thrombosis ${ }^{23}$. Defects in the protein $C$ pathway, also known as APC resistance, is often caused by a missense mutation in the FV gene (factor $\mathrm{V}$ Leiden) and is associated with an increased risk for venous thrombosis ${ }^{24,25}$. Furthermore, Eitzman et al. revealed a correlation between factor $V$ Leiden homozygosity and enhanced arterial thrombosis and atherosclerosis ${ }^{26}$. The third inhibitor of coagulation is the AT pathway which functions as a general protease inhibitor. AT deficiencies are associated with severe venous thromboembolic disease ${ }^{27}$. A correlation between AT deficiencies and arterial thrombosis needs to be further elucidated. Thrombin generation however, appears to be associated with mortality in subjects at risk of cardiovascular disease (Lowe et al., unpublished data)

Besides coagulation, inflammation is a major contributor in the cardiovascular disease process. Several studies revealed a link between inflammatory markers and the risk for coronary heart disease and cardiovascular death ${ }^{28-30}$. The link between inflammation and coagulation is extensively studied over the last 
years. The most important contributors that link the coagulation and the inflammatory process are thought to be the protease activated receptors (PARs). PARs are cleaved by coagulation proteases leading to intracellular signaling which results in the activation of inflammation and apoptosis ${ }^{31}$. Inhibition of coagulation can therefore result in the inhibition of several other cellular processes like inflammation. A number of anti-coagulants are therefore, besides their anti-coagulant function, also known for their cytoprotective properties. TFPI has been demonstrated to have some protective effects in ischemic injury but the underlying mechanisms need to be further elucidated. In rabbits, TFPI appears to positively affect neurologic function repair after ischemia/reperfusion injury to the spinal cord. The number of TFPI treated animals retaining neurological function after occlusion was significantly higher compared to the placebo treated animals suggesting a role for TFPI in preventing ischemia/reperfusion injury ${ }^{32}$. In a rat model of renal ischemia/ reperfusion, the results also suggest a role for TFPI in prevention of ischemia/ reperfusion injury ${ }^{33}$. AT administration was revealed to be protective via its antithrombotic and anti-inflammatory properties in animal models of ischemia/ reperfusion of intestinal as well as renal injury ${ }^{34,35}$.

The anti-coagulants used in the experiments described in this thesis, ASIS (or FVIlai) and APC, also have cytoprotective properties and will be discussed in detail below.

In chapter 2 and 3, ASIS administration in a myocardial ischemia/reperfusion injury model revealed a protective effect shown by a decrease in infarct size and reduction in a number of inflammatory markers. However, no effect on apoptosis was detectable. In chapter 2, the optimal time point of ASIS administration was assessed and set at repeated administration time points, one during ischemia and one during reperfusion. ASIS administration at a single time point during only the ischemic phase or the reperfusion phase revealed different effects regarding infarct size and cell signaling mechanism. Administration of single doses of ASIS did, however, not retrieve the optimal effect obtained when administering ASIS at 2 time points. An explanation for this phenomenon could be found in the fact that both the ischemic and the reperfusion process are recognized by distinct cellular processes. While the ischemic process is mostly recognized by injury due to oxygen depletion due to a fall in ATP content and a disturbed ion balance resulting in cell swelling and death, the reperfusion process is mostly characterized by an inflammatory 
response and apoptosis ${ }^{36}$. Due to the diversity of molecular processes during both ischemia and reperfusion, administration of ASIS during both processes seems pivotal to obtain an optimal effect on recovery from myocardial injury.

In chapter 3 , the specific working mechanism of ASIS on reduction of I/R injury was explored. ASIS is already known for its anti-inflammatory properties but the exact working mechanism was not yet revealed. The anti-inflammatory role of FVIlai was first demonstrated using a sepsis baboon model in which administration of FVIlai attenuated fibrinogen depletion and decreased proinflammatory cytokine responses ${ }^{37,38}$. In a rat model of intestinal ischemia/ reperfusion, FVIlai had anti-inflammatory properties. Pretreatment with FVIlai in this ischemia/reperfusion model reduced the permeability of the endothelial barrier, myeloperoxidase (MPO) activity and the matrix inflammatory protein (MIP)-2 levels ${ }^{39}$. An anti-apoptotic role for FVIlai has not yet been revealed. The results as described in chapter 3 revealed an important role for the NF-KB signaling pathway in the working mechanism of ASIS. The transcription factor $\mathrm{NF}-\mathrm{KB}$ is primarily involved in immune and inflammatory responses ${ }^{40}$ and is shown to be activated after myocardial ischemia ${ }^{41}$. Furthermore, inhibition of IKK $\beta$ is shown to be cardio protective upon myocardial ischemia ${ }^{42}$ and mice deficient in the p50 subunit of NF-KB revealed reduced myocardial ischemia/ reperfusion injury ${ }^{43}$.

In chapter 4, a cytoprotective effect of APC was revealed upon myocardial ischemia/reperfusion injury. The cytoprotective properties of APC were, however, shown in a number of animal studies but this was the first study in which both an anti-inflammatory and an anti-apoptotic role for APC were detected in a myocardial ischemia/reperfusion model. The first evidence for the anti-inflammatory function of APC was shown by Taylor et al. in 1987 who showed that injection of APC improved the survival rate in a sepsis baboon model ${ }^{44}$. In a murine model of focal ischemic stroke, APC has been proven to have anti-inflammatory, antithrombotic, and neuroprotective effects. Administration of APC increased the average survival time and restored cerebral blood flow after cerebral artery occlusion. Cellular effects of APC on stroke were recognized by a decrease in leukocyte infiltration and fibrin deposition and a reduction in ICAM-1 at the blood brain barrier preventing neutrophil adhesion ${ }^{45}$. APC has been shown to have anti-inflammatory properties in an acute ischemia reperfusion model in the skeletal muscle where APC reduced MPO content and electrical properties of skeletal muscle ${ }^{46}$. Mizutani et al. 
demonstrated a reduction in ischemia/reperfusion induced renal injury by $A P C^{47}$. APC has anti-inflammatory properties in a rat model of spinal cord ischemia/reperfusion by inhibition of neutrophil activation. Here APC reduced micro-infarctions and histological changes, and decreased levels of IL-8, MPO and TNF- $\alpha$ normally elevated due to ischemia/reperfusion ${ }^{48}$. Cheng et al. have shown an anti-apoptotic role for APC in an ischemic human brain endothelium injury model. The anti-apoptotic properties of APC were demonstrated in hypoxic human brain endothelium by inhibition of transcription of both tumor suppression protein p53 and apoptosis associated $\mathrm{Bax} / \mathrm{Bcl}-2$ and caspase-3 pathways ${ }^{49}$. In this study as described in chapter 4 , a specific role for PAR-1 was addressed in the protective effects of APC. Before, the presence of PAR-1 was shown to be necessary in the protective mechanisms of APC ${ }^{49}$. PAR-1 deficient mice on the other hand showed that PAR-1 contributes to cardiac remodeling and hypertrophy but revealed no effect on infarct size ${ }^{50}$.

When the anti-coagulants ASIS or APC were used in a renal ischemia/ reperfusion injury model, no effect on renal injury or on inflammation or apoptosis was detected as described in chapter 5. So far, ASIS was not used as an anti-coagulant in a renal ischemia/reperfusion model; hence APC was shown to be protective against renal injury due to ischemia or diabetes ${ }^{47,51}$. In the latter model however, human APC was systemically over expressed; such expression can inflict local renal protection, different from effects obtained by infusion of APC. Other anti-coagulants also showed protective effects upon renal ischemia/reperfusion injury but different experimental models were used which raises problems when comparing the results ${ }^{52,53}$.

An important question that can be raised upon comparison of the results described in this thesis is the distinct effects of the anti-coagulants ASIS and APC on both myocardial as well as renal ischemia/reperfusion injury. One has to take into account that the amount of injury was higher in the renal ischemia/ reperfusion experiment where the whole kidney was clamped, compared to the myocardial ischemia/reperfusion experiment where only a part of the heart was occluded. Besides, APC was administered in a higher dose $(1 \mathrm{mg} / \mathrm{kg})$ and at a different time points earlier in the ischemic phase in the renal ischemia/ reperfusion model. However, no effects on renal injury, inflammation, or apoptosis were detectable in the kidney. 
Since PAR-1 and the NF-KB gene seem to play an important role in the working mechanism of both APC and ASIS respectively, an explanation for the different effects in both the kidney and the heart might be explained by the tissue distribution of both NF-KB and PAR-1. Within the heart, PAR-1 is expressed in the cardiomyocytes, while in the kidney, PAR-1 is expressed on the epithelial and mesangial cells of the glomeruli ${ }^{54,55}$. PAR $-1^{-1-}$ animals were in both the kidney and the heart protected from injury due to ischemia/reperfusion. In a renal ischemia/reperfusion model, PAR-1 ${ }^{-/}$mice were protected from renal failure and mortality and a myocardial ischemia/reperfusion model showed less hypertrophy in PAR-1\% mice but did not reveal a reduction in infarct size ${ }^{50,56}$. Furthermore, APC requires PAR-1 in both the kidney and the heart to exert a protective effect ${ }^{49,51,57}$ indicating that the working mechanism of APC in the heart and in the kidney is quite similar. However, renal injury due to ischemia is mostly located within the tubuli ${ }^{58}$ whereas PAR-1 is located within the glomeruli54, possibly explaining the lack of effect of APC on renal ischemia/ reperfusion injury when using a comparable dose as in the myocardial ischemia/reperfusion study. The NF-kB pathway is also involved in renal as well as in myocardial injury and inactivation of this pathway appears to be protective against injury as NF-KB suppression prevents ischemic injury in both organs ${ }^{41,43,59}$. Neither the NF-KB pathway nor PAR-1 expression can explain fully the opposite effects of APC and ASIS on myocardial as well as renal injury, so further research regarding this interesting finding is needed.

\section{Clinical USE OF ANTI-COAgUlants}

The use of anti-coagulants as anti-inflammatory therapeutics has already been extensively investigated in patients with sepsis. These studies were mainly based on the highly promising effects of each of the compounds AT, APC and TFPI to lower mortality due to sepsis in baboon models ${ }^{44,60,61}$. All three anticoagulants were tested in clinical trials of sepsis patients. In contrast to the experimental studies, of all three agents, only APC appeared to reduce mortality in sepsis patients with $6.1 \%$ (absolute risk reduction) as shown in the PROWESS trial. However, this study suffered from various methodological difficulties that made interpretation difficult. Besides, in follow up studies it appeared that APC was only effective in those patients with most severe sepsis, while the outcome was negative or even somewhat worse in patients with less 
severe sepsis APACHE scores. From a mechanistic point of view it was remarkable that no anti-inflammatory effects of the use of APC were noted, in spite of the initially reported reduction in plasma IL-6 level. In addition, a drawback of the APC-treatment in all patients is the increased bleeding risk ${ }^{62}$. The anti-coagulants AT and TFPI failed to reduce mortality due to sepsis, while their application was also accompanied by an increased bleeding risk ${ }^{63,64}$.

The basis for the discrepancies or the lack of effects among outcomes in clinical trials can be due to many reasons, e.g. the time points and dose of administration used, or heterogeneity among sepsis patients in those trials. For this reason, the question remains if the extrapolation of animal models to the human situation is allowed and of course also holds true for ischemia/ reperfusion injury models. Despite the promising results of the use of anticoagulants as protection against ischemia/reperfusion injury in animal models, none of these are tested so far for their anti-inflammatory or anti-apoptotic characteristics in human studies although the increased bleeding risk observed for these anti-coagulants would play a less prominent role in a thrombotic disease status. The interface between coagulation and inflammation is, although its participation in a lot of disease processes, not completely unraveled and research within this field needs to be further extended.

\section{FUTURE PLANS}

Due to its clinical relevance, APC will be used in further research to reveal its exact working mechanism. A number of studies already indicated the importance of PAR-1, but so far no specific distinction was made between contribution of the anti-coagulant effect of APC on one hand and the cell signaling effects on the other hand. In order to investigate this, APC mutant proteins will be developed that contain either an anti-coagulant function without having an effect on cell signaling, or a mutant form that shows cell signaling properties without exerting anti-coagulant activities. Furthermore, these molecules show a prolonged half life in comparison to wild type APC.

Some studies are already performed with APC mutant molecules. The results point to differences in the relative importance of the anti-coagulant over the PAR mediated functions of APC, in relation to outcome. In a sepsis model, usage of a non-anticoagulant form of APC provided an equal protective effect 
compared to wild type APC with regard to survival rates while the risk for bleeding is reduced ${ }^{65}$. In an acute kidney injury model, however, both anticoagulant and the PAR mediated signaling effects of APC offered protection against renal injury ${ }^{57}$. In a model of ischemic stroke where the anti-coagulant activity of $A P C$ is undesirable given the substantial detrimental consequences of bleeding, the non-anticoagulant 3K3A-APC mutant was more effective in reducing cerebral damage than wild type $A P C$, without apparent increased risk for bleeding 66 .

Each of these studies demonstrates that the different properties of APC may be important dependent on the pathophysiological situation as well as the organ involved. It is evident that detailed knowledge of these functional properties of APC in relation to cellular functions and protective effects on entire organs are urgently needed, before any step towards the clinical arena can be made with good faith. Whether in the clinical situation of marked patient heterogeneity, compounds like APC and ASIS will stand in lowering complex diseases like myocardial infarction and stroke remains highly speculative at this stage. However, the prospect of being able to produce APC mutant molecules that maintain cell protective effects, have less hemorrhagic potential and have a prolonged half life, open new ways for therapeutic modification of such complex disease. 


\section{REFERENCES}

1. Dhalla NS, Elmoselhi AB, Hata $T$, Makino N. Status of myocardial antioxidants in ischemia-reperfusion injury. Cardiovasc Res. 2000;47:446-456.

2. Baud L, Ardaillou R. Involvement of reactive oxygen species in kidney damage. Br Med Bull. 1993;49:621-629.

3. Frangogiannis NG, Smith CW, Entman ML. The inflammatory response in myocardial infarction. Cardiovasc Res. 2002;53:31-47.

4. Thurman JM. Triggers of inflammation after renal ischemia/reperfusion. Clin Immunol. 2007;123:7-13.

5. Valen G. Signal transduction through nuclear factor kappa B in ischemiareperfusion and heart failure. Basic Res Cardiol. 2004;99:1-7.

6. Sung FL, Zhu TY, Au-Yeung KK, Siow YL, O K. Enhanced MCP-1 expression during ischemia/reperfusion injury is mediated by oxidative stress and NF-kappaB. Kidney Int. 2002;62:1160-1170.

7. Krown KA, Page MT, Nguyen C, Zechner D, Gutierrez V, Comstock KL, Glembotski CC, Quintana PJ, Sabbadini RA. Tumor necrosis factor alphainduced apoptosis in cardiac myocytes. Involvement of the sphingolipid signaling cascade in cardiac cell death. J Clin Invest. 1996;98:2854-2865.

8. Scaffidi P, Misteli T, Bianchi ME. Release of chromatin protein HMGB1 by necrotic cells triggers inflammation. Nature. 2002;418:191-195.

9. Knies UE, Behrensdorf HA, Mitchell CA, Deutsch U, Risau W, Drexler HC, Clauss M. Regulation of endothelial monocyte-activating polypeptide II release by apoptosis. Proc Natl Acad Sci U S A. 1998;95:12322-12327.

10. Abbate A, Bussani R, Amin MS, Vetrovec GW, Baldi A. Acute myocardial infarction and heart failure: role of apoptosis. Int J Biochem Cell Biol. 2006;38:1834-1840.

11. Dagher PC. Apoptosis in ischemic renal injury: roles of GTP depletion and p53. Kidney Int. 2004;66:506-509.

12. Kaushal GP, Basnakian AG, Shah SV. Apoptotic pathways in ischemic acute renal failure. Kidney Int. 2004;66:500-506.

13. Chertow GM, Normand SL, Silva LR, McNeil BJ. Survival after acute myocardial infarction in patients with end-stage renal disease: results from the cooperative cardiovascular project. Am J Kidney Dis. 2000;35:1044-1051.

14. Kasiske BL, Guijarro C, Massy ZA, Wiederkehr MR, Ma JZ. Cardiovascular disease after renal transplantation. J Am Soc Nephrol. 1996;7:158-165.

15. Gho BC, Schoemaker RG, van den Doel MA, Duncker DJ, Verdouw PD. Myocardial protection by brief ischemia in noncardiac tissue. Circulation. 1996;94:2193-2200. 
16. Takaoka A, Nakae I, Mitsunami K, Yabe T, Morikawa S, Inubushi T, Kinoshita M. Renal ischemia/reperfusion remotely improves myocardial energy metabolism during myocardial ischemia via adenosine receptors in rabbits: effects of "remote preconditioning". J Am Coll Cardiol. 1999;33:556-564.

17. Bertina RM. Elevated clotting factor levels and venous thrombosis. Pathophysiol Haemost Thromb. 2003;33:395-400.

18. Morange PE, Blankenberg S, Alessi MC, Bickel C, Rupprecht HJ, Schnabel R, Lubos E, Munzel T, Peetz D, Nicaud V, Juhan-Vague I, Tiret L. Prognostic value of plasma tissue factor and tissue factor pathway inhibitor for cardiovascular death in patients with coronary artery disease: the AtheroGene study. J Thromb Haemost. 2007;5:475-482.

19. Campo G, Valgimigli M, Ferraresi P, Malagutti P, Baroni M, Arcozzi C, Gemmati D, Percoco G, Parrinello G, Ferrari R, Bernardi F. Tissue factor and coagulation factor VII levels during acute myocardial infarction: association with genotype and adverse events. Arterioscler Thromb Vasc Biol. 2006;26:2800-2806.

20. Tardy-Poncet B, Tardy B, Laporte S, Mismetti P, Amiral J, Piot M, Reynaud J, Campos L, Decousus H. Poor anticoagulant response to tissue factor pathway inhibitor in patients with venous thrombosis. J Thromb Haemost. 2003;1:507-510.

21. Dahm A, Van Hylckama Vlieg A, Bendz B, Rosendaal F, Bertina RM, Sandset PM. Low levels of tissue factor pathway inhibitor (TFPI) increase the risk of venous thrombosis. Blood. 2003;101:4387-4392.

22. Maly M, Vojacek J, Hrabos V, Kvasnicka J, Salaj P, Durdil V. Tissue factor, tissue factor pathway inhibitor and cytoadhesive molecules in patients with an acute coronary syndrome. Physiol Res. 2003;52:719-728.

23. Broekmans AW, Veltkamp JJ, Bertina RM. Congenital protein C deficiency and venous thromboembolism. A study of three Dutch families. N Engl J Med. 1983;309:340-344.

24. Bertina RM, Koeleman BP, Koster T, Rosendaal FR, Dirven RJ, de Ronde H, van der Velden PA, Reitsma PH. Mutation in blood coagulation factor $\mathrm{V}$ associated with resistance to activated protein C. Nature. 1994;369:64-67.

25. Castoldi $E$, Rosing J. Factor $V$ Leiden: a disorder of factor $V$ anticoagulant function. Curr Opin Hematol. 2004;11:176-181.

26. Eitzman DT, Westrick RJ, Shen Y, Bodary PF, Gu S, Manning SL, Dobies SL, Ginsburg D. Homozygosity for factor $V$ Leiden leads to enhanced thrombosis and atherosclerosis in mice. Circulation. 2005;111:1822-1825.

27. Beresford CH. Antithrombin III deficiency. Blood Rev. 1988;2:239-250. 
28. Ernst $E$, Hammerschmidt $D E$, Bagge $U$, Matrai A, Dormandy JA. Leukocytes and the risk of ischemic diseases. JAMA. 1987;257:2318-2324.

29. Koenig W, Sund M, Frohlich M, Fischer HG, Lowel H, Doring A, Hutchinson WL, Pepys MB. C-Reactive protein, a sensitive marker of inflammation, predicts future risk of coronary heart disease in initially healthy middleaged men: results from the MONICA (Monitoring Trends and Determinants in Cardiovascular Disease) Augsburg Cohort Study, 1984 to 1992. Circulation. 1999;99:237-242.

30. Lindahl B, Toss $H$, Siegbahn A, Venge $P$, Wallentin L. Markers of myocardial damage and inflammation in relation to long-term mortality in unstable coronary artery disease. FRISC Study Group. Fragmin during Instability in Coronary Artery Disease. N Engl J Med. 2000;343:1139-1147.

31. Strukova S. Blood coagulation-dependent inflammation. Coagulationdependent inflammation and inflammation-dependent thrombosis. Front Biosci. 2006;11:59-80.

32. Koudsi B, Chatman DM, Ballinger BA, Ferguson EW, Kraemer BA, Miller GA, Wun TC, Farr G, Money SR. Tissue factor pathway inhibitor protects the ischemic spinal cord. J Surg Res. 1996;63:174-178.

33. Ushigome H, Sano H, Okamoto M, Kadotani Y, Nakamura K, Akioka K, Yoshimura R, Ohmori $\mathrm{Y}$, Yoshimura $\mathrm{N}$. The role of tissue factor in renal ischemic reperfusion injury of the rat. J Surg Res. 2002;102:102-109.

34. Schoots IG, Levi M, van Vliet AK, Maas AM, Roossink EH, van Gulik TM. Inhibition of coagulation and inflammation by activated protein $\mathrm{C}$ or antithrombin reduces intestinal ischemia/reperfusion injury in rats. Crit Care Med. 2004;32:1375-1383.

35. Ozden A, Sarioglu A, Demirkan NC, Bilgihan A, Duzcan E. Antithrombin III reduces renal ischemia-reperfusion injury in rats. Res Exp Med (Berl). 2001;200:195-203.

36. Lopez-Neblina F, Toledo AH, Toledo-Pereyra LH. Molecular biology of apoptosis in ischemia and reperfusion. J Invest Surg. 2005;18:335-350.

37. Welty-Wolf KE, Carraway MS, Miller DL, Ortel TL, Ezban M, Ghio AJ, Idell $S$, Piantadosi CA. Coagulation blockade prevents sepsis-induced respiratory and renal failure in baboons. Am J Respir Crit Care Med. 2001;164:1988-1996.

38. Taylor FB, Chang AC, Peer G, Li A, Ezban M, Hedner U. Active site inhibited factor VIla (DEGR VIla) attenuates the coagulant and interleukin- 6 and -8 , but not tumor necrosis factor, responses of the baboon to LD100 Escherichia coli. Blood. 1998;91:1609-1615. 
39. Olanders K, Borjesson A, Zhao X, Andersson R. Effects of anticoagulant treatment on intestinal ischaemia and reperfusion injury in rats. Acta Anaesthesiol Scand. 2005;49:517-524.

40. Baldwin AS, Jr. The NF-kappa B and I kappa B proteins: new discoveries and insights. Annu Rev Immunol. 1996;14:649-683.

41. Li C, Browder W, Kao RL. Early activation of transcription factor NFkappaB during ischemia in perfused rat heart. Am J Physiol. 1999;276:H543-552.

42. Moss NC, Stansfield WE, Willis MS, Tang RH, Selzman CH. IKKbeta inhibition attenuates myocardial injury and dysfunction following acute ischemia-reperfusion injury. Am J Physiol Heart Circ Physiol. 2007;293:H2248-2253.

43. Frantz S, Tillmanns J, Kuhlencordt PJ, Schmidt I, Adamek A, Dienesch C, Thum T, Gerondakis S, Ertl G, Bauersachs J. Tissue-specific effects of the nuclear factor kappaB subunit p50 on myocardial ischemia-reperfusion injury. Am J Pathol. 2007;171:507-512.

44. Taylor FB, Jr., Chang A, Esmon CT, D'Angelo A, Vigano-D'Angelo S, Blick KE. Protein $C$ prevents the coagulopathic and lethal effects of Escherichia coli infusion in the baboon. J Clin Invest. 1987;79:918-925.

45. Shibata M, Kumar SR, Amar A, Fernandez JA, Hofman F, Griffin JH, Zlokovic BV. Anti-inflammatory, antithrombotic, and neuroprotective effects of activated protein $C$ in a murine model of focal ischemic stroke. Circulation. 2001;103:1799-1805.

46. Dillon JP, Laing AJ, Cahill RA, O'Brien GC, Street JT, Wang JH, Mc Guinness A, Redmond HP. Activated protein C attenuates acute ischaemia reperfusion injury in skeletal muscle. J Orthop Res. 2005;23:1454-1459.

47. Mizutani A, Okajima K, Uchiba M, Noguchi T. Activated protein C reduces ischemia/reperfusion-induced renal injury in rats by inhibiting leukocyte activation. Blood. 2000;95:3781-3787.

48. Hirose K, Okajima K, Taoka Y, Uchiba M, Tagami H, Nakano K, Utoh J, Okabe $\mathrm{H}$, Kitamura $\mathrm{N}$. Activated protein $\mathrm{C}$ reduces the ischemia/ reperfusion-induced spinal cord injury in rats by inhibiting neutrophil activation. Ann Surg. 2000;232:272-280.

49. Cheng T, Liu D, Griffin JH, Fernandez JA, Castellino F, Rosen ED, Fukudome $\mathrm{K}$, Zlokovic BV. Activated protein C blocks p53-mediated apoptosis in ischemic human brain endothelium and is neuroprotective. Nat Med. 2003;9:338-342.

50. Pawlinski R, Tencati M, Hampton CR, Shishido T, Bullard TA, Casey LM, Andrade-Gordon P, Kotzsch M, Spring D, Luther T, Abe J, Pohlman TH, Verrier ED, Blaxall BC, Mackman N. Protease-activated receptor-1 
contributes to cardiac remodeling and hypertrophy. Circulation. 2007;116:2298-2306.

51. Isermann B, Vinnikov IA, Madhusudhan T, Herzog S, Kashif M, Blautzik J, Corat MA, Zeier M, Blessing E, Oh J, Gerlitz B, Berg DT, Grinnell BW, Chavakis T, Esmon CT, Weiler H, Bierhaus A, Nawroth PP. Activated protein $C$ protects against diabetic nephropathy by inhibiting endothelial and podocyte apoptosis. Nat Med. 2007;13:1349-1358.

52. Mizutani A, Okajima K, Uchiba M, Isobe H, Harada N, Mizutani S, Noguchi T. Antithrombin reduces ischemia/reperfusion-induced renal injury in rats by inhibiting leukocyte activation through promotion of prostacyclin production. Blood. 2003;101:3029-3036.

53. Frank RD, Holscher T, Schabbauer G, Tencati M, Pawlinski R, Weitz Jl, Mackman N. A non-anticoagulant synthetic pentasaccharide reduces inflammation in a murine model of kidney ischemia-reperfusion injury. Thromb Haemost. 2006;96:802-806.

54. Steinberg SF. The cardiovascular actions of protease-activated receptors. Mol Pharmacol. 2005;67:2-11.

55. Rondeau E, Vigneau C, Berrou J. Role of thrombin receptors in the kidney: lessons from PAR1 knock-out mice. Nephrol Dial Transplant. 2001;16:1529-1531.

56. Sevastos J, Kennedy SE, Davis DR, Sam M, Peake PW, Charlesworth JA, Mackman N, Erlich JH. Tissue factor deficiency and PAR-1 deficiency are protective against renal ischemia reperfusion injury. Blood. 2007;109:577-583.

57. Gupta A, Gerlitz B, Richardson MA, Bull C, Berg DT, Syed S, Galbreath EJ, Swanson BA, Jones BE, Grinnell BW. Distinct Functions of Activated Protein C Differentially Attenuate Acute Kidney Injury. J Am Soc Nephrol. 2008.

58. Bayati A, Kallskog O, Wolgast M. The long-term outcome of postischaemic acute renal failure in the rat. I. A functional study after treatment with SOD and sucrose. Acta Physiol Scand. 1990;138:25-33.

59. Henke N, Schmidt-Ullrich R, Dechend R, Park JK, Qadri F, Wellner M, Obst M, Gross V, Dietz R, Luft FC, Scheidereit C, Muller DN. Vascular endothelial cell-specific NF-kappaB suppression attenuates hypertensioninduced renal damage. Circ Res. 2007;101:268-276.

60. Taylor FB, Jr., Emerson TE, Jr., Jordan R, Chang AK, Blick KE. AntithrombinIII prevents the lethal effects of Escherichia coli infusion in baboons. Circ Shock. 1988;26:227-235.

61. Taylor FB, Jr. Studies on the inflammatory-coagulant axis in the baboon response to $\mathrm{E}$. coli: regulatory roles of proteins $\mathrm{C}, \mathrm{S}, \mathrm{C} 4 \mathrm{bBP}$ and of inhibitors of tissue factor. Prog Clin Biol Res. 1994;388:175-194. 
62. Bernard GR, Vincent JL, Laterre PF, LaRosa SP, Dhainaut JF, LopezRodriguez A, Steingrub JS, Garber GE, Helterbrand JD, Ely EW, Fisher CJ, Jr. Efficacy and safety of recombinant human activated protein $C$ for severe sepsis. N Engl J Med. 2001;344:699-709.

63. Warren BL, Eid A, Singer P, Pillay SS, Carl P, Novak I, Chalupa P, Atherstone A, Penzes I, Kubler A, Knaub S, Keinecke HO, Heinrichs H, Schindel F, Juers $\mathrm{M}$, Bone RC, Opal SM. Caring for the critically ill patient. High-dose antithrombin III in severe sepsis: a randomized controlled trial. JAMA. 2001;286:1869-1878.

64. Abraham E, Reinhart K, Opal S, Demeyer I, Doig C, Rodriguez AL, Beale R, Svoboda P, Laterre PF, Simon S, Light B, Spapen H, Stone J, Seibert A, Peckelsen C, De Deyne C, Postier R, Pettila V, Artigas A, Percell SR, Shu V, Zwingelstein C, Tobias J, Poole L, Stolzenbach JC, Creasey AA. Efficacy and safety of tifacogin (recombinant tissue factor pathway inhibitor) in severe sepsis: a randomized controlled trial. JAMA. 2003;290:238-247.

65. Kerschen EJ, Fernandez JA, Cooley BC, Yang XV, Sood R, Mosnier LO, Castellino FJ, Mackman N, Griffin JH, Weiler H. Endotoxemia and sepsis mortality reduction by non-anticoagulant activated protein C. J Exp Med. 2007;204:2439-2448.

66. Wang Y, Thiyagarajan M, Chow N, Singh I, Guo H, Davis TP, Zlokovic BV. Differential Neuroprotection and Risk for Bleeding From Activated Protein C With Varying Degrees of Anticoagulant Activity. Stroke. 2008. 


Addendum 



\section{AdDENDUM 1}

MOUSE MYOCARDIAL ISCHEMIA/REPERFUSION MODEL

All animal experiments were approved by the Animal Ethics Committee of the Maastricht University. Male C57Black/6 mice (Charles River Laboratories, Sulzfeld, Germany), 8 weeks old, and 22 to $28 \mathrm{~g}$ were housed under normal conditions: temperature was kept constant at $20-24{ }^{\circ} \mathrm{C}$ and food and water were provided ad libitum. Myocardial I/R was induced according to the method of Jong et al. (Jong et al., Comp Med 2003;53:522-6). Mice were anesthetized with isoflurane (induced with 3-4 \% and maintained with 1.5-2.5 \%) and were ventilated (frequency: $210 / \mathrm{min}$, volume: $250 \mu \mathrm{l}$ ). $30 \mathrm{~min}$ before the procedure, buprenorphine (Temgesic, $0.1 \mathrm{mg} / \mathrm{kg}$ ) was given subcutaneously. Body temperature was assessed using a rectal probe and ECGs were recorded. On day zero a lateral thoracotomy was performed during a preparative surgery. A suture (8-0 monofilament polypropylene suture, Johnson \& Johnson, New Jersey, US) was placed around the left anterior descending artery (LAD) and the endings of the suture were tunneled through an Intramedic PE-10 tube (Alimed, MA, US). The suture endings were saved under the skin until 7 days after preparative surgery. To induce ischemia, the suture was tightened. After $1 \mathrm{hr}$ of ischemia the suture was loosened and reperfusion was induced for varying reperfusion times. 


\section{ADDENDUM 2}

\section{PlASMA COLLECTION}

After the requested reperfusion time, sodium citrate (3.2\%) was injected directly into the vena cava. Blood was drawn from the vena cava and directly centrifuged at RT a first time at $4000 \mathrm{rpm}$ and a second time at $13000 \mathrm{rpm}$, each for 10 minutes (Sommeyer et al.Thromb J 2005;22:3-12).

\section{TISSUE COLLECTION}

After sacrificing, two groups were obtained for further analysis: one group for RNA and protein analysis and the other group for paraffin tissue sections. After blood collection the tissue was rinsed with $0.9 \% \mathrm{NaCl}$ and subsequently removed. The tissues were either frozen in liquid nitrogen for protein and RNA analysis or stored in paraformaldehyde (4\%) for paraffin tissue sections. The tissues were dry frozen and pulverized (Heart tissue: the right ventricles of the hearts were removed and the left ventricles were used; Renal tissue: the whole left kidney was used). For protein analysis, $10 \mathrm{mg}$ of the powdered tissue was dissolved in $28 \mathrm{mM}$ of n-octyl $\beta$-D-Glucopyranoside (Sigma, US) to disintegrate the cell membranes and to release the protein content in the solution. After centrifugation (14000 rpm, 10 minutes at RT), total protein concentrations were determined in the supernatant using the Bio-Rad Dc Protein Assay (Bio-Rad Laboratories, Veenendaal, the Netherlands). All samples were diluted to a total protein concentration of 1 or $5 \mathrm{mg} / \mathrm{ml}$ protein. $10 \mathrm{mg}$ of tissue powder was dissolved in $1 \mathrm{ml}$ of Tri Reagent (Sigma, US) for total RNA isolation and RNA was further isolated according the manufacturer's instructions. 


\section{ADDENDUM 3}

EVANS BLUE/TTC STAINING

Infarct size was assessed according to Erlich et al. (Erlich et al., Am J Pathol 2000;157:1849-1862). At the end of the reperfusion period, the LAD was reoccluded and Evans Blue dye (Sigma, US) was injected i.v. and allowed to circulate for 2 minutes. The healthy, perfused tissue stained blue and the area (normally) supplied by the ligated vessel (area at risk, AAR) remained pale. After excision of the heart, it was placed in a brain slicer (Braintree scientific, Inc, US) and frozen at $-20^{\circ} \mathrm{C}$ for 15 minutes. Subsequently the tissue was cut into 0.5 $\mathrm{mm}$ thick slices and stained with 2,3,5-triphenyltetrazolium (TTC, Sigma, US) for $20 \mathrm{~min}$ at $37^{\circ} \mathrm{C}$. Within the AAR, TTC stained the healthy tissue brick red while the area of infarction (AOI) remained pale. Pictures of the slices were taken and were analyzed with Adobe Photoshop CS2 to determine the AOI/AAR ratios. 


\section{ADDENDUM 4}

\section{TF ACTIVITY}

TF activity was determined in the $1 \mathrm{mg} / \mathrm{ml}$ protein sample dilutions using a home-made TF activity assay. In brief, samples were incubated for $10 \mathrm{~min}$ at $37^{\circ} \mathrm{C}$ with a mixture consisting of $2.8 \mathrm{nM}$ recombinant FVIla (Novo, Denmark), $278 \mathrm{nM}$ bovine FX, $10 \mathrm{mM} \mathrm{Ca}^{2+}$ and $40 \mu \mathrm{M}$ 20/80 phosphatidylserine/ phosphathidylcholine vesicles in Tris buffer (15.4 M Tris, $5.7 \mathrm{M} \mathrm{NaCl}, \mathrm{pH}=7.35$ ). Chromogenic substrate S2765 (BIOMAT B.V., Maastricht, The Netherlands) was added and the amount of factor Xa formed was measured kinetically at $405 \mathrm{~nm}$ for 10 minutes. Innovin (Dade Behring, US) was used as reference and control points with a reference curve ranging from 0.39 to $6 \mathrm{pM}$ (Loubele et al. J Thromb Haemost 2009; 7: 290-298). 


\section{Color Figures}

ChAPTER 3, Figure 2

Chapter 3, Figure 7
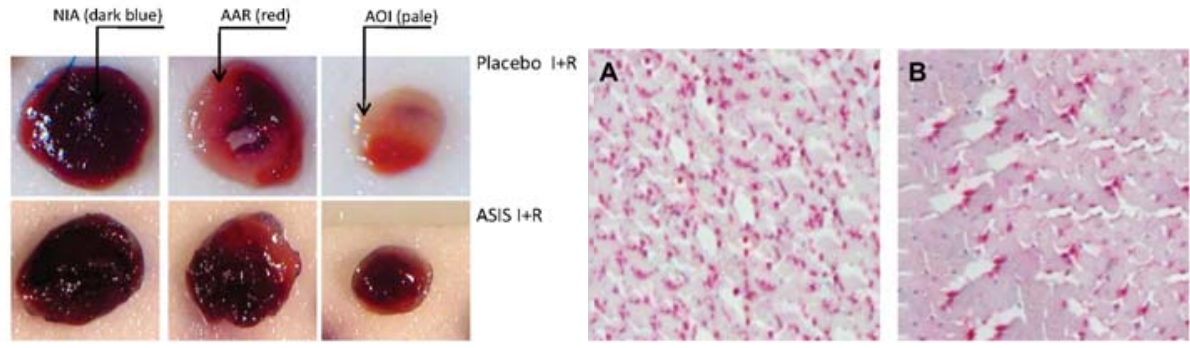

CHAPTER 4, FIGURE 4

A Placebo, 2 hrs R, 20x magn.

APC, 2 hrs R, 20x magn.
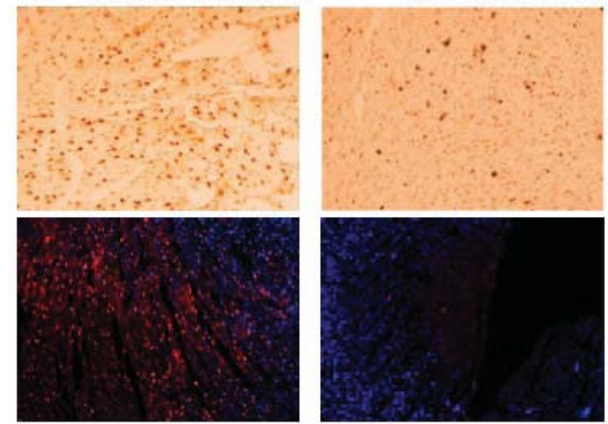

ChAPTER 5, Figure 2

CHAPTER 5, FiguRE 7
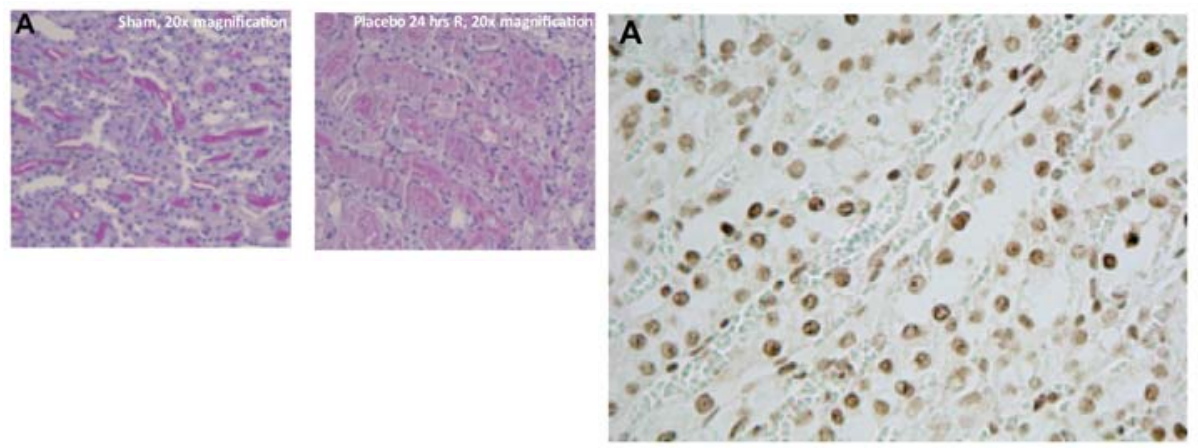



\section{Summary/Samenvatting}





\section{INHIBITION OF ISCHEMIC ORGAN DAMAGE WITH ANTI-COAGULANT AGENTS}

Cardiovascular disease remains the most important cause of death within the western world. A major cause of cardiovascular disease is atherosclerosis, in which the formation of atherosclerotic plaques leads to occlusion of the affected vessel. This process can take place either via narrowing of the vessel lumen due to the plaque or via the activation of the coagulation cascade upon plaque rupture. Occlusion of a major artery, such as a coronary artery, leads to ischemia due to oxygen depletion of the affected tissue, resulting in cell death. To limit the injury caused by the ischemic process, reperfusion or opening of the occluded vessel is necessary to restore the blood flow within the affected organ. The process of reperfusion is, however, not without risk as it is associated with inflammation indicated by an infiltration of inflammatory cells and the up-regulation of a number of inflammatory cytokines such as interleukin (IL)- 6 and $-1 \beta$. This inflammatory process results in regulated cell death or apoptosis via a number of cellular signaling pathways. Ischemia/ reperfusion injury has different consequences when distinct organs like the heart and the kidney are affected. After myocardial ischemia/reperfusion injury, the contractile function of the heart is reduced due to inflammatory and apoptotic processes resulting in a reduced heart function. Limitation of inflammation and apoptosis could result in an improved contractile function of the heart muscle after a myocardial injury. Within the kidney, limitation of ischemia/reperfusion injury is of great importance with organ transplants. Reduction of inflammation and apoptosis would limit the chance of acute renal failure and graft rejection upon kidney transplantation.

Coagulation and inflammation play an important role in the processes of ischemia and reperfusion and several studies revealed interacting mechanisms between the coagulation and inflammatory pathways via signaling through protease activated receptors or PARs. For this reason, anti-coagulants are, besides for their anti-coagulant function, also studied for their cytoprotective effects probably mediated via PARs. A number of in vitro and in vivo studies revealed cytoprotective effects for the two anti-coagulants investigated in this thesis namely active site inhibited FVIIa, or ASIS, and activated protein C or APC upon ischemia/reperfusion injury. ASIS is an inactive form of the coagulation factor VIla and in complex with tissue factor (TF) it can no longer activate the coagulation cascade. Within a myocardial ischemia/reperfusion model, ASIS has shown to be protective but an exact working mechanism was not yet revealed. 
A second anti-coagulant, APC, is activated upon thrombin generation and inhibits the coagulation factors $V a$ and VIIIa. In a number of ischemia/ reperfusion models including a renal ischemia/reperfusion and a stroke model, APC is shown to be protective but so far no study revealed a protective effect of APC on myocardial ischemia/reperfusion injury. Chapter $\mathbf{2}$ and $\mathbf{3}$ of this thesis were used to determine the effect of ASIS in a myocardial ischemia/reperfusion injury model and to reveal the working mechanism. Chapter 4 describes the use of APC within a myocardial ischemia/reperfusion model and looked further into the cell signaling mechanisms involved. Chapter 5 describes the effects of both anti-coagulants ASIS and APC in a renal ischemia/reperfusion model where a comparison is made with the use of anti-coagulants in different renal ischemia/reperfusion models.

In chapter 1 an overview is given of the pathophysiology of both renal and myocardial ischemia/reperfusion in which a focus is made on inflammation and apoptosis and this in relation to the cell signaling pathways involved. Furthermore, the specific functions related to coagulation and cytoprotection of APC and ASIS are described in relation to cell signaling.

Chapter 2 describes the effects of ASIS when administered during different time points of the ischemic and the reperfusion phase in a myocardial ischemia/ reperfusion model. The effects of ASIS administration were determined in regard to myocardial infarct size, overall coagulation parameters, and cell signaling pathways. ASIS was administered during the ischemia phase, during the ischemia and reperfusion phase, or during reperfusion only. Analysis of the infarct size and TF activity levels revealed the most optimal effect of ASIS when administered during ischemia and during reperfusion. Furthermore, cell signaling effects related to NF-KB signaling where also maximally influenced when ASIS was administered during both ischemia and reperfusion. From these results, the optimal time point of ASIS administration was set at during the ischemic and the reperfusion phase and this was used in all further experiments.

Chapter 3 revealed a positive effect of ASIS administration during ischemia and reperfusion on myocardial ischemia/reperfusion injury and this effect was sustained upon prolonged reperfusion times varying between 2 and $24 \mathrm{hrs}$. ASIS decreased the infarct size during a 2, 6 and $24 \mathrm{hrs}$ reperfusion period compared to placebo administration. RNA analysis revealed a strong down- 
regulation of a number of genes involved in NF-KB signaling upon ASIS administration. Furthermore, protein analysis revealed reduced levels of nuclear activated NF-KB and proteins regulated by NF-KB including TF and IL-6, upon ASIS administration. The anti-inflammatory effect of ASIS was further proven by reduced leukocyte infiltration within the ischemic area of the heart. Analysis of the influence of ASIS on apoptosis did not reveal an anti-apoptotic effect of the anti-coagulant as shown by RNA analysis of a number of apoptotic genes and apoptosis staining. From this chapter we conclude that the diminished amount of myocardial ischemia/reperfusion injury after ASIS administration is primarily due to attenuated inflammation-related lethal ischemia/reperfusion injury, probably mediated through the NF-KB mechanism.

In chapter 4 APC was shown to reduce myocardial ischemia/reperfusion injury during a 2, 6, and $24 \mathrm{hrs}$ reperfusion period. APC administration during ischemia as well as reperfusion reduced myocardial infarct size, whereas administration of the non-specific anti-coagulant heparin did not reveal a protective effect. Analysis of the effect of APC on inflammation revealed reduced interleukin levels and decreased leukocyte infiltration upon APC administration. Furthermore a strong anti-apoptotic effect of APC was detectable as shown by a reduction of the RNA expression levels of a number of pro-apoptotic genes and a reduction in apoptotic cells within the infarcted area upon APC administration. RNA analysis of a number of genes involved in the NF-KB pathway did not reveal an effect of APC. Blocking PAR-1, however, reversed the protective effects of $A P C$ on myocardial infarct size indicating that PAR-1 is necessary for APC to exert its protective effects. From these experiments we can conclude that APC exerts strong protective effects on early myocardial ischemia/reperfusion injury, primarily via inhibition of apoptosis and inflammation, regulated via PAR-1.

Since ASIS and APC showed strong cytoprotective effects in a myocardial ischemia/reperfusion model, both anti-coagulants were administered in a renal ischemia/reperfusion model. The results as described in chapter $\mathbf{5}$ did, however, not reveal a protective effect of ASIS or APC on renal injury. On a systemic level, neither APC nor ASIS influenced blood urea nitrogen and creatinin levels, nor was histopatholological scoring of the renal sections affected. On a cellular level, no overall effect of APC or ASIS was detectable on inflammation or apoptosis. An explanation for this can be in the variety of different renal ischemia/reperfusion models used in the literature. From this 
study we can conclude that the anti-coagulants ASIS and APC do not have protective effects in renal ischemia/repefusion injury regarding the processes of inflammation and apoptosis and this in contrast to the protective effects of these anti-coagulants in other models of ischemia/reperfusion injury.

In chapter 6 all findings described in this thesis are being discussed in conjunction with the clinical implications of these studies. With these studies we gained a better insight into the working mechanisms of the anti-coagulants ASIS and APC regarding their anti-inflammatory and anti-apoptotic properties in 2 ischemia/reperfusion models, revealing different effects of both anticoagulants in distinct organs. 


\section{HET BEPERKEN VAN ISCHEMISCHE ORGAANSCHADE MET ANTI-BLOEDSTOLLENDE MIDDELEN}

Hart- en vaatziekten zijn de belangrijkste doodsoorzaak in de Westerse wereld en zijn vaak het gevolg van atherosclerose, een ziekte die door de vorming van atherosclerotische plaques leidt tot de occlusie van de aangedane bloedvaten. Deze occlusie vindt enerzijds plaats door de vernauwing van het lumen van het bloedvat door plaquevorming en anderzijds via een bloedstolsel dat gevormd wordt door de activering van de stollingscascade als gevolg van het scheuren van de plaque. Occlusie van de arterie kan aanleiding geven tot ischemie, ofwel zuurstoftekort in het aangedane weefsel, dat kan resulteren in celdood. Een voorbeeld hiervan is het hartinfarct. Om de schade, ontstaan door het ischemisch proces, te beperken moet het afgesloten bloedvat terug geopend worden, ook wel reperfusie genoemd. Het reperfusie proces is echter niet zonder risico aangezien het gepaard gaat met een ontstekingsreactie, gekenmerkt door infiltratie van ontstekingscellen en vrijgave van een aantal ontstekingseiwitten zoals interleukine- 6 en $-1 \beta$. Dit ontstekingsproces kan vervolgens weer leiden tot gereguleerde celdood of apoptose en dit via regulatie van verschillende cel signaleringroutes. Ischemie/reperfusie schade heeft diverse gevolgen wanneer verschillende organen zoals het hart of de nieren aangedaan worden. Bij ischemie/reperfusie schade van het hart wordt de samentrekkende functie van de hartspier gereduceerd door de ontstekingen celdoodprocessen wat uiteindelijk resulteert in hartfalen. Beperking van ontsteking en celdood kan resulteren in een verbeterde samentrekkende functie van de hartspier na een hartinfarct. In de nier is de beperking van de ischemie/reperfusie schade vooral van belang bij niertransplantaties. Afname van ontsteking en celdood beperkt de kansen op acuut nierfalen en afstoting van het getransplanteerde orgaan.

Bloedstolling en ontsteking spelen een belangrijke rol in het bepalen van ischemie/reperfusie schade en verschillende studies hebben reeds een belangrijke interactie tussen stolling en ontsteking laten zien en dit vooral via cel signalering door protease geactiveerde receptoren of PARs. Antistollingsmiddelen zijn, behalve om hun antistollende functie, om deze reden dan ook gekend vanwege een celbeschermende functie via regulatie door deze PARs. Een aantal in vivo en in vitro studies hebben aangetoond dat de twee anti-stollingsmiddelen die in dit proefschrift bestudeerd werden, namelijk ASIS en APC, ook celbeschermende effecten hebben bij ischemie/reperfusie schade. 
De exacte werkingsmechanismen van deze middelen werden echter nog niet achterhaald. Het antistollend middel ASIS is een inactieve vorm van de stollingsfactor VIla die een complex vormt met TF maar waarbij de overige factoren van de stollingscascade niet geactiveerd worden. ASIS werd reeds als interventie gebruikt in een hart ischemie/reperfusiemodel waar het een beschermend effect had, maar het exacte werkingsmechanisme werd nog niet achterhaald. Het tweede antistollingsmiddel APC wordt gevormd wanneer trombine gevormd wordt en leidt tot proteolytische inactivering van de stollingsfactoren Va en VIIla. In een aantal ischemie/reperfusie modellen waaronder in de nier en in het brein werd reeds aangetoond dat APC een beschermende werking heeft, maar tot nu toe werd dit nog niet aangetoond in een hart ischemie/reperfusie model. In hoofdstuk $\mathbf{2}$ en $\mathbf{3}$ van dit proefschrift werd het effect van ASIS bepaald op hart ischemie/reperfusie schade en werd het exacte werkingsmechanisme bepaald. In hoofdstuk 4 werd APC gebruikt als interventie in een hart ischemie/reperfusie model en werd het effect op schade en het werkingsmechanisme achterhaald. In hoofdstuk 5 tenslotte, werden de 2 antistollingsmiddelen ASIS en APC gebruikt in een nier ischemia/reperfusie model waarbij er een vergelijking werd gemaakt met eerdere studies waarbij antistolling als interventie gebruikt werd.

In hoofdstuk 1 wordt een overzicht gegeven van de pathofysiologie van zowel hart als nier ischemie/reperfusie. Hierbij ligt de focus op de rol van ontsteking en apoptose in deze processen en de relatie met de cel signaleringsroutes die hierin betrokken zijn. Verder worden ook de verschillende functies van zowel het ASIS als het APC met betrekking tot hun antistollende en celbeschermende eigenschappen besproken.

Hoofdstuk 2 beschrijft de effecten van het anti-stollingseiwit ASIS dat tijdens verschillende tijdspunten van zowel de ischemie als de reperfusie fase wordt toegediend in een hart ischemie/reperfusie model in de muis. De effecten van ASIS toediening tijdens enkel de ischemische fase, de ischemie en reperfusie fase of enkel tijdens de reperfusie fase werden bepaald en dit ten aanzien van de infarctgrootte, stollingsparameters en cel signaleringsroutes. Het effect van ASIS was maximaal op gebied van afname in infarctgrootte en afname in TF activiteit niveaus wanneer het tijdens de ischemie en de reperfusie fase toegediend werd. Ook uit analyse van cel signaleringsroutes betrokken bij NF$\mathrm{KB}$ signalering, bleek dat toediening van ASIS tijdens ischemie en reperfusie optimaal was. Uit deze resultaten werd besloten dat toediening van ASIS tijdens 
ischemie en reperfusie het meest optimale moment was en dit toedieningsmoment werd dan ook gebruikt in de verdere experimenten.

In hoofdstuk 3 worden de effecten van ASIS toediening tijdens ischemie en reperfusie in een hart ischemie/reperfusie model in de muis beschreven waarbij er gebruik gemaakt werd van verschillende reperfusietijden variërend tussen 2 en 24 uur. ASIS toediening verminderde de infarctgrootte voor zowel een 2, 6, als 24 uur durende reperfusietijd. RNA analyse van een aantal genen betrokken in NF-KB signalering liet een belangrijke afname zien van genexpressie na ASIS toediening. Verder verminderde de toediening van ASIS ook de NF-KB eiwitniveaus, alsook de eiwitniveaus van een aantal genen gereguleerd door NF-KB waaronder TF en interleukine (IL)-6. De ontstekingsremmende effecten van ASIS werden aangetoond door een verminderde leukocyten infiltratie in het ischemische deel van het hart wanneer ASIS werd toegediend en dit in vergelijking met toediening van een placebo. De anti-apoptotische werking van ASIS werd onderzocht door middel van RNA analyse en kleuring van de apoptotische cellen met behulp van DNA laddering maar een apoptotisch effect van ASIS kon niet aangetoond worden. Uit dit hoofdstuk kunnen we concluderen dat ASIS een beschermende werking heeft na hart ischemie/reperfusie schade en dit via NF-кB signaleringsroutes die een verminderde ontsteking maar geen afname in apoptose tot gevolg hebben.

Hoofdstuk 4 beschrijft de resultaten van APC toediening in een hart ischemie/ reperfusie model in de muis. Interventie met APC resulteerde in een verminderde infarctgrootte en dit in tegenstelling tot interventie met een nietspecifiek anti-stollingsmiddel heparine waarbij de infarctgrootte niet beïnvloed werd. APC toediening resulteerde in een afname in interleukines in het hart en een afname in de infiltratie van leukocyten. Verder had APC een sterk antiapoptotisch effect en dit was te zien in zowel een afname in apoptotische cellen in het ischemische deel van het hart als in de verminderde aanmaak van een aantal proapoptotische genen. Signalering via NF-KB was niet beïnvloed door toediening van APC maar verdere experimenten lieten zien dat PAR-1 signalering nodig is voor de beschermende werking van APC. Uit dit hoofdstuk kunnen we besluiten dat APC een beschermend effect heeft op hart ischemie/ reperfusieschade via een reducering van ontsteking en apoptose, gereguleerd door PAR-1 signalering. 
Aangezien zowel ASIS als APC een beschermend effect hebben op hartschade na ischemie/reperfusie, werden beide middelen ook gebruikt in een nier ischemie/reperfusie model in de muis. De resultaten zoals beschreven in hoofdstuk 5 laten echter geen beschermend effect van ASIS noch van APC zien op nier ischemie/reperfusie schade. Nierschade werd bepaald door middel van bloed ureum en creatinine levels en door middel van scoring van de niercoupes voor schade. De resultaten lieten echter geen verschil zien tussen ASIS of APC toediening en de toediening van een placebo. Op cellulair niveau was er geen verschil zichtbaar op zowel ontstekings- als celdoodmechanismen bij ASIS of APC toediening. Uit de data beschreven in dit hoofdstuk kunnen we concluderen dat ASIS en APC geen effect hebben in het door ons gebruikte nier ischemie/reperfusie model, dit in tegenstelling tot eerdere studies die wel een beschermend effect zien van het remmen van de bloedstolling op schade in de nier.

In hoofdstuk 6 ten slotte worden alle bevindingen zoals beschreven in dit proefschrift bediscussieerd en worden de mogelijke klinische toepassingen geanalyseerd. Met de studies zoals beschreven in dit proefschrift, zijn we tot een beter inzicht gekomen in het werkingsmechanisme van zowel ASIS als APC met betrekking tot niet enkel hun antistollende eigenschappen maar ook met betrekking tot hun celbeschermende functies. In dit proefschrift werden twee verschillende modellen voor ischemie en reperfusie gebruikt waarbij er verschillende effecten zichtbaar waren voor het gebruik van gelijkaardige interventies. Dit impliceert dat er binnen diverse organen en celtypes verschillende routes werkzaam zijn bij het bepalen van schade door middel van ischemie/reperfusie. 




\section{Publications}





\section{PAPERS}

STBG Loubele, CA Spek, P Leenders, R van Oerle, HL Aberson, K Hamulyák, G Ferrel, $\mathrm{CT}$ Esmon, $\mathrm{HMH}$ Spronk, $\mathrm{H}$ ten Cate. Activated protein $\mathrm{C}$ protects against myocardial ischemia/reperfusion injury via inhibition of apoptosis and inflammation. Arteriosler Thromb Vasc Biol 2009: Apr. 16 (epub ahead of print).

STBG Loubele, HMH Spronk, $\mathrm{H}$ ten Cate. Activated protein C: a promising drug with multiple effects. Mini Reviews in Medicinal Chemistry 2009; 9(5):620-626.

STBG Loubele, CA Spek, P Leenders, R van Oerle, HL Aberson, D van der Voort, K Hamulyák, LC Petersen, HM Spronk , H Ten Cate . Active site inhibited factor VIla attenuates myocardial ischemia/reperfusion injury in mice. Journal of Thrombosis and Haemostasis 2009;7: 290-8. Commentary: Pawlinski R, Mackman N. Tissue factor and heart inflammation. J Thromb Haemost 2009; 7: 288-289.

Loubele S, Ten Cate $\mathrm{H}$. Local administration of recombinant human antithrombin in a mouse model of peritoneal sepsis. Journal of Thrombosis and Haemostasis 2006; 4(11): 2340-42.

JM Cosemans, MJ Kuijpers, C Lecut, STBG Loubele, S Heeneman, M JandrotPerrus, JW Heemskerk. Contribution of platelet glycoprotein VI to the thrombogenic effect of collagens in fibrous atherosclerotic lesions. Atherosclerosis 2005; 181 (1): 19-27. 


\section{ABSTRACTS}

Loubele STBG, Frederix K, Oerle van R, Voort van der D, Spronk HMH, Cate ten $\mathrm{H}$. Localization and activity of tissue factor and factor VII in mouse organs. Biomedica 2004, Liège, Belgium; poster presentation.

Loubele STBG, Frederix K, Oerle van R, Strzelecka A, Spronk HMH, Hamulyák K, Voort van der $\mathrm{D}$, Cate ten $\mathrm{H}$. ASIS blocks tissue factor activity in the heart after ischemia/reperfusion in mice. ISTH 2005, Sydney, Australia; oral presentation.

Loubele STBG, Frederix K, Oerle van R, Strzelecka A, Spronk HMH, Hamulyák K, Voort van der $\mathrm{D}$, Cate ten $\mathrm{H}$. Plasminogen activator inhibitor-1 plasma levels increase after myocardial ischemia/reperfusion injury in mice. ISTH 2005, Sydney, Australia; poster presentation.

Frederix K, Loubele STBG, Oerle van R, Hamulyák K, Spronk HMH, Cate ten $\mathrm{H}$. Activity and localization of tissue factor and factor VII in organs of normal and endotoxemic mice. ISTH 2005, Sydney, Australia; poster presentation.

Spronk HMH, Huugen D, Frederix K, Loubele STBG, Oerle van $\mathrm{R}$, Cate ten $\mathrm{H}$, Heeringa P. A hypercoagulable state in myeloperoxidase deficient mice. ISTH 2005, Sydney, Australia; poster presentation.

Loubele STBG, Frederix K, Leenders P, Oerle van R, Hamulyák K, Spek CA, Spronk $\mathrm{HMH}$, Voort van der $\mathrm{D}$, Cate ten $\mathrm{H}$. Active site inhibited factor VII reduces myocardial infarct size after ischemia/reperfusion injury in mice via tissue factor/NF-KB mediated mechanisms. BSH 2006, Edinburgh, UK; oral presentation.

Loubele STBG, Leenders P, Oerle van R, Hamulyák K, Buurman WA, Spronk $\mathrm{HMH}$, Voort van der $\mathrm{D}$, Cate ten $\mathrm{H}$. The use of the anti-coagulants active site inhibited factor VII and activated protein $\mathrm{C}$ in a renal ischemia/reperfusion model. NVTH 2007, Koudekerke, the Netherlands; oral presentation.

Loubele STBG, Leenders P, Oerle van R, Hamulyák K, Spek CA, Spronk HMH, Voort van der $\mathrm{D}$, Cate ten $\mathrm{H}$. Active site inhibited factor VII reduces myocardial infarct size after ischemia/reperfusion injury in mice via tissue factor/NF-KB mediated mechanisms. ISTH 2007, Geneva, Switzerland; poster presentation.

Loubele STBG, Leenders P, Oerle van R, Hamulyák K, Buurman WA, Spronk $\mathrm{HMH}$, Voort van der D, Cate ten $\mathrm{H}$. Active site inhibited factor VII has a 
protective role in renal ischemia/reperfusion injury via anti-inflammatory mechanisms. ISTH 2007, Geneva, Switzerland; poster presentation.

Loubele STBG, Leenders P, Oerle van R, Hamulyák K, Reutelingsperger C, Spek $\mathrm{CA}$, Esmon CT, Spronk HMH, Cate ten H. Activated Protein C (APC) attenuates myocardial ischemia/reperfusion injury via an inhibition of apoptosis and inflammation. ATVB 2008, Atlanta, US; oral presentation.

Loubele STBG, Spek CA, Leenders P, Oerle van R, Hamulyák K, Spronk HMH, Cate ten $\mathrm{H}$. Active Site Inhibited factor VIla (ASIS) attenuates myocardial ischemia/reperfusion injury mediated by the NF-KB pathway. ATVB 2008, Atlanta, US; poster presentation.

Loubele STBG, Leenders P, Oerle van R, Hamulyák K, Reutelingsperger C, Spek $\mathrm{CA}$, Esmon CT, Spronk HMH, Cate ten H. Activated Protein C (APC) attenuates myocardial ischemia/reperfusion injury via an inhibition of apoptosis and inflammation. IVBM 2008, Sydney, Australia; poster presentation.

Loubele STBG, Spek CA, Leenders P, Oerle van R, Hamulyák K, Spronk HMH, Cate ten $\mathrm{H}$. Active Site Inhibited factor VIla (ASIS) attenuates myocardial ischemia/reperfusion injury mediated by the NF-KB pathway. IVBM 2008, Sydney, Australia; oral presentation.

\section{AWARDS}

Finalist Junior Investigator Award for Women at the Arteriosclerosis, Thrombosis and Vascular Biology Annual Conference 2008, Atlanta, US. 

Curriculum Vitae 

Sarah Loubele was born on July 30th, 1981 in Turnhout, Belgium. She completed her secondary education at the Heilig-Hart-College in Lanaken (Belgium) in 1999. In 2001 she obtained her Bachelor degree in Biomedical Sciences at the University of Hasselt, Belgium. In 2001, she started with her master study in Biomedical Sciences, specialization Biological Health Science. She obtained her master in Biomedical Sciences in 2003 at the University of Hasselt/Maastricht University. In 2003 she started as a technician at the Human Biology department at Maastricht University where she was involved in nutritional research. In 2004 she started, under supervision of Prof. Dr. H. ten Cate, as a PhD student at the departments of Biochemistry and Internal Medicine at the Maastricht University, the Netherlands where she performed research on the use of the anti-coagulants APC and ASIS in mouse models for renal and myocardial ischemia/reperfusion injury. In January 2009, she started as a post-doc at the departments of Biochemistry and Internal Medicine at the Maastricht University to determine the possible beneficial effects of mutant APC proteins on myocardial ischemia/reperfusion injury. 



\section{Dankwoord}



$\mathrm{Nu}$ we aan het laatste maar daarom niet minder belangrijk deel van mijn proefschrift gekomen zijn, is het tijd om iedereen te bedanken zonder wie dit proefschrift er nooit zou gekomen zijn:

Beste prof. Ten Cate of beter Hugo, hoe zenuwachtig ik ook was om bij jou op sollicitatiegesprek te komen, hoe sneller ik weer was gerustgesteld eens we aan het gesprek begonnen waren. De rust en de kalmte waarmee jij met mensen omgaat, is bewonderenswaardig en komt zeker goed van pas in ons veelzijdige $\mathrm{CTH}$ lab. Ik zou je graag willen bedanken voor de vrijheid en alle mogelijkheden die je me hebt gegeven om dit proefschrift tot een goed einde te brengen en voor de kans om verder in jou lab te mogen blijven werken. Ook bedankt voor alle buitenlandse bezoekjes die ik heb mogen meemaken ook al had je me misschien liever voor langere tijd in het buitenland gezien.

Henri, bedankt voor al je hulp die van ontelbare waarde is. Ik kon voor alles bij je aankloppen en sta dan ook niet voor niets bovenaan je email statistieken. Ook bedankt voor alle leuke uitjes samen, van een praatje aan de andere kant van de wereld, camperen in Frankrijk, tot pijnlijke voeten en meerdere bezoekjes aan de Apple store in New York. Maar buiten een goede wetenschapper ben je natuurlijk ook een fantastische papa voor Max en Sven. Ik hoop dat ik de combinatie werk-gezin even goed kan volbrengen!

Karly, bedankt voor je hulp en voor je positieve en leerzame commentaren tijdens de werkbesprekingen en bij het lezen van mijn papers.

Beste Peter, bedankt voor de bergen werk die je hebt verzet om dit proefschrift tot stand te brengen, voor je flexibiliteit als we een keertje langer moesten blijven, voor je enthousiasme en inleving in het onderzoek en voor alle leuke gesprekjes die ook wel eens niet over werk gingen. Agnieszka, ook bedankt voor de samenwerking in het begin van mijn promotietraject en voor de keertjes dat je voor Peter inviel.

Daniëlle, ook al ben je al een tijdje weg bij ons toch mis ik nog steeds onze maandagochtend roddels. Bedankt voor je hulp om een beetje orde en structuur in mijn onderzoek te krijgen. Het is toch aardig gelukt ook al ben ik een beetje koppig. Fijn dat we nog steeds vriendinnen zijn. Ik hoop dat we nog vaak samen Belgische frietjes mogen eten met je lieve dochter.

Mijn 2 paranimfen: Arne, hoeveel liter cola light (en later cola zero) zouden we tijdens onze promotietijd gedronken hebben? Volgens Hugo zitten er zelfs 
geheime krachten in! Het was leuk om iemand te hebben die op hetzelfde moment op het einde van zijn promotietraject zat. Bedankt voor alle leuke babbels en uitstapjes en veel succes met je verdere loopbaan als arts. En natuurlijk niet te vergeten maak er een prachtige dag van samen met Steffie. Machiel, een beetje wetenschapper maar vooral een arts in hart en nieren. Jij weet over alles wel mee te praten. Bedankt voor alle leuke uitjes en soms ook medisch adviezen. Veel succes met al je vrouwen en ik kom zeker nog eens langs voor opvoedtips.

René of beter Bert, ook al zijn we soms wel een keer verloren gelopen met jou als deskundige wandelgids, die veldwandeling 'by night' met prachtig uitzicht over Geneve is memorabel. In het lab wist je echter altijd de weg te vinden. Bedankt om me al de kneepjes van het labwerk bij te brengen en voor al je hulp.

Diane, bedankt voor al de metingen die je voor me gedaan hebt maar zeker ook voor alle leuke babbels. Ik hoop nog vaak van je lekkere koekjes te mogen genieten en veel succes met je buikdanscarrière. Patricia, jij bent er wat later bij gekomen en het heeft het lab zeker wat kleur gegeven. Het is altijd erg gezellig om bij jullie te komen printen. Ik hoop dat jullie potje snel gevuld zal zijn voor die plant of vis of hond...

José, de FXII kenner van het lab. Ook al hebben we nooit rechtstreeks samen gewerkt, ik kon altijd bij je terecht voor praktische dingen in het lab. Veel succes met je verder onderzoek.

Kim, je bent ondertussen verhuisd naar Luik maar toch horen we mekaar nog wel om even bij te kletsen over de laatste roddels. Je zei het al, we zijn zowat tegenovergestelde types maar toch waren uitstapjes altijd erg leuk. Veel succes met je post-doc carrière in Luik en met je grote liefde Dan.

All the foreigners in our lab, Marina you certainly improved my Italian. You were a good teacher. The best of luck back in Italy. Julian, I enjoyed our trip to Sydney despite the many pictures and the malysian police! Thank you so much for all the help with the photoshop things, it certainly made my thesis look much better not to say perfect. My roommate Evren, although we are not always best friends (as you phrase it so nicely: 'I like you, most of the times'), we also have a lot of fun. Good luck with the particulate matter.

Ook bedankt aan iedereen die rechtstreeks of onrechtstreeks met het lab verbonden is voor jullie inbreng in de werkbesprekingen en de leuke labuitjes 
samen: Kristien, onze ietwat verstrooide Belg, Paola, eerste hulp bij de promotie papierberg en plaatjesexpert, Iris, onze hoofdbehandelaarster, Joke, Carina, Petra, alle stagiairs en iedereen die ik vergeten ben.

Mijn andere kamergenoot Kristof, je bent misschien wel de rustigste persoon die ik ken. En dat in tegenstelling tot je neef Nico. Leuk dat we op hetzelfde moment ouders worden! Bedankt voor al jullie leuke gesprekjes en veel geluk met jullie kids.

Ondertussen is ook ons nieuwe project gestart: Gerry, bedankt voor je hulp met de APC mutanten. Ik hoop dat we er een mooi paper van kunnen maken. Roy en Simone, bedankt voor al je hulp met het celwerk. Karin, veel geluk met je promotietraject.

De collega's van Amsterdam: Arnold bedankt voor je inbreng en erg zinvolle commentaren bij de artikels. Hella bedankt voor alle MLPA metingen.

Ook bedankt aan Jan, de vakgroepvoorzitter, alle (ex-)AIO`s en de rest van biochemie. En natuurlijk niet te vergeten Trees bedankt voor al je hulp met het papierwerk en als ik maar weer eens niet wist hoe ik moest faxen en natuurlijk voor al de leuke babbels en reisverhalen.

Werken kan ook niet zonder de nodige ontspanning en die was er voor mij op het volleybalveld. ledereen van Sparvoc, maar vooral onze oude harde kern: potsie, pruuk, natje, jo, fie, eef en natuurlijk ook mijn zusje bedankt voor alles ontspannende uurtjes op en naast het plein (en natuurlijk niet te vergeten mijn zalige vrijgezellenweekend!). Het was geweldig jullie 'captain loubel` te zijn en ik hoop dat we nog een keer een reünie matchke kunnen spelen. Ook aan alle andere vrienden, het is teveel jullie allemaal persoonlijk te noemen maar bedankt voor de leuke etentjes, babbels en adviezen over baby`s. Ze gaan vast en zeker van pas komen.

Ze zeggen wel eens je familie kies je niet, maar als ik mocht kiezen zou het zeker dezelfde zijn! Zowel de Loubellen als de Giebelkes (en aanhang natuurlijk) om het maar even zo te noemen, bedankt voor alle leuke feestjes, liedjes, gedichtjes,... Het is fijn te weten dat er zoveel mensen achter je staan. Bedankt dat jullie er vandaag bij zijn! Graag wil ik nog even ons wandel- en vlaaiclubje noemen. Fien en Moeke, binnenkort groottante en overgrootmoeder, bedankt voor de goede zorgen voor onze hondjes en de hulp in het huishouden. Ik hoop dat we nog vele jaartjes samen kunnen wandelen en gaan skiën natuurlijk. 
Aan mijn 2 vakes die er helaas niet meer kunnen bij zijn. Vake van de molen, van $u$ heb ik vast en zeker mijn liefde voor de natuur en de wetenschap geërfd. Wat die zoektocht naar vogeltjes toch heeft opgeleverd. Vake chel, ook al heb ik u niet lang gekend, uit alle verhalen weet ik zeker dat ik u liefde voor het leven heb geërfd. Ik had graag een keer samen op de latten gestaan.

Ma en Michel, met jullie heb ik nog een paar extra ouders erbij. Bedankt voor alle gezellige etentjes en vooral bedankt om me te leren skiën. Binnenkort beginnen jullie aan je rol als grootouders en ik weet zeker dat jullie dat heel goed gaan doen!

Mama en Papa, met jullie heb ik de beste ouders (en binnenkort grootouders) die ik me maar kan voorstellen. Bedankt voor alles kansen die jullie me hebben gegeven! Mama, we lijken erg veel op mekaar: onze liefde voor dessertjes en lekker eten, een beetje tegenzin aan sporten wetende dat het eigenlijk moet, en dan die vervelende 5 kilootjes die er eigenlijk afmoeten maar toch weer telkens bijkomen! Ik hoop dat ik binnenkort mijn eigen mamarol met evenveel glans doorsta! Papa, met de jaren begin ik veel meer van mezelf in jou te herkennen. Als je weer vol enthousiasme over je werk vertelt, kan ik me in heel veel dingen terugvinden en ik hoop dan ook dat ik een beetje van die kwaliteiten geërfd om een mooie carrière uit te bouwen. Bedankt voor de vele uurtje bijles vroeger en zie ondanks dat ik niet wist hoeveel keer een kwart in een geheel ging is het toch nog enigszins goed gekomen! Zus of is het al tante Ben, we zijn zowat tegenovergestelde karakters maar met de jaren zijn we buiten zussen ook vriendinnen geworden. Mijn vrijgezellenweekend en de trouw zal ik nooit vergeten en ik weet zeker dat je het als tante evengoed zal doen! Ondertussen heb je na wat zoeken ook je eigen leven opgebouwd en ik hoop dat we nog vele gezellige winkel- en kantine uurtjes zullen hebben.

Last but not least: de 2 mannen in mijn leven. Gielke, zoals je al door een deel van de familie genoemd wordt, het is fijn om te weten dat we daar eigenlijk met 2 staan. Ik kan niet wachten tot je er bent! Mijn allerliefste Guy, de laatste 5 jaar waren natuurlijk niet alleen maar promoveren maar we hebben een heel leven samen opgebouwd. Samen gaan wonen, hondjes opgevoed, getrouwd, huisje verbouwd, af en toe was het een moeilijke combinatie maar we hebben de proef met glans doorstaan. Binnenkort beginnen we aan de waarschijnlijk grootste uitdaging en ik weet zeker dat het ons zal lukken. Bedankt voor alle liefde en steun. KVY 